\title{
Synthesis and properties of hydrazones bearing amide, thioamide and amidine functions
}

\author{
Nataliya P. Belskaya, ${ }^{a}$ Wim Dehaen, ${ }^{b}$ and Vasiliy A. Bakulev ${ }^{a *}$ \\ ${ }^{a}$ TheUrals State Technical University, 620002, Ekaterinburg, Russia \\ ${ }^{b}$ Department of Chemistry, K.U. Leuven, Celestijnenlaan 200F, B-3001 Leuven, Belgium \\ E-mail: bakulev@mail.ustu.ru
}

\begin{abstract}
This review provides detailed methods for the synthesis, structures and chemical properties of hydrazones bearing carboxamide, thioamide and amidine functions. The main accent was put on the cyclization reactions leading to pyrazoles, thiazoles, 1,2,3-triazoles, 1,2,3-thiadiazoles, 1,2,4triazines and other heterocyclic compounds. In addition, we have reviewed methods for the synthesis of substrates for pericyclic reactions from the hydrazones.
\end{abstract}

Keywords: Hydrazone, carboxamide, thioamide, amidines, cyclization

\section{Table of Contents}

1. Introduction

2. Syntheses of hydrazono-amides, -thioamides and -amidines

2.1 Condensation reaction of hydrazines with carbonyl compounds

2.2 Coupling of diazonium salts with active methylene compounds

2.3 Synthesis of hydrazones by modification of the substituents

3. Structure of hydrazono-amides, -thioamides and -amidines

3.1 Hydrazono-amides

3.2 Hydrazono-thioamides

3.3 Hydrazono-amidines

4. Chemical properties of hydrazono-amides, -thioamides and -amidines

4.1 Reactions with nucleophiles

4.2 Reactions with electrophiles

4.3 Oxidation and reduction

4.4 Use of hydrazono-amides, -thioamides and -amidines in the synthesis of heterocyclic compounds 
4.4.1 Reactions with derivatives of formic acid, ketones, carbon disulfide and thiophosgene

4.4.2 Reactions with $\alpha$-halocarbonyl compounds

4.4.3 Reactions with acetylenecarboxylic esters

4.4.4 Reactions with reagents containing electrophilic and nucleophilic functions

4.4.5 Intramolecular cyclization reactions

4.4.6 Cycloaddition reactions

4.4.7. Oxidative cyclization reactions

5. Hydrazono-thioamides for the synthesis of substrates for pericyclic transformations

Conclusions

Acknowledgements

References

\section{Introduction}

Hydrazones and their derivatives constitute a versatile class of compounds in organic chemistry. These compounds have interesting biological properties, such as anti-inflammatory, analgesic, anticonvulsant, antituberculous, antitumor, anti-HIV and antimicrobial activity. ${ }^{1}$ Hydrazones are important compounds for drug design, as possible ligands for metal complexes, organocatalysis and also for the syntheses of heterocyclic compounds. ${ }^{2}$ The ease of preparation, increased hydrolytic stability relative to imines, and tendency toward crystallinity are all desirable characteristics of hydrazones. Due to these positive traits, hydrazones have been under study for a long time, but much of their basic chemistry remains unexplored.

Hydrazones contain two connected nitrogen atoms of different nature and a $\mathrm{C}-\mathrm{N}$ double bond that is conjugated with a lone electron pair of the terminal nitrogen atom. These structural fragments are mainly responsible for the physical and chemical properties of hydrazones (Figure 1). Both nitrogen atoms of the hydrazone group are nucleophilic, although the amino type nitrogen is more reactive. The carbon atom of hydrazone group has both electrophilic and nucleophilic character. ${ }^{3}$

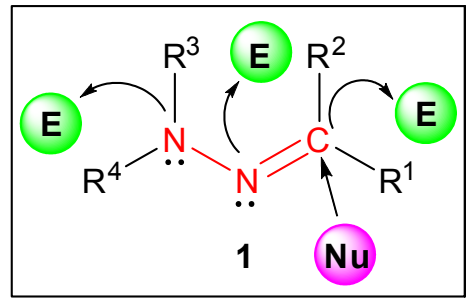

$\mathrm{E}=$ Electrophile

$\mathrm{Nu}=$ Nucleophile

Figure 1. Classification of active centers. 
Due to the capability to react with electropilic and nucleophilic reagents, hydrazones are widely used in organic synthesis, especially for the preparation of heterocyclic compounds. It is worth mentioning the synthesis of indoles 3 according to the Fischer reaction, ${ }^{3 a}$ the synthesis of 4-thiazolidin-4-ones $4,^{\text {,a }}$ the synthesis of azetidines $5^{4}$ by [2+2] cycloaddition and different syntheses of various five-membered heterocyclic compounds 6 by 1,3-dipolar cycloaddition of azomethine imines ${ }^{5}$ that are formed by a 1,2- $H$-shift as depicted in the Scheme 1.
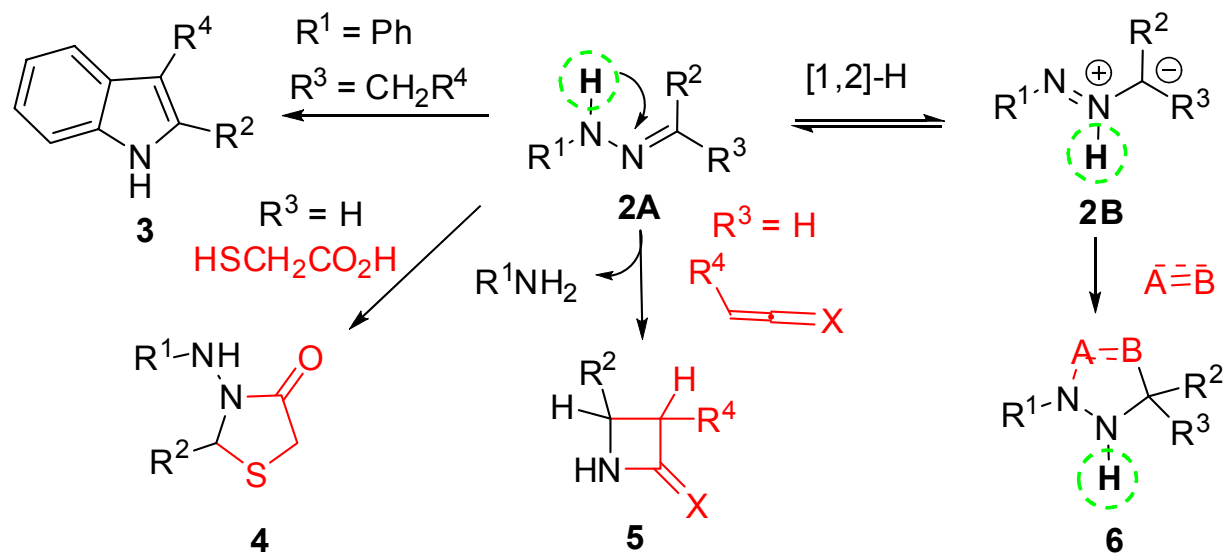

\section{Scheme 1}

The introduction of functional groups in the hydrazone molecules expands the scope of use of the latter in organic synthesis. Moreover, the combination of the hydrazono group with other functional groups leads to compounds with unique physical and chemical properties. Hydrazones containing a halo atom in $\alpha$ - or $\beta$-positions have been explored for many years as ways to generate nitrile imines $^{6}$ and 1,2-diaza-1,3-butadienes ${ }^{7}$ that are active intermediates in cycloaddition chemistry. The amidrazones and thiosemicarbazones are well documented because of their biological activity and use in the synthesis of heterocyclic compounds. ${ }^{3 a, 8}$ Synthetic approaches and chemical reactivity of the hydrazones substituted with ester and cyano groups were first reported in 1894 but new findings were continuously added, some only recently. ${ }^{9}$ We are reporting here a review on the synthesis, spectral and chemical properties of hydrazones of type 7 containing amide, thioamide and amidine groups (Figure 2). The structure 8 represents a special case where these groups are incorporated into a ring.
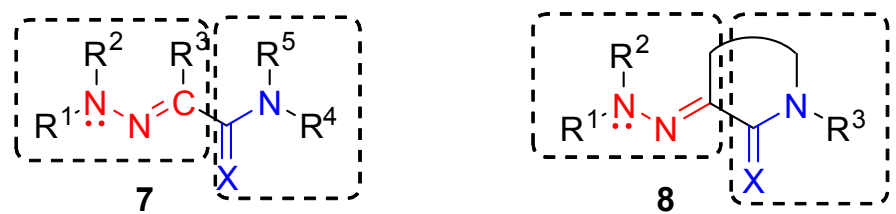

$$
\mathrm{X}=\mathrm{O}, \mathrm{S}, \mathrm{NH}
$$

Figure 2. Structures of hydrazones with amide, thioamide and amidine groups 


\section{Syntheses of hydrazono-amides, -thioamides and-amidines}

\subsection{Condensation reaction of hydrazines with carbonyl compounds}

The most general and oldest method for the synthesis of hydrazones is the reaction of hydrazines with carbonyl compounds. ${ }^{3,10}$ Because of the high nucleophilicity of both hydrazine nitrogen atoms the use of this method is difficult for the preparation of hydrazones bearing carbonyl and other electrophilic substituents. In fact, hydrazones bearing thioamide and amidine moieties are not available by this method at all.

The amide group is less reactive than the ester and ketone functions. Therefore, amidohydrazones 11 may be selectively prepared by reaction of alkyl- or arylhydrazines 9 with 2-oxo2-phenylacetamides 10 (Scheme 2). ${ }^{11}$

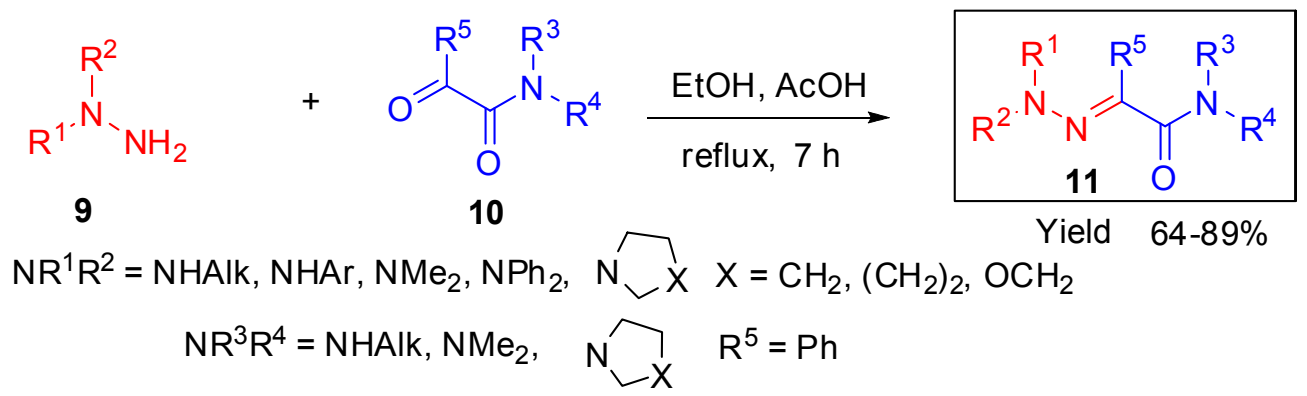

\section{Scheme 2}

The use of the benzyl protecting group allowed the authors ${ }^{11 \mathrm{fg}}$ to obtain the bis-hydrazones 15 and 16. The first stage of the method is the condensation of the dihydrazines 12, where two nitrogen atoms are protected by benzyl groups, with two equivalents of methyl benzoylformate 13. Then bis(hydrazonoester) $\mathbf{1 4}$ was transformed into the bis(hydrazonoamide) $\mathbf{1 5}$ by the action of dimethylaluminium dimethylamide formed in situ by addition of dimethylamine to trimethylaluminium (Scheme 3). The benzyl groups were removed by hydrogenolysis at the last step. 

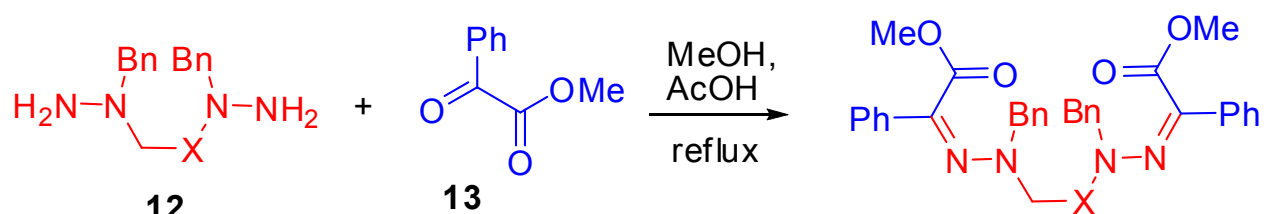

$$
\mathrm{X}=\mathrm{CH}_{2},\left(\mathrm{CH}_{2}\right)_{2}
$$

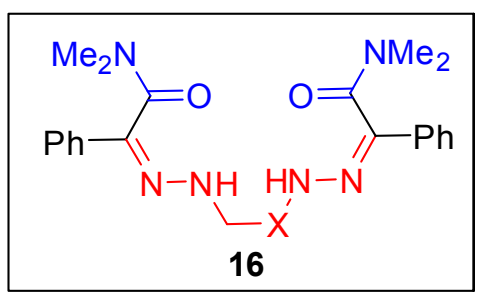

Yield $53 \%$

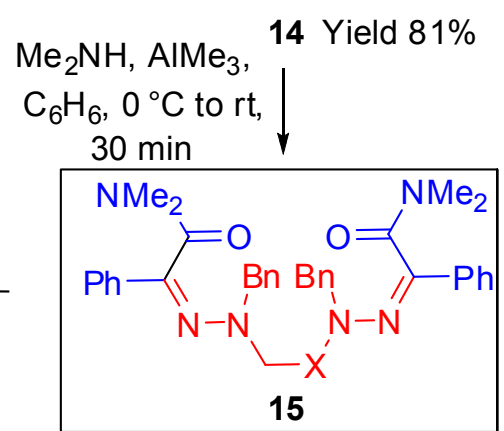

Yield $91 \%$

\section{Scheme 3}

It is interesting to note that the reaction of N-methyl- $\alpha$-chloroacetoacetamide $\mathbf{1 7}$ with ethyl carbazate in ethanol affords $\mathrm{N}$-acylhydrazones $\mathbf{1 8}$ as the only product. The expected substitution of chlorine atom was not observed (Scheme 4). ${ }^{12}$

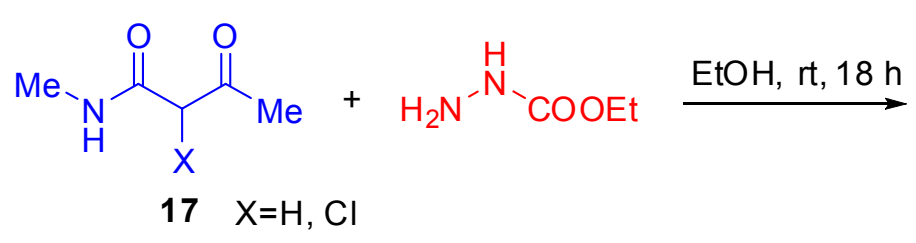

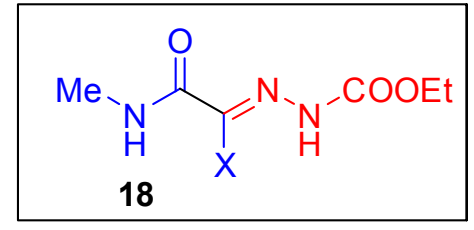

Yield $\quad 77-85 \%$

\section{Scheme 4}

Since indole derivatives exhibit interesting biological properties, a series of hydrazones 20 bearing an amide group incorporated into an indole moiety were prepared by reactions of isatines 19 with hydrazines $9\left(\mathrm{R}^{2}=\mathrm{H}\right) .{ }^{13}$ Compounds $20\left(\mathrm{R}^{1}=4-\mathrm{SO}_{2} \mathrm{NH}_{2} \mathrm{C}_{6} \mathrm{H}_{4}\right)$ represent a novel class of CDK2 (cyclin-dependent kinase 2) inhibitor (Scheme 5). Members of this series of inhibitors cause an arrest of the cell cycle and exhibit a selective killing effect on several tumor cell lines. ${ }^{13 a}$ Hydrazones of angular isatines were synthesized to check their antiviral activity. ${ }^{13 b}$ Compounds 20 with an acylhydrazono group prepared by this reaction exhibited the inhibition of cannabinoid receptors $2 .^{13 \mathrm{c}, \mathrm{d}}$ 


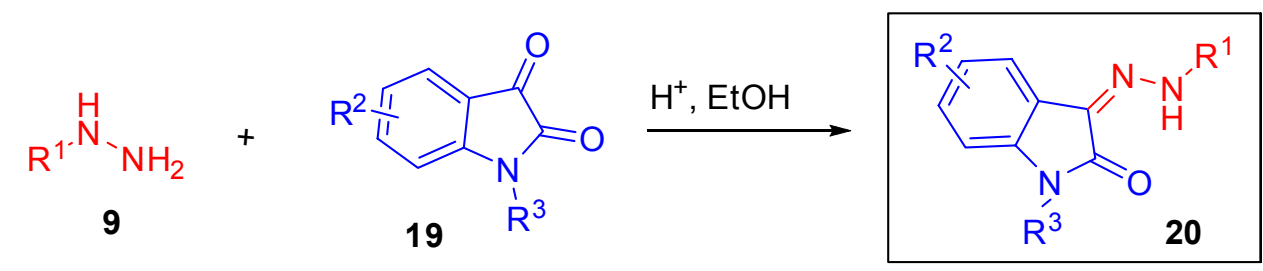

$\mathrm{R}^{1}=\mathrm{CONH}_{2}, \mathrm{CONHPh}, \mathrm{CSNH}_{2}, \mathrm{CSNHPh}, \mathrm{C}(\mathrm{NH}) \mathrm{NH}_{2}$, COAlk, COPh, $\mathrm{SO}_{2} \mathrm{Ph}, \mathrm{Ar}$

$\mathrm{R}^{2}=\mathrm{H}, \mathrm{Hlg}, \mathrm{SO}_{2} \mathrm{NH}_{2}, \mathrm{NO}_{2}$, Alk, OAlk, OPh, $\mathrm{CH}_{2} \mathrm{OH}, \mathrm{CONH}_{2}, \mathrm{OH}, \mathrm{NMe}_{2} \mathrm{R}^{3}=\mathrm{H}$, Alk

\section{Scheme 5}

The synthesis of 2-hydrazonocoumarines $\mathbf{2 2}$ was carried out based on the reaction of imine 21 with alkyl-, benzyl-, and arylhydrazines 9 (Scheme 6). ${ }^{14}$
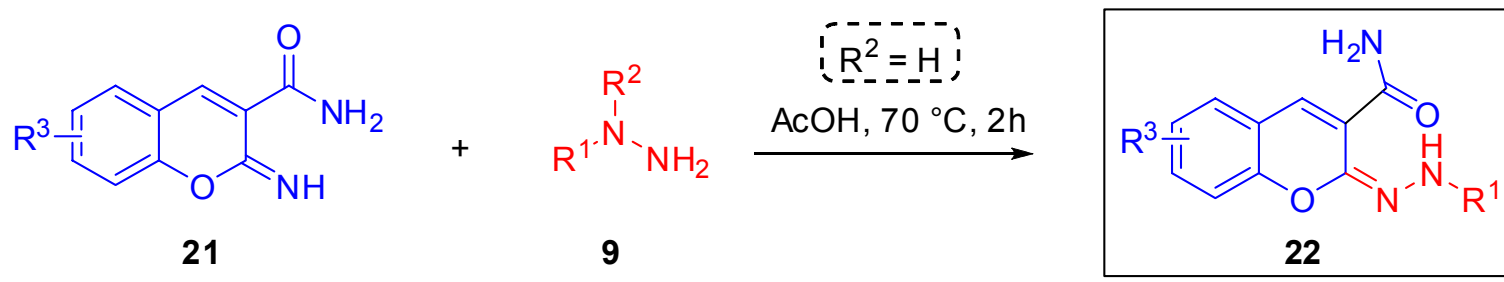

$\mathrm{R}^{1}=t-\mathrm{Bu}, \mathrm{Bn}, \mathrm{Ph}, 2-\mathrm{MeC}_{6} \mathrm{H}_{4}, 4-\mathrm{EtC}_{6} \mathrm{H}_{4}, 4-\mathrm{HO}_{2} \mathrm{CC}_{6} \mathrm{H}_{4}, 4-\mathrm{NO}_{2} \mathrm{C}_{6} \mathrm{H}_{4}$, $3-\mathrm{FC}_{6} \mathrm{H}_{4}, 4-\mathrm{MeOC}_{6} \mathrm{H}_{4}, 4-\mathrm{BrC}_{6} \mathrm{H}_{4}, 3-\mathrm{ClC}_{6} \mathrm{H}_{4}, 3,4-\mathrm{Me}_{2} \mathrm{C}_{6} \mathrm{H}_{3}$ $\mathrm{R}^{3}=\mathrm{H}, 8-\mathrm{MeO}$, 8-EtO, 6-Me, 6-Cl, 6-Br, 7-OH, 6-F, 6-t-Bu, 8-OH, 6-MeO

\section{Scheme 6}

To improve this protocol, microwave-assisted organic synthesis was used. Under these conditions, a full conversion of the starting imines $\mathbf{2 1}$ into the desired 2-hydrazono- $2 \mathrm{H}$ chromenes 22 took place in a reduced ( $2 \mathrm{~h}$ to $2 \mathrm{~min}$ ) reaction time. ${ }^{14}$

\subsection{Coupling of diazonium salts with active methylene compounds}

The coupling of diazonium compounds with active methylene compounds is one of the oldest methods for the synthesis of arylhydrazones. ${ }^{3,10,15}$ In a typical reaction between compounds $\mathbf{2 3}$, containing two electron-withdrawing groups, with aryl(hetaryl)diazonium chloride $\mathbf{2 4}$ an unstable azo intermediate $\mathbf{2 5}$ is considered to form, which spontaneously tautomerizes into the hydrazone $\mathbf{2 6}$ (Scheme 7). The reaction is usually carried out in a cold aqueous solution buffered with sodium acetate, but the $\mathrm{pH}$ of the medium can be lowered for strongly activated methylene compounds. 


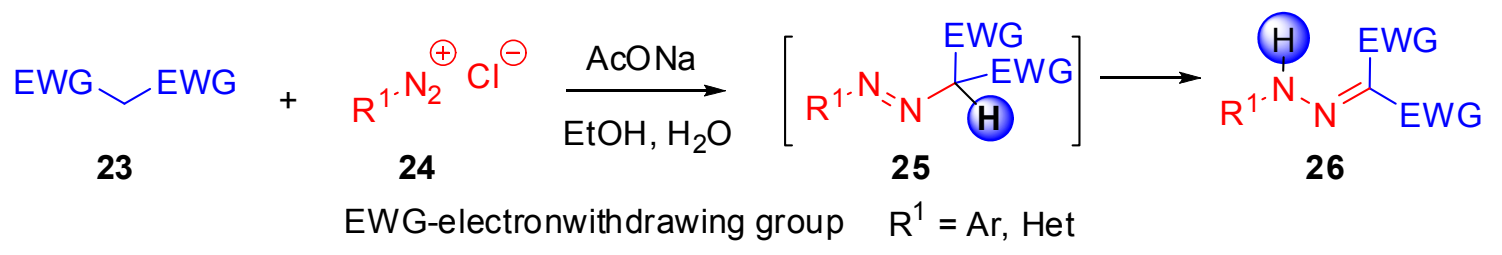

\section{Scheme 7}

There are many papers published in the literature where a large variety of compounds of type 27 were involved in the reaction. Thus, arylhydrazonoacetamides $28(X=O)^{16}$ and thioamides $(X=S)^{17}$ with various substituents $R^{1}-R^{4}$ were prepared by the method (Scheme 8 ).

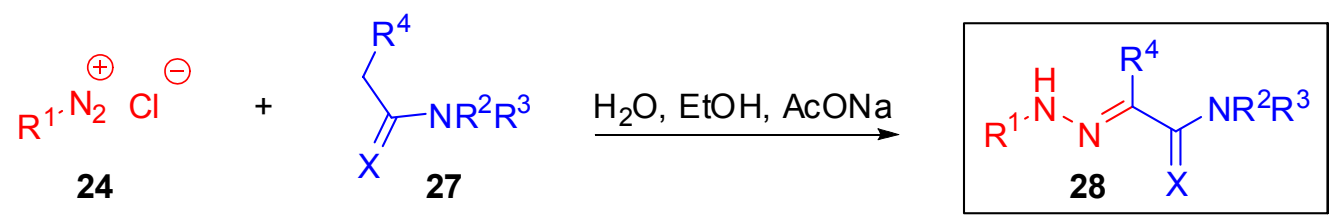

$\mathrm{X}=\mathrm{O} \mathrm{R}^{1}=\mathrm{Ar}$, Het

$\mathrm{NR}^{2} \mathrm{R}^{3}=\mathrm{NH}_{2}, \mathrm{NHAlk} \mathrm{NHCO}_{2} \mathrm{Et}, \mathrm{NHAr}, \mathrm{NAlk}_{2}, \mathrm{~N}_{-\mathrm{X}}^{\mathrm{X}} \mathrm{X}=\mathrm{CH}_{2},\left(\mathrm{CH}_{2}\right)_{2},\left(\mathrm{CH}_{2}\right)_{3}, \mathrm{OCH}_{2}, \mathrm{CH}_{2} \mathrm{NMe}$

$\mathrm{R}^{4}=\mathrm{CN}, \mathrm{CO}_{2} \mathrm{Et}$, COMe, COPh, $\mathrm{CONH}_{2}$, CONHAlk, CONHAr, CONAlk $2, \mathrm{H}, \mathrm{Alk}, \mathrm{Ph}$

$\mathrm{X}=\mathrm{S} \mathrm{R}^{1}=\mathrm{Ar} \quad \mathrm{NR}^{2} \mathrm{R}^{3}=\mathrm{NH}_{2}, \mathrm{NHMe}, \mathrm{NHC}_{6} \mathrm{H}_{11}-$ cyclo, NHPh

\section{Scheme 8}

Interestingly, 3-methyl-2-oxo-1,2-dihydroquinoxaline 29 can react with benzenediazonium salts $24\left(\mathrm{R}^{1}=\mathrm{Ar}\right)$ at relatively elevated temperature to give 3-(arylhydrazono)methyl-2-oxo-1,2dihydroquinoxalines $\mathbf{3 0} .{ }^{18}$ In this case, the methyl group takes part in the azo-coupling reaction (Scheme 9).

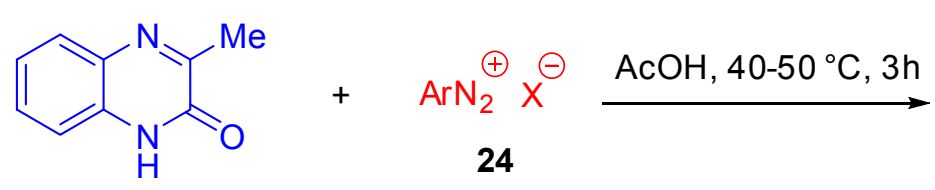

29

$\mathrm{Ar}=4-\mathrm{NO}_{2} \mathrm{C}_{6} \mathrm{H}_{4}, 4-\mathrm{NH}_{2} \mathrm{SO}_{2} \mathrm{C}_{6} \mathrm{H}_{4}, 4-\mathrm{EtO}_{2} \mathrm{CC}_{6} \mathrm{H}_{4}, 4-\mathrm{CNC}_{6} \mathrm{H}_{4}$, 4- $\mathrm{ClC}_{6} \mathrm{H}_{4}, \mathrm{Ph}, 4-\mathrm{AlkC}_{6} \mathrm{H}_{4}, 3-\mathrm{CNC}_{6} \mathrm{H}_{4}, 3-\mathrm{ClC}_{6} \mathrm{H}_{4}, 3-\mathrm{AlkOC}_{6} \mathrm{H}_{4}$

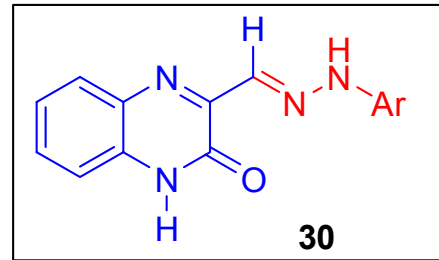

Yield 48-53\% 13 examples

\section{Scheme 9}

A series of arylhydrazonothioacetanilides 32 were prepared by the Japp-Klingemann reaction, which is an azo coupling accompanied by the elimination of one of the two electronwithdrawing groups such as $\mathrm{COOH}, \mathrm{COMe}, \mathrm{CONH}_{2}$ and $\mathrm{COOEt}$ (Scheme 10). ${ }^{19}$ 


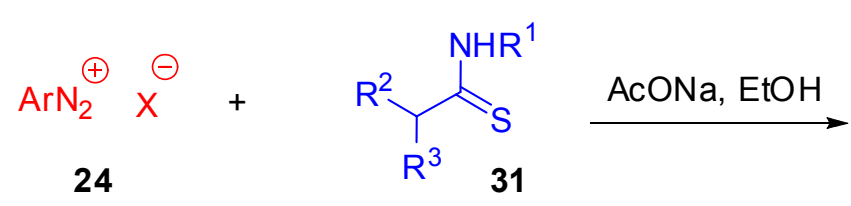

$\mathrm{Ar}=4-\mathrm{MeOC}_{6} \mathrm{H}_{4}, 4-\mathrm{MeC}_{6} \mathrm{H}_{4}, \mathrm{Ph}, 4-\mathrm{ClC}_{6} \mathrm{H}_{4}, 4-\mathrm{NO}_{2} \mathrm{C}_{6} \mathrm{H}_{4}$

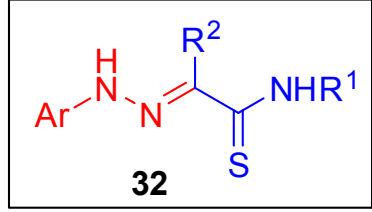

Yield $38-92 \%$

$\mathrm{R}^{1}=\mathrm{Ph}, 4-\mathrm{ClC}_{6} \mathrm{H}_{4} \quad \mathrm{R}^{2}=\mathrm{CO}_{2} \mathrm{Et}, \mathrm{COMe}, \mathrm{CONH}_{2}$, CONHAlk, CONHPh

$\mathrm{R}^{3}=\mathrm{COMe}, \mathrm{CO}_{2} \mathrm{Et}, \mathrm{CONH}_{2}, \mathrm{COOH}$

\section{Scheme 10}

The use of Japp-Klingemann reaction is also a convenient method for the synthesis of hydrazonoacetamides 34 bearing halogen atom (Scheme 11). ${ }^{16,20}$
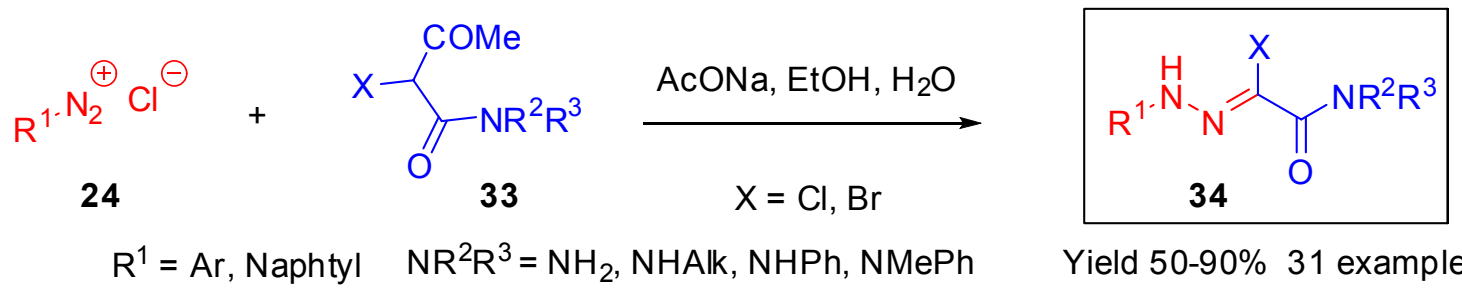

Yield 50-90\% 31 examples

\section{Scheme 11}

Isatine hydrazones 36 were prepared either by condensation of isatine with hydrazines 9 or by the alternative process of azo coupling of aryldiazonium salts 24 with indole-2-one 35 (Scheme 12). ${ }^{21}$ The combination of two methods allowed to prepare a library of hydrazones $\mathbf{3 6}$ where R includes aryl, alkyl, carbamoyl and thiocarbamoyl moieties.

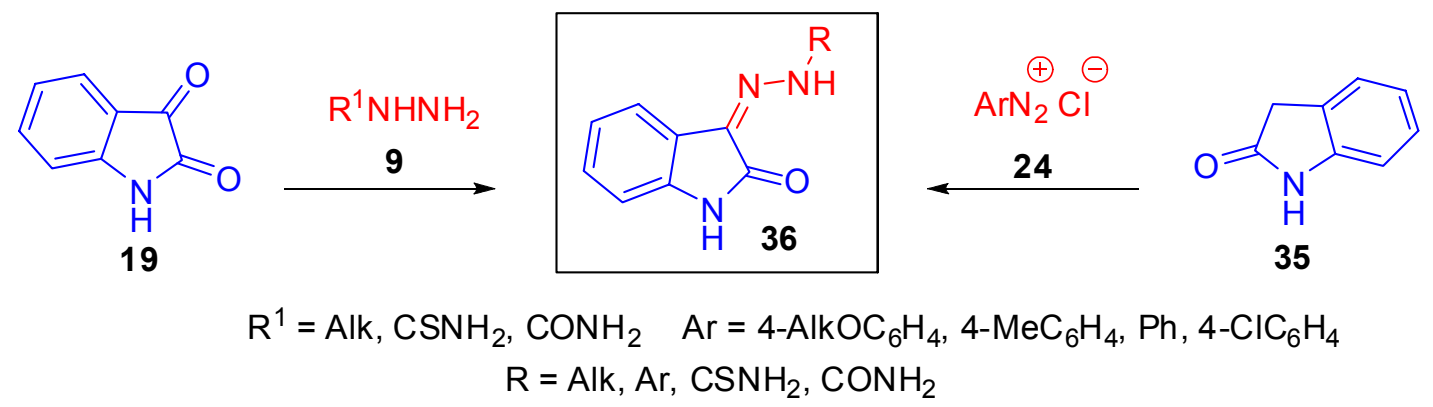

\section{Scheme 12}

The azo coupling reaction is also used to prepare 4-arylhydrazonopyrazol-5-ones and imines 38 (Scheme 13). ${ }^{22}$ 


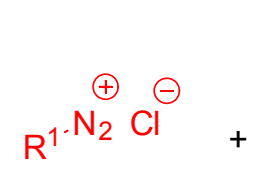

24

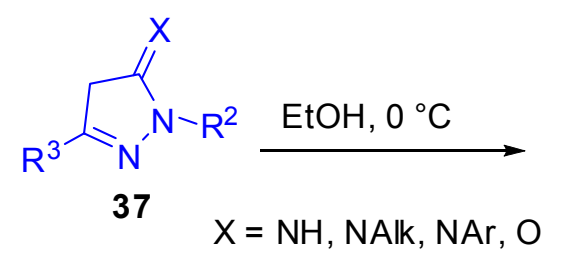

$\mathrm{R}^{1}=\mathrm{Ar}$, Het $\mathrm{R}^{2}=\mathrm{Alk}, \mathrm{Ar} \mathrm{R}^{3}=\mathrm{Alk}, \mathrm{Ar}, \mathrm{NHPh}$

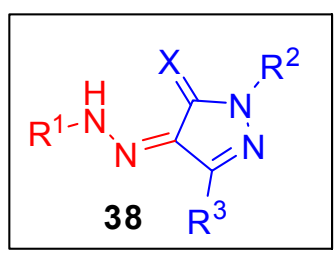

Yield $82-85 \%$

\section{Scheme 13}

The coupling of aryldiazonium chloride $\mathbf{2 4}\left(\mathrm{R}^{1}=\mathrm{Ar}\right)$ with malonamidines 39 was used to prepare arylhydrazonomalonamidines $\mathbf{4 0}$ (Scheme 14 ). ${ }^{23}$

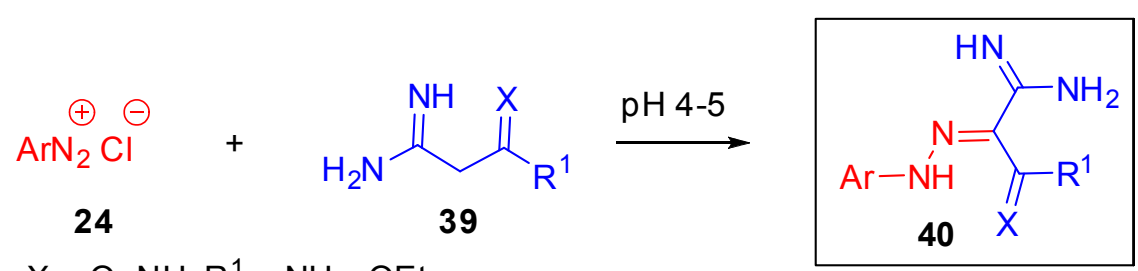

$\mathrm{X}=\mathrm{O}, \mathrm{NH}, \mathrm{R}^{1}=\mathrm{NH}_{2}, \mathrm{OEt}$

Yield 77-93\% 5 examples

\section{Scheme 14}

These compounds are not stable and partial decomposition during the preparation takes place. To prepare these compounds one should keep the $\mathrm{pH}$ of medium well within the narrow interval of $4-5 .^{23 a-c}$

It is worth noting that the synthetic method for hydrazones by the azo coupling reaction is more suitable to prepare compounds bearing carbamoyl, thiocarbamoyl and amidine groups than the alternative method based on the reaction of carbonyl compounds with hydrazines.

\subsection{Synthesis of hydrazones by modification of the substituents}

Hydrazono-amides $\mathbf{4 2}, \mathbf{4 3}$ can be prepared by reaction of hydrazono-esters with amines or by hydrolysis of a cyano group of hydrazonomalononitriles (Scheme 15). ${ }^{161,24}$ The reaction in sulfuric acid accompanied by sulfonation to give final compounds 43 . These reactions are not widely used in organic synthesis because of the availability of hydrazono-amides by other methods. 


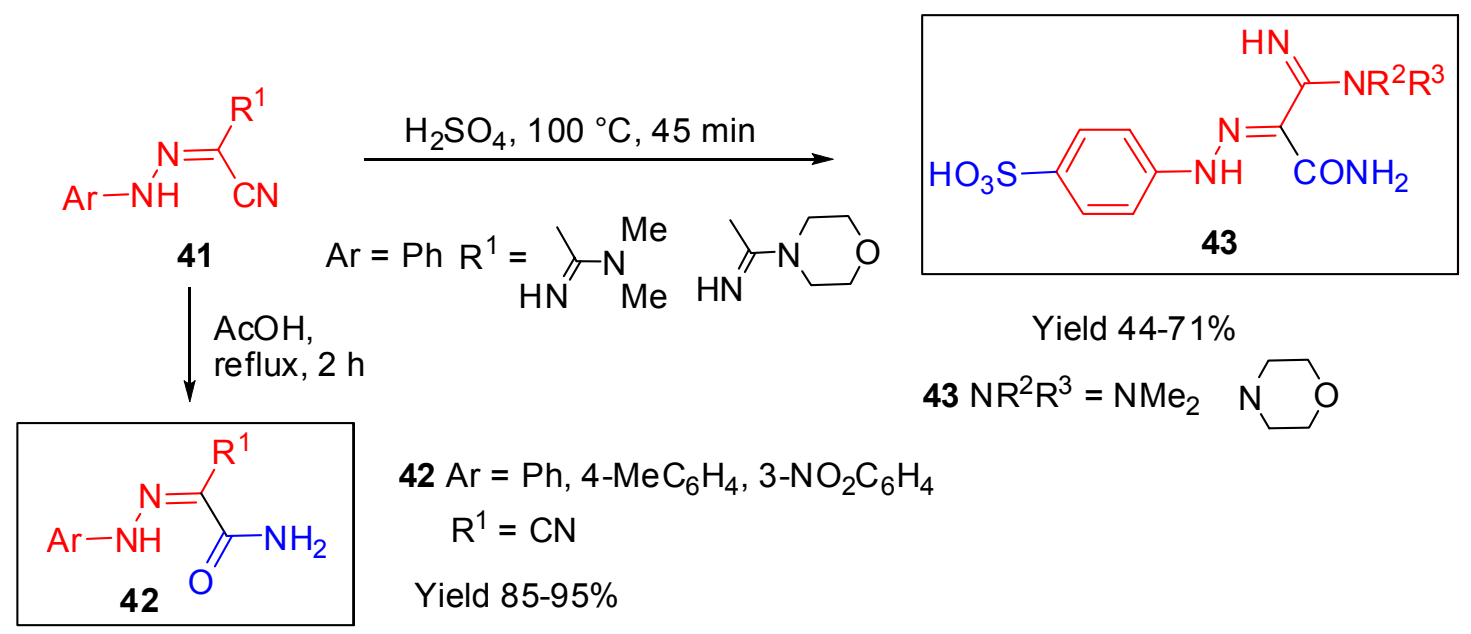

\section{Scheme 15}

A large series of 2-hydrazonothioacetamides $\mathbf{4 4}$ were obtained by reaction of nitriles $\mathbf{4 1}$ either with hydrogen sulfide in basic solutions or by treatment with dialkylphosphinodithioic acids (Scheme 16). ${ }^{16 \mathrm{j}, 25}$

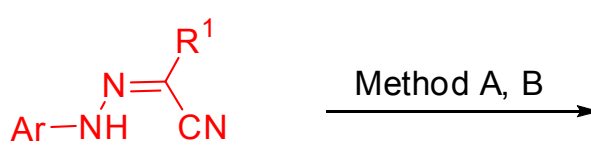

41

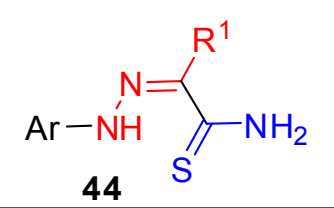

Method A: Yield 55-68\%

$$
\begin{array}{lll}
\text { Method A: } \mathrm{H}_{2} \mathrm{~S}, \text { Pyridine } & \text { Method } \mathrm{B}: \mathrm{R}^{1} \mathrm{R}^{2} \mathrm{P}(\mathrm{S}) \mathrm{SH}, & \text { Method A: Yield 55-68\% } \\
\text { (or DMF, TEA), rt, } 2 \mathrm{~h} & \mathrm{C}_{6} \mathrm{H}_{6} \text { or } \mathrm{CCl}_{4}, \mathrm{rt}, 1-5 \mathrm{~h} & \text { Method B: Yield 9-38\% }
\end{array}
$$

$\mathrm{Ar}=4-\mathrm{MeOC}_{6} \mathrm{H}_{4}, \mathrm{Ph}, 4-\mathrm{ClC}_{6} \mathrm{H}_{4}, 3-\mathrm{CF}_{3} \mathrm{C}_{6} \mathrm{H}_{4}, 4-\mathrm{EtO}_{2} \mathrm{CC}_{6} \mathrm{H}_{4}, 4-\mathrm{NO}_{2} \mathrm{C}_{6} \mathrm{H}_{4}$

$\mathrm{R}^{1}=\mathrm{CO}_{2} \mathrm{Et}, \mathrm{CONH}_{2}$, CONHAlk, CONHAr, O

$\mathrm{X}=\mathrm{CH}_{2},\left(\mathrm{CH}_{2}\right)_{2},\left(\mathrm{CH}_{2}\right)_{3}, \mathrm{OCH}_{2}, \mathrm{CH}_{2} \mathrm{NMe}$

\section{Scheme 16}

Reaction of hydrazono-amides with Lawesson's reagent represents an alternative method to prepare thioamides 45 (Scheme 17). ${ }^{11 \mathrm{a}-\mathrm{e}, 26}$ Tetradentate bis-hydrazones 46 were prepared successfully in a similar way. ${ }^{11 f-g}$ 


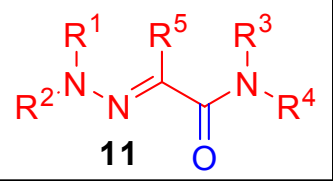

$$
\begin{aligned}
& \underset{80{ }^{\circ} \mathrm{C}, 5 \mathrm{~h}}{\stackrel{\mathrm{LR}, \mathrm{C}_{6} \mathrm{H}_{6}}{\longrightarrow}}
\end{aligned}
$$

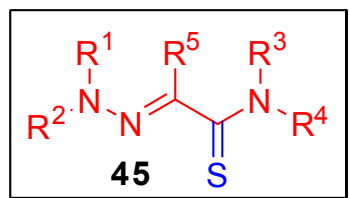

$\mathrm{LR}=4 \mathrm{MeOC}_{6} \mathrm{H}_{4}-\mathrm{S}_{S^{\prime \prime}}^{\prime \prime} \mathrm{S}^{\prime \prime} \mathrm{P}^{\prime \prime \prime}-\mathrm{C}_{6} \mathrm{H}_{4} \mathrm{OMe}-4$

Yield $67-95 \% 31$ examples

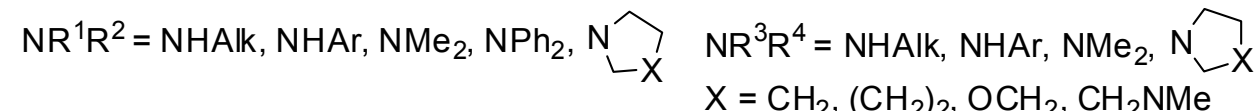

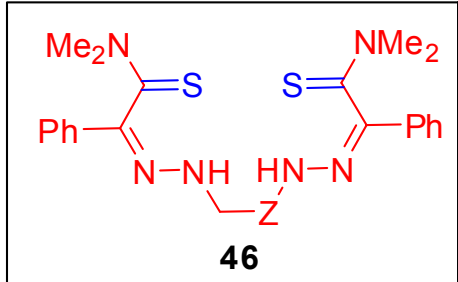

$\mathrm{Z}=\mathrm{CH}_{2},\left(\mathrm{CH}_{2}\right)_{2}$

\section{Scheme 17}

Hydrazone 36 has been shown to react with Lawesson's reagent to form 3-hydrazono-2thioindole 47 (Scheme 18). Furthermore, the product of the reaction of compound 36 $\left(\mathrm{R}^{1}=\mathrm{CSNH}_{2}\right)$ with bromoacetophenones 48 , namely amide 49 is also capable of reacting with Lawesson's reagent to form indole-2-thione $\mathbf{5 0} .^{21}$
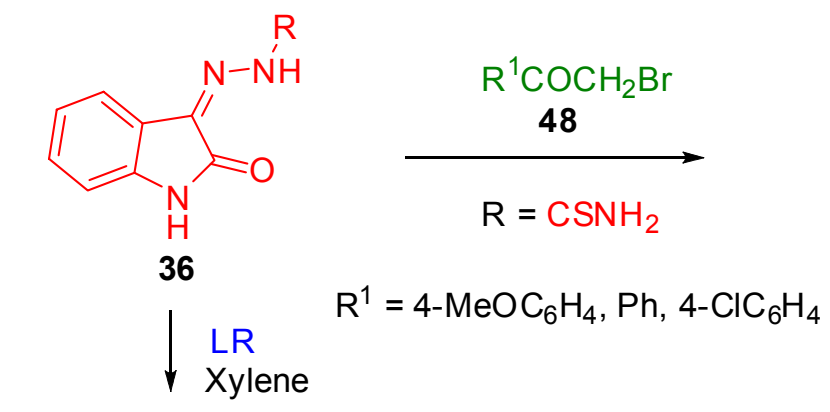

$\mathrm{R}^{1}=4-\mathrm{MeOC}_{6} \mathrm{H}_{4}, \mathrm{Ph}, 4-\mathrm{ClC}_{6} \mathrm{H}_{4}$

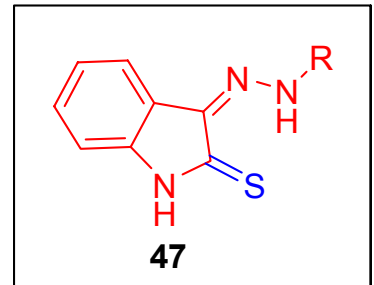

Yield $51-87 \% 7$ examples
$47 \mathrm{R}=\mathrm{Alk}$, 4-AlkOC $6 \mathrm{H}_{4}$, $\mathrm{Ph}, 4-\mathrm{ClC}_{6} \mathrm{H}_{4}$
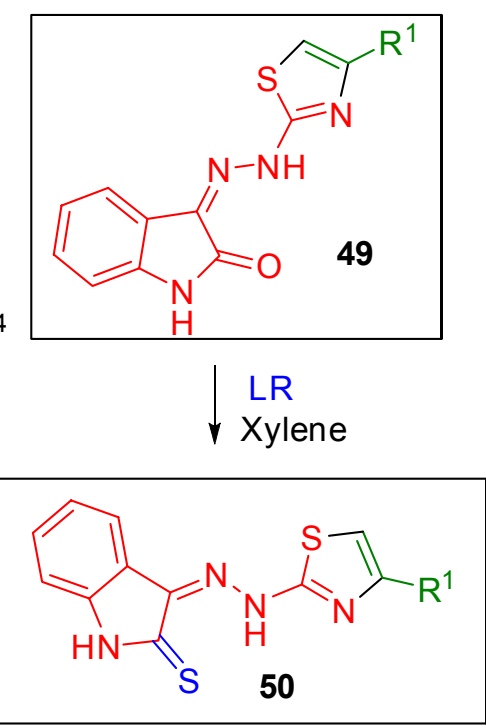

Yield $70-99 \% \quad 3$ examples

\section{Scheme 18}

3-Hydrazonopyrazole-2-thione $\mathbf{5 2}$ was prepared by both thionation of amide $\mathbf{3 8}$ with Lawesson's reagent and by a two step synthesis via chlorination of $\mathbf{3 8}$ with phosphorus pentachloride followed by substitution of chlorine to the thione function by reaction with sodium sulfide (Scheme19). ${ }^{22 \mathrm{c}, \mathrm{d}}$ 


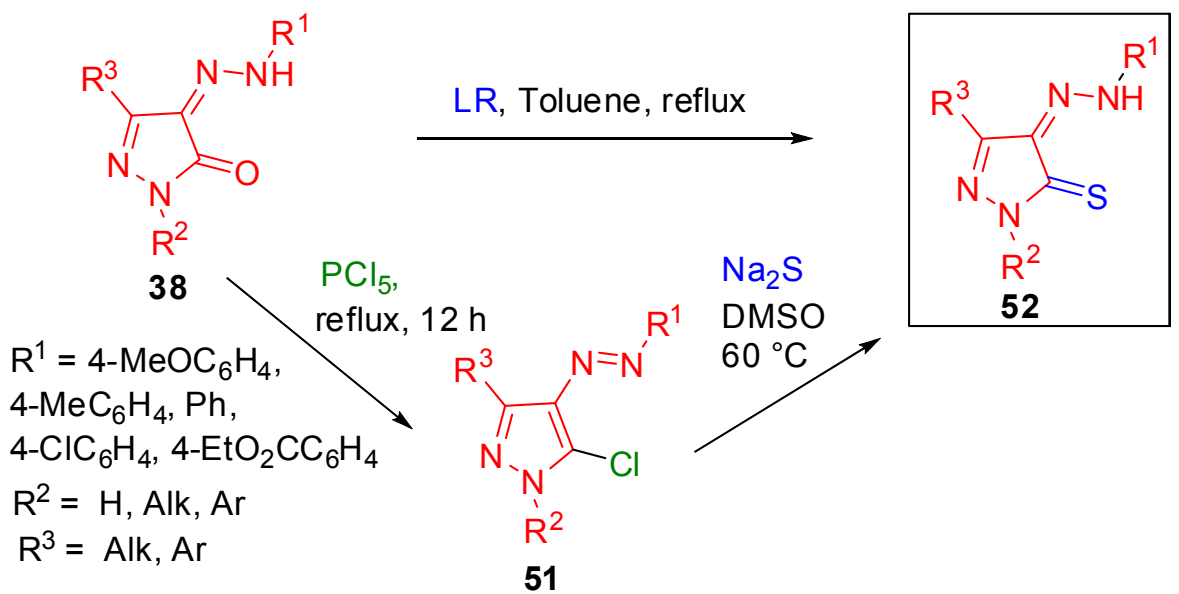

\section{Scheme 19}

There are only few examples of the synthesis of 2-arylhydrazonoacetamidines $\mathbf{4 0}$ by reaction of aryldiazonium salts with malonamidines known (Scheme 14). The alternative route for the synthesis of this type of hydrazones is the reaction of 2-arylhydrazonomalononitriles 41 with amines 53 (Scheme 20). ${ }^{24,27}$

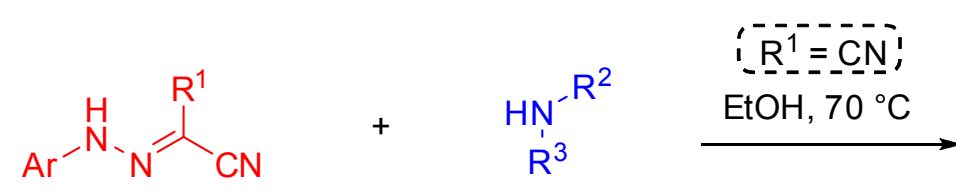

41

$\mathrm{Ar}=4-\mathrm{MeOC}_{6} \mathrm{H}_{4}, 4-\mathrm{MeC}_{6} \mathrm{H}_{4}, \mathrm{Ph}$ 4- $\mathrm{ClC}_{6} \mathrm{H}_{4}, 4-\mathrm{FC}_{6} \mathrm{H}_{4}, 3,5-\mathrm{F}_{2} \mathrm{C}_{6} \mathrm{H}_{3}$, $2,4-\mathrm{Cl}_{2} \mathrm{C}_{6} \mathrm{H}_{3}, 4-\mathrm{EtO}_{2} \mathrm{CC}_{6} \mathrm{H}_{4}, 4-\mathrm{NO}_{2} \mathrm{C}_{6} \mathrm{H}_{4}$

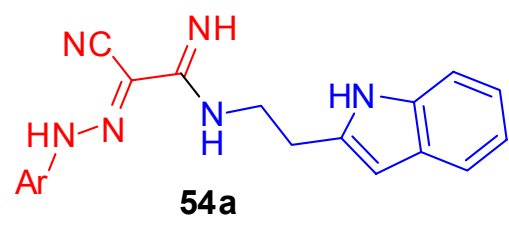

53 Examples:

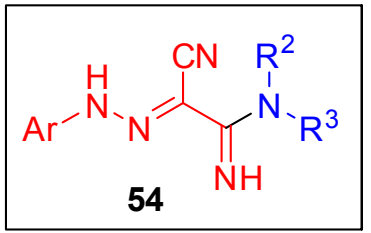

Yield $50-90 \% 37$ examples $\mathrm{NR}^{2} \mathrm{R}^{3}=\mathrm{NH}_{2}, \mathrm{NHAlk}, \widehat{\mathrm{N}} \mathrm{X}=\mathrm{CH}_{2},\left(\mathrm{CH}_{2}\right)_{2}, \mathrm{OCH}_{2}, \mathrm{CH}_{2} \mathrm{NMe}$

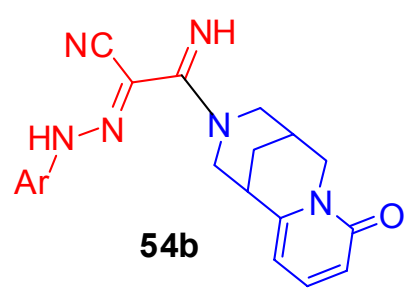

\section{Scheme 20}

This method has been applied successfully to prepare amidines $\mathbf{5 4 a , b , c}$ derived from biologically relevant product moieties, such as tryptamine, cytisine and piperazine. ${ }^{27}$

Addition of two molecules of glycine to malononitrile 41 took place under high temperature to form bis-amidine 55 that readily cyclized to bis-imidazolinone 56 in boiling glacial acetic acid (Scheme 21). ${ }^{161}$ 


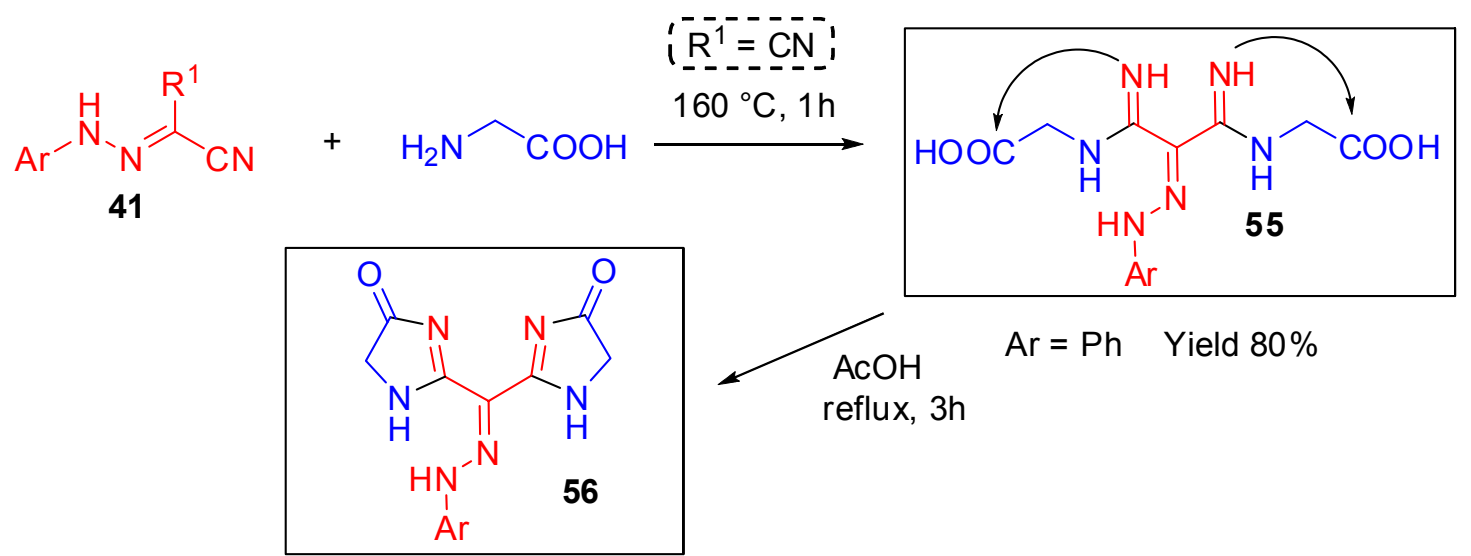

\section{Scheme 21}

2-Chloro-2-arylhydrazonoacetamides $\mathbf{5 9}$ can be prepared by the reaction of acid $\mathbf{5 7}$ with thionyl chloride followed by substitution with amines (Scheme 22). ${ }^{20 \mathrm{~b}}$ In a second stage, the chlorine of chlorohydrazone $\mathbf{5 9}$ can be substituted by the amino moiety as a result of its reaction with various amines to form 2-amino-2-phenylhydrazonoacetamides $\mathbf{6 0}$ exhibiting interesting biological properties. ${ }^{20 b, 28}$

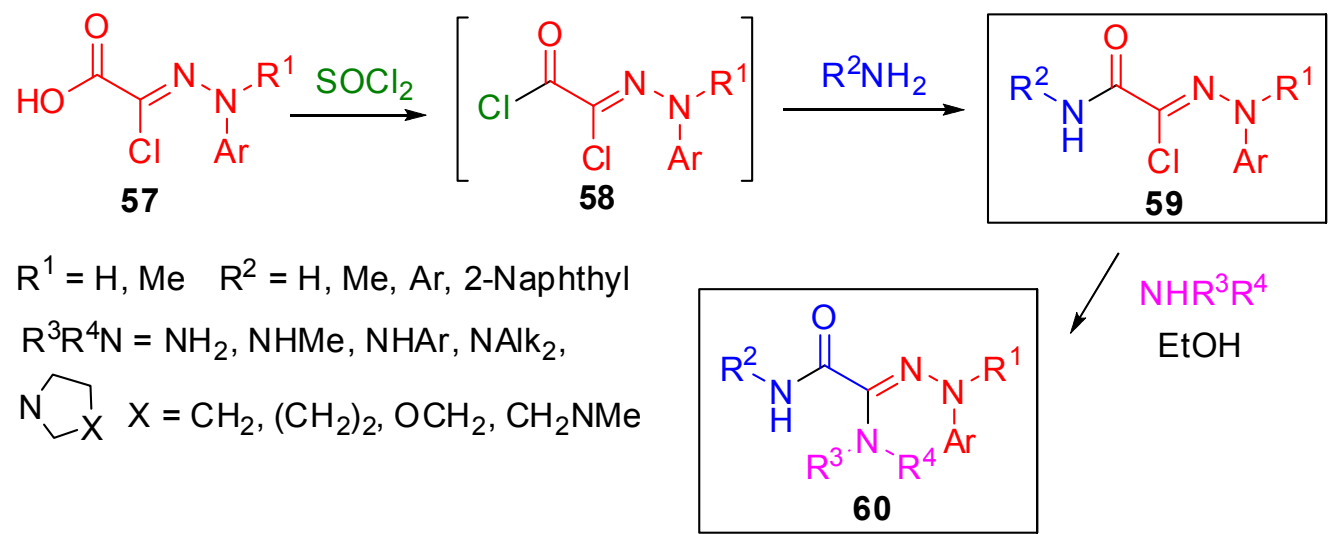

\section{Scheme 22}

2-Oxo-2-(phenylamino)acetohydrazonoyl chloride 59a was produced by the reaction of 2oxo-2-(phenylamino)acetyl chloride 61 with N-methyl-N-phenylhydrazine followed by treatment of the intermediate hydrazide $\mathbf{6 2}$ with phosphorus pentachloride in toluene to form the final product (Scheme 23). ${ }^{28 a}$ 


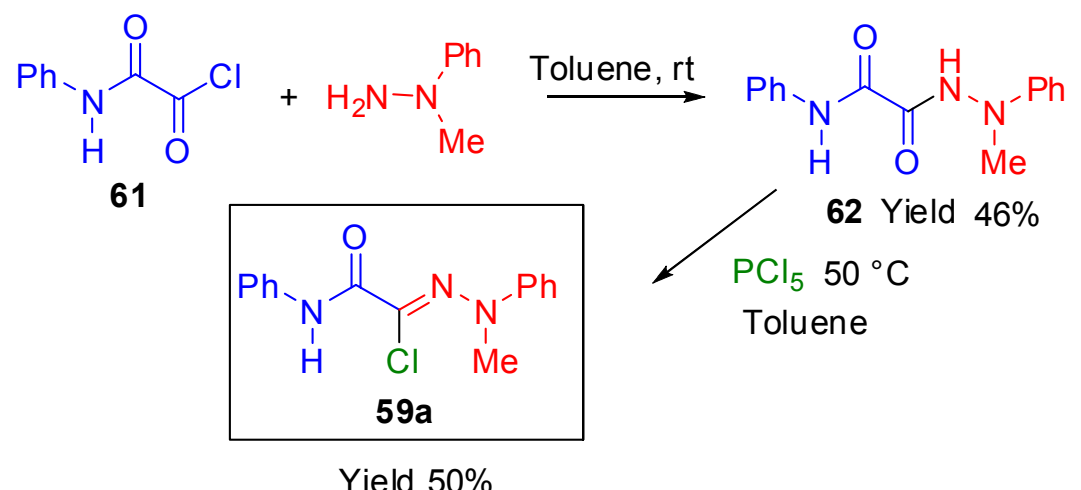

\section{Scheme 23}

4-Arylhydrazono-1H-pyrazoles can be easily prepared by the reaction of arylhydrazonomalononitrile, ${ }^{29}$ - arylhydrazonocyanoacetate, ${ }^{30}$ arylhydrazonoacetoacetate ${ }^{31}$ and arylhydrazono-3-ketiminobutyronitriles ${ }^{32}$ with hydrazine (Scheme 24). Depending on the type of EWG, 3-amino-, 3-oxo- and 3-methylpyrazoles $\mathbf{3 8}$ can be prepared by this method.

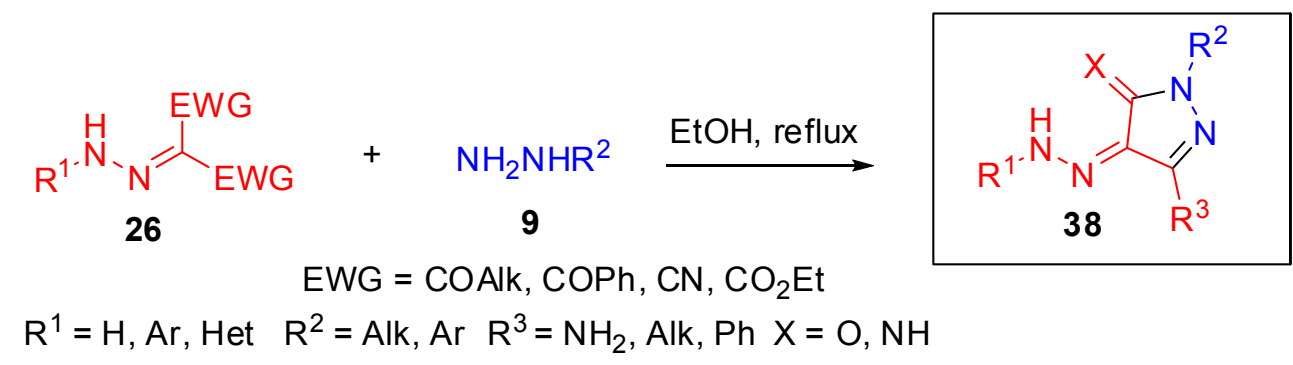

\section{Scheme 24}

Indeed, reactions of carbonyl compounds with hydrazines, coupling of diazonium salts with malonamides, malonthioamides and malonamidines and elaboration of preformed hydrazones constitute an arsenal of synthetic methods to hydrazones containing amide, thioamide and amidine groups.

\section{Structure of hydrazonoamides -thioamides and -amidines}

The hydrazono-amide, -thioamide, and -amidine molecules contain a $\pi$-system of two double bonds and an $\mathrm{NH}$-fragment that provides the basis for the azo-hydrazone tautomerism and Z,Estereoisomerism. The lone electron pairs of the heteroatoms and the NH-bonds can form hydrogen bonds and may stabilize both tautomer forms and stereoisomers. This section contain data on the azo-hydrazone tautomerism, the $Z, E$ stereoisomerism and the hydrogen bonds. 
The azo-hydrazone tautomerism has been investigated by numerous workers with a view to prove the existence of an equilibrium, to investigate the influence of substituents, solvents, temperature and to gain an understanding on the (non)existence of this thermodynamic equilibrium. ${ }^{33}$ These investigations have been conducted by a combination of spectroscopic (IR, UV, NMR ${ }^{1} \mathrm{H},{ }^{13} \mathrm{C},{ }^{15} \mathrm{~N}$ ) and computational methods and they have shown the existence of most compounds in the form of hydrazones rather than azo compounds (Scheme 25). ${ }^{3,9,11 b, 13 a, 16 i \text {, }}$ $16 \mathrm{~m}, 21,22 \mathrm{a}$

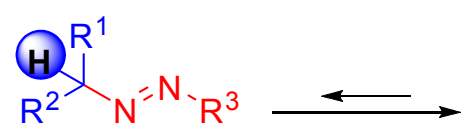

25 azo-

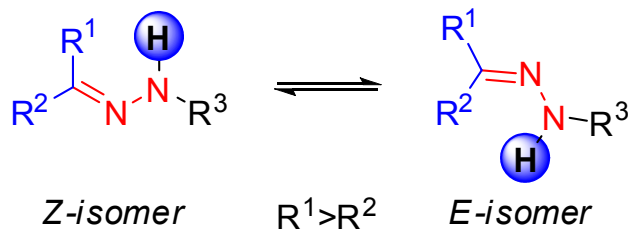

26 hydrazono-

\section{Scheme 25}

\subsection{Hydrazono-amides}

The study of the fine structure of hydrazones by various spectral methods and by single crystal $\mathrm{X}$-ray diffraction analysis has focused in major part on 2-hydrazonoacetamides. This is explained by the wide availability of many derivatives of this series and with their importance as pigments and biologically active compounds. ${ }^{28,33}$

The absorption pattern in the UV region for hydrazono-amides substituted by keto-, cyano-, amino groups and by chlorine was in each case characterized by the presence of three bands. The first one is located in the range of $390-350 \mathrm{~nm}$; the second band is located in the $290-250 \mathrm{~nm}$ region and the third one is below $240 \mathrm{~nm} .^{16 \mathrm{~g}-\mathrm{im}, 28 \mathrm{a}}$ The introduction of electron-acceptor substituents to arylhydrazonoyl fragment was shown to lead to a bathochromic shift of the first band. $^{16 \mathrm{~m}}$

UV spectra of azo compounds are characterized by an intensive wave maximum at 270-280 $\mathrm{nm}$. In contrast to azo compounds, a weak absorption band (or no band) for hydrazones is located at 284 to $295 \mathrm{~nm}$ and a strong absorption band is observed at 390-320 nm, which distinguishes these two types of compounds. ${ }^{34}$ It is worth noting that this absorption is shifted to higher wavelength in the case of the $E$-isomer in comparison with the Z-isomer, possibly due to the different hydrogen bonding in both isomers. ${ }^{28 c}$

Indeed the data of UV spectra are rather in accordance with the hydrazone than with the azo structure.

The IR spectra of hydrazono-amides also confirm their structures as hydrazones. The IR spectra of hydrazono-amides contain an NH bond stretching at $3500-3100 \mathrm{~cm}^{-1}$ corresponding to amide and hydrazono groups, three bands in the region of $1700-1500 \mathrm{~cm}^{-1}$ of $\mathrm{C}=\mathrm{O}$ bond $(1690$ $\left.1670 \mathrm{~cm}^{-1}\right)$, aromatic $\mathrm{C}=\mathrm{C}$ bonds $\left(1600 \mathrm{~cm}^{-1}\right)$, and $\mathrm{C}=\mathrm{N}$ bond $\left(1560-1570 \mathrm{~cm}^{-1}\right)$ (Scheme 26$) .{ }^{16 \mathrm{~g}-}$ $\mathrm{i}, \mathrm{m}, 28$ 


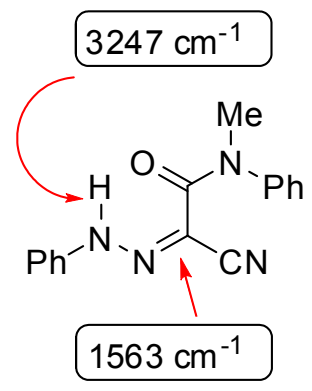

28a

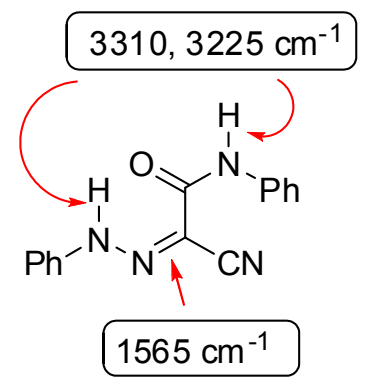

28b

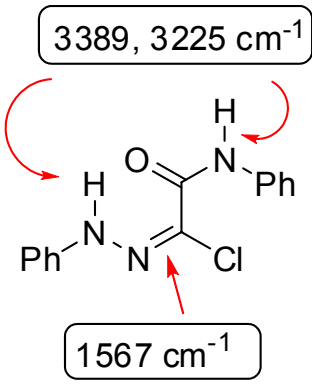

$34 a$

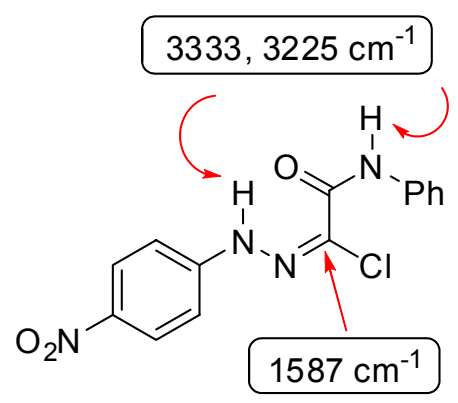

$34 b$

\section{Scheme 26}

The presence of a $\mathrm{C}=\mathrm{N}$ bond in the molecules affects the position of the $\mathrm{CN}$ stretching, shifting it to $2220 \mathrm{~cm}^{-1}$. A shift of the $\mathrm{CO}$ bond stretching to lower wavenumber has been observed in the IR spectra of hydrazones 28,34 due to both conjugation with $\mathrm{C}=\mathrm{N}$ bond and formation of a hydrogen bond with the carbonyl group. ${ }^{16 \mathrm{~h}}$

The ${ }^{1} \mathrm{H},{ }^{13} \mathrm{C}$ and ${ }^{15} \mathrm{~N}$ NMR spectroscopic techniques and an X-ray diffraction of single crystals are much more informative tools for the study of the fine structure of hydrazono-amides including information on $Z, E$-isomerism and hydrogen bonding.

The presence of a signal in the ${ }^{1} \mathrm{H}$ NMR spectra in the region of 8-15 ppm gives evidence of the presence of an ArNH fragment and confirms the hydrazone structure. Furthermore, the downfield shift of this signal is characteristic for the formation of an intramolecular hydrogen bond of the NH proton. The amide proton $(-\mathrm{NH}-\mathrm{C}=\mathrm{O})$ is found back as a singlet at $\delta 10.98$ 11.16 , and the hydrazone proton $(>\mathrm{C}=\mathrm{N}-\mathrm{NH})$ shows a singlet at $\delta 13.90-14.32 .^{3,33 \mathrm{~b}}$ The strongest hydrogen bonds are presented in the amides of 2-hydrazonoacetoacetic acid $\mathbf{2 8}\left(\mathrm{X}=\mathrm{O}, \mathrm{R}^{4}=\mathrm{Ac}\right)$. For this type of compounds, one can propose keto-hydrazone and azo-enol tautomer forms. The X-ray analysis of azo-pigment Maize 1 (28c) allows to rule out the azo-enol form 28c from consideration for crystalline state (Scheme 27). ${ }^{33 a}$

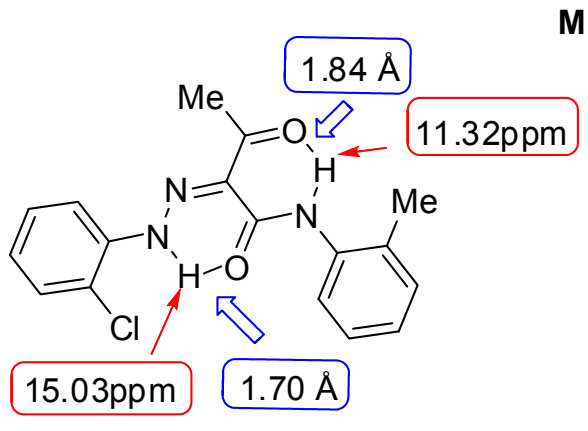

28c keto-hydrazone

Maize 1

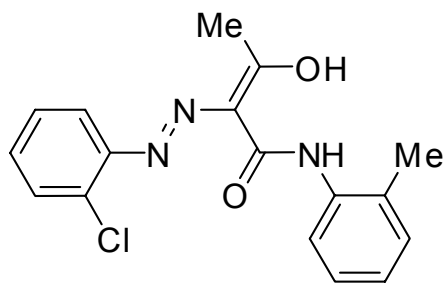

28c azo-enol

Scheme 27 
The signals of the $\mathrm{NHN}=\mathrm{C}$ proton of hydrazonoyl chlorides $34\left(\mathrm{X}=\mathrm{Cl}, \mathrm{R}^{1}=\mathrm{Ar}\right.$, $\mathrm{NR}^{2} \mathrm{R}^{3}=\mathrm{NHAr}$ ) in the ${ }^{1} \mathrm{H}$ NMR spectra are upfield shifted in comparison with ketone hydrazones 63 and are slightly down shifted in comparison with arylhydrazone of acetone 64 (Scheme 28). ${ }^{28 \mathrm{a}, 35}$

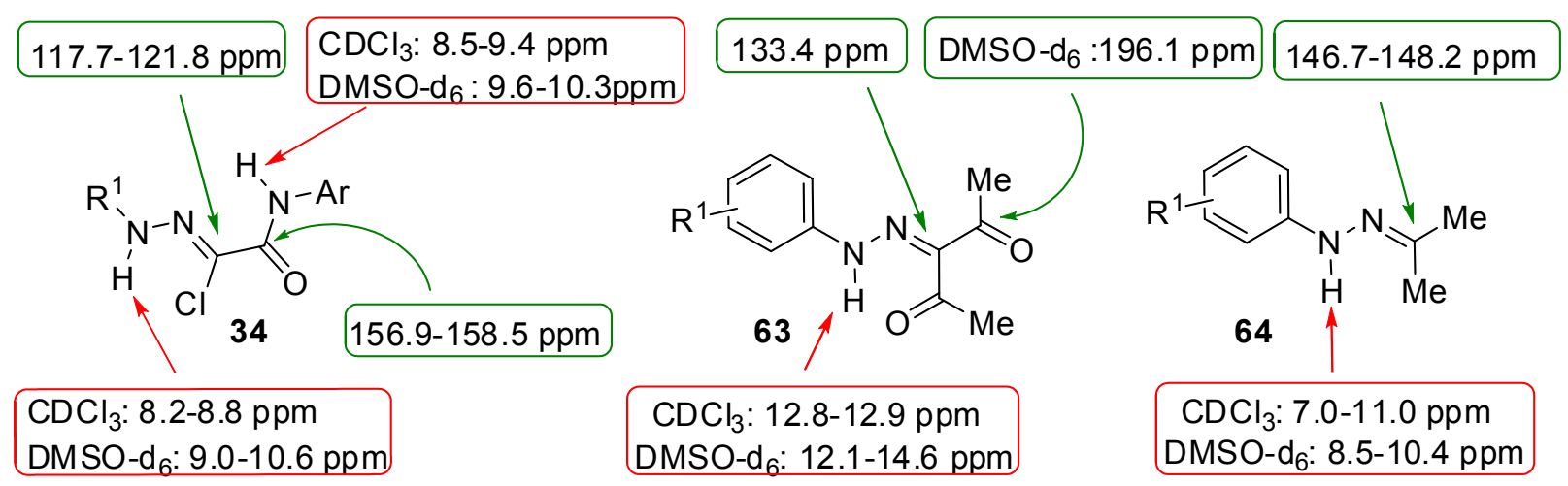

\section{Scheme 28}

Similar to the trends seen in the ${ }^{1} \mathrm{H}$ NMR spectra, the signal of iminyl carbon of hydrazonoyl chlorides 34 in the ${ }^{13} \mathrm{C}$ NMR spectra is upfield shifted for more than $25 \mathrm{ppm}$ in comparison with acetone N-phenylhydrazones $\mathbf{6 4}$ and for $15 \mathrm{ppm}$ in comparison with 2arylhydrazonoacetoacetates $\mathbf{6 3}$ (Scheme 28). ${ }^{3,35}$

The data of single crystal X-ray diffraction of of arylhydrazonoyl chloride $\mathbf{3 4}$ show the coplanarity of the amide and the hydrazono fragments with a deviation from planarity of only 7$9^{\circ}$ (Scheme 29). Two intramolecular hydrogen bonds $\mathrm{N}-\mathrm{H}-\mathrm{Cl}$ and $\mathrm{N}-\mathrm{H}-\mathrm{N}$ are present in the molecule as shown in Scheme 29. Both compounds, as shown by X-ray analysis, are Zconfigured. $^{28 a}$
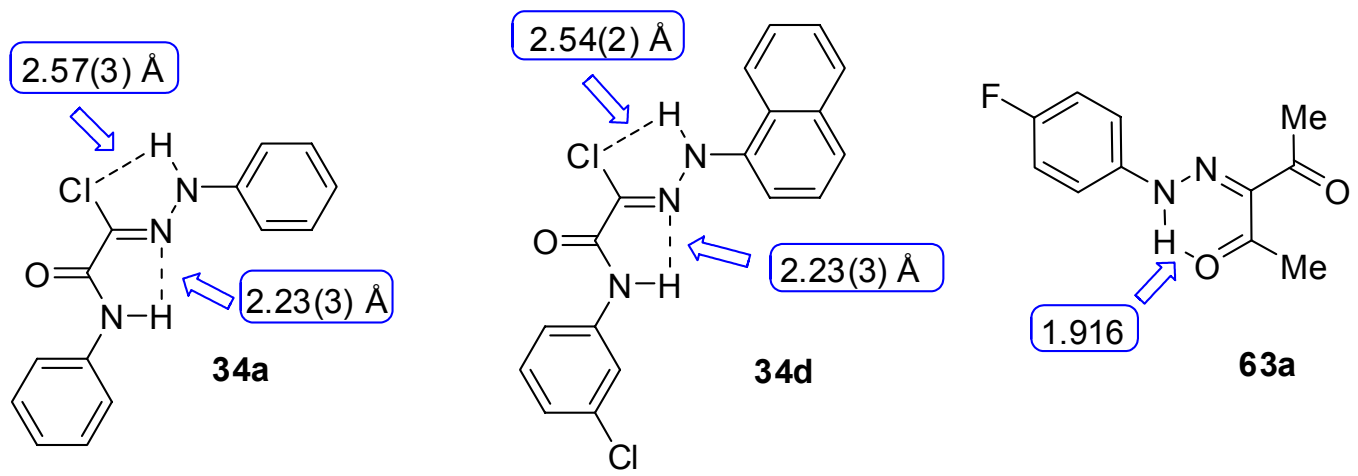

\section{Scheme 29}

NMR spectra of amidrazones of type $\mathbf{6 0}$ (Scheme 22) are rather complex and often contain sets of signals for protons of various isomers. The introduction of an amino group leads to the 
possibility of formation of new hydrogen bonds, that can stabilize stereoisomers with various positions of carbonyl and $\mathrm{C}=\mathrm{N}$ bonds of the hydrazono group. Crude products of different reaction mixtures were investigated by ${ }^{1} \mathrm{H}$ NMR spectroscopy. It could be observed that the mixture contained variable amounts of $E$-isomers but always less than $50 \%$. NOE experiments with compound $60 \mathrm{a}\left(\mathrm{R}^{1}=\mathrm{Ph}, \mathrm{R}^{2}=\mathrm{Ph}, \mathrm{NR}^{3} \mathrm{R}^{4}=\mathrm{NMe}_{2}\right)$ revealed that it exists as a mixture of $Z$ - and $E$-isomers (Scheme 30 ) where the $Z$-isomer is the major product. ${ }^{28 \mathrm{c}}$
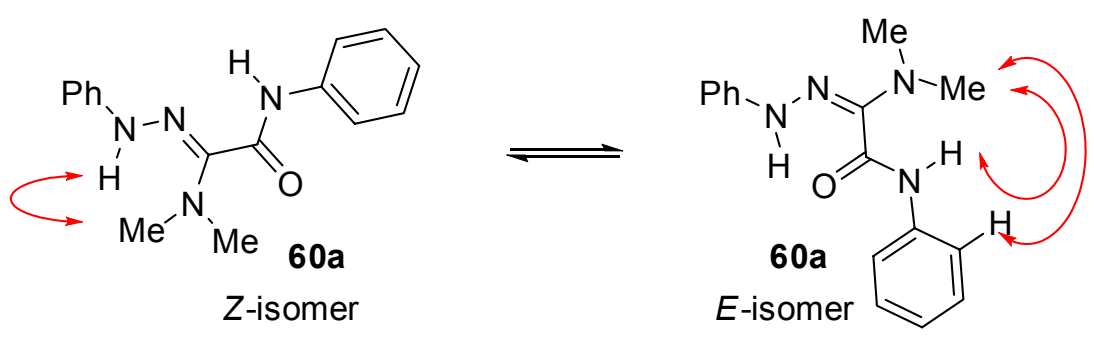

\section{Scheme 30}

In some cases, $Z$ - and $E$-isomers of hydrazones $\mathbf{6 0}$ could be separated from the crude products by fractional crystallization or column chromatography. X-ray diffraction analysis of the hydrazones $\mathbf{6 0 b}, \mathbf{c}$ confirmed that these compounds are $Z$-configured (Scheme 31 ). ${ }^{28 \mathrm{c}}$

\section{Scheme 31}
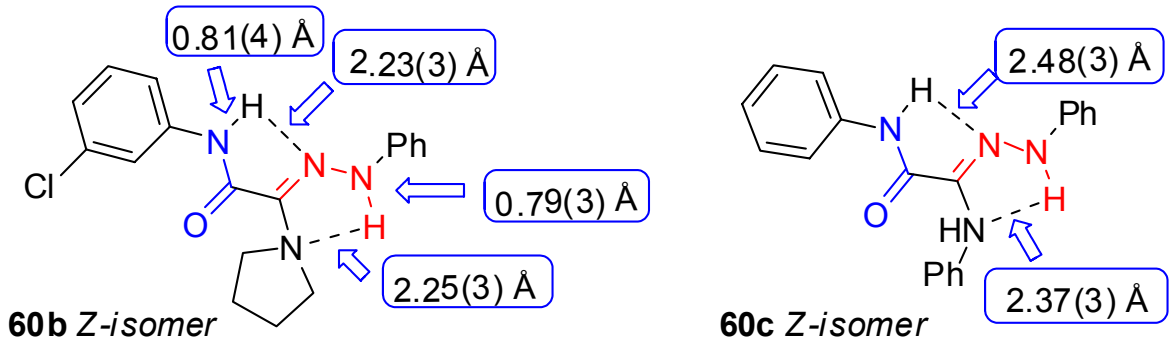

Unfortunately, all efforts to get crystals of $E$-isomers $60 \mathrm{a}$ resulted in the isolation of crystals of an $E / Z$-isomer mixture in ratio 1:1 (Scheme 32 ). ${ }^{28 \mathrm{c}}$

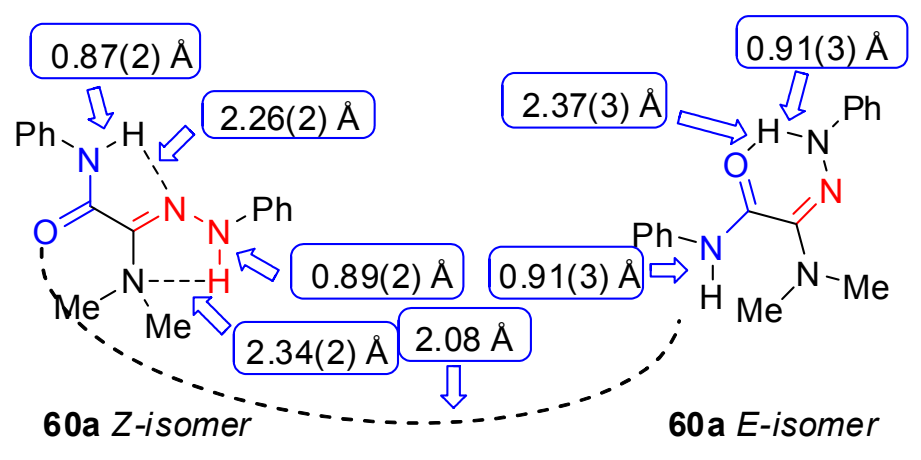

Scheme 32 
Similar to Z-60b,c, that is stabilized by two intramolecular hydrogen bonds (Scheme 31), E60a has also two hydrogen bonds one of them is between the carbonyl oxygen atom and the NH of the hydrazono group and another one between the $\mathrm{NH}$ of the amide fragment and the oxygen atom of the carbonyl group of the $Z / E$-isomer $60 \mathbf{a}$ as shown in Scheme 32.

The formation of two intramolecular hydrogen bonds is confirmed by the shift of signals for the amide NH proton and of the carbon signal the $\mathrm{C}=\mathrm{N}-\mathrm{NHAr}$ group of Z-60 that is upfield shifted in comparison with the $E$-isomer. On the contrary the proton signal of the hydrazono group is downfield shifted (Scheme 33). ${ }^{28 \mathrm{c}}$

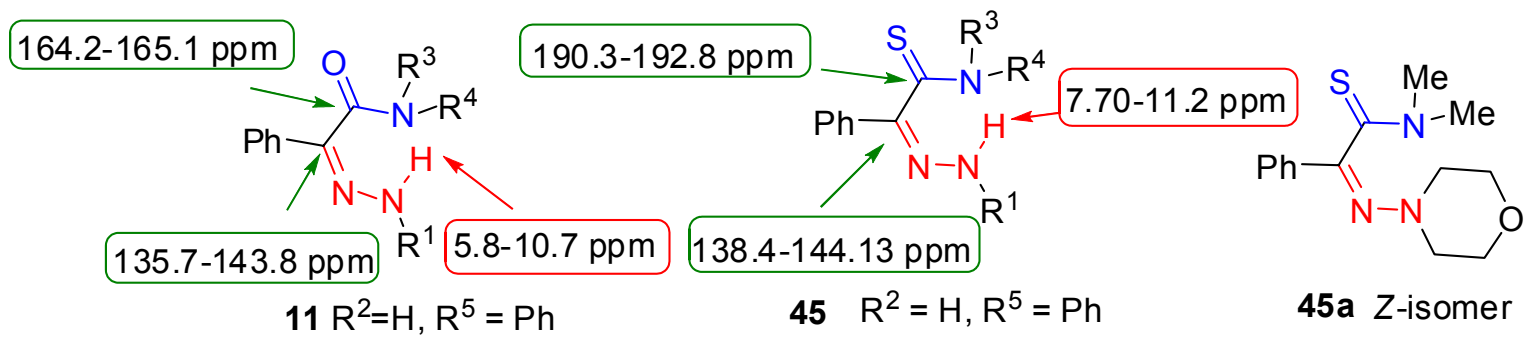

\section{Scheme 33}

$A b$ initio calculations, carried out at the RHF/6-31G* level ${ }^{28 c}$ demonstrated that the $Z$ isomers of compounds 60 containing either dimethylamino or morpholino groups at position 2 are thermodynamically more stable than the $E$-isomers. The energy differences between the $Z$ and $E$-isomers range between $1.411 \mathrm{kcal} / \mathrm{mol}$.

On the other hand, F. Krauth et $a l^{28 \mathrm{~d}}$ calculated the energy of $Z$-, and $E$-isomers for hydrazones 60 bearing a piperidine ring at position 2 by the B3LYP/6-31G(d) method and confirmed the higher stability of $E$-isomer for compounds 60d,e and equal stability for the isomers of $60 \mathrm{f}$ (Scheme 34).

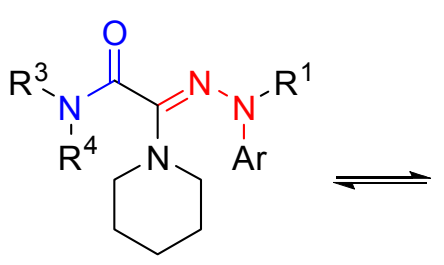

60 Z-isomer

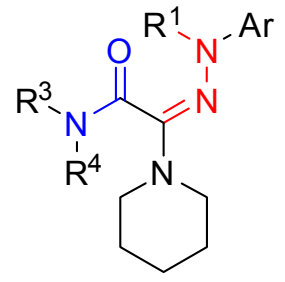

60 E-isomer

$\begin{array}{ccccc}60 & \mathrm{Ar} & \mathrm{R}^{1} & \mathrm{NR}^{3} \mathrm{R}^{4} & \Delta \mathrm{E}, \mathrm{kcal} / \mathrm{mol} \\ \text { d } & \mathrm{Ph} & \mathrm{Me} & \mathrm{NHPh} & 6.44 \\ \text { e } & \mathrm{Ph} & \mathrm{H} & \mathrm{NHPh} & 8.11 \\ \text { f } & 4-\mathrm{MeC}_{6} \mathrm{H}_{4} & \mathrm{H} & \mathrm{NMe}_{2} & 0\end{array}$

\section{Scheme 34}

It is worth noting that intra- and intermolecular hydrogen bond interactions, which are identified in solid state of compounds 60 (Scheme 30-33), may not be present in polar solvents. All compounds were found to form $E / Z$-equilibrium in solution. ${ }^{28}$ 


\subsection{Hydrazono-thioamides}

The fine structure of hydrazono-thioamides has been studied to a lesser extent as hydrazonoamides. As the rule, authors publish limited data sufficient to identify the common structure and purity of prepared compounds.

The study of the NMR spectra of thioamides $\mathbf{4 5}$ shows that the NH proton signals and the carbon signals of the $\mathrm{C}=\mathrm{N}-\mathrm{NH}$ fragment are downfield shifted in comparison with amide $\mathbf{1 1}$ as shown in Scheme 35. Single crystal X-ray diffraction analysis of compound 45a has shown that hydrazono-thioamides of this type mainly exist in the $Z$-isomeric form. ${ }^{11 b}$

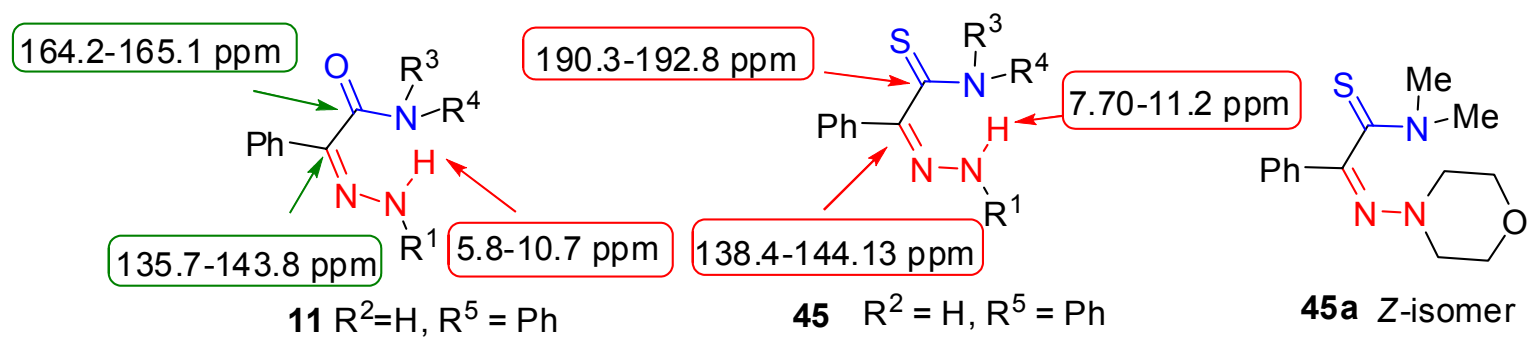

\section{Scheme 35}

Apart from other compounds of this series, hydrazones 45 b-d $\left(R^{2}=H, R^{5}=P h\right.$, $\mathrm{NR}^{3} \mathrm{R}^{4}=\mathrm{NHMe}, \quad \mathrm{NR}^{1} \mathrm{R}^{2}=$ morpholin-4-yl (b); $\mathrm{NR}^{1} \mathrm{R}^{2}=\mathrm{NHC}_{6} \mathrm{H}_{4} \mathrm{Cl}-4$ (c); $\mathrm{NR}^{1} \mathrm{R}^{2}=\mathrm{NHC}_{6} \mathrm{H}_{4} \mathrm{Me}-4$ (d)) are a mixture of isomers that were separated by column chromatography. According to the NMR spectra, each isomer transforms to the original mixture in chloroform within $1 \mathrm{~h}$.

Hydrazones of isatine 20, 36, 49 (Schemes 5,12,18) and the corresponding thio derivatives 47, 50 (Schemes 18), as viewed by their ${ }^{1} \mathrm{H}$ NMR spectra and data of X-ray analysis' 47a $(\mathrm{R}=\mathrm{Me}),{ }^{21} 20\left(\mathrm{R}^{1}=\mathrm{PhCO}, \mathrm{R}^{2}=\mathrm{MeO}, \mathrm{R}^{3}=\mathrm{C}_{6} \mathrm{H}_{11} \text { (a), } \mathrm{R}^{1}=\mathrm{PhCO}, \mathrm{R}^{2}=\mathrm{H}, \mathrm{R}^{3}=\mathrm{C}_{6} \mathrm{H}_{11} \text { (b) }\right)^{13 \mathrm{a}}$ exist predominantly in the $Z($ cis $)$-conformation, both in solution and in the solid state. This is due to the hydrogen bonding between the hydrazone $\mathrm{NH}$ and the carbonyl or thiocarbonyl group of indolinone (resp. thioindolinone)(Scheme 36).

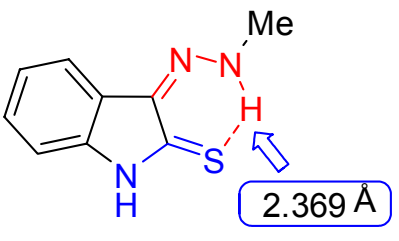

47a Z-isomer

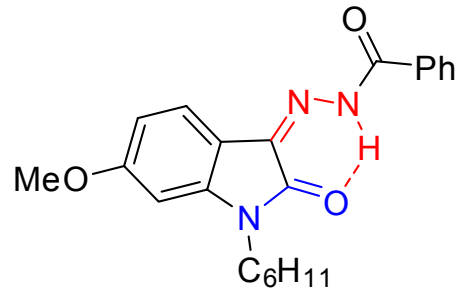

20a Z-isomer

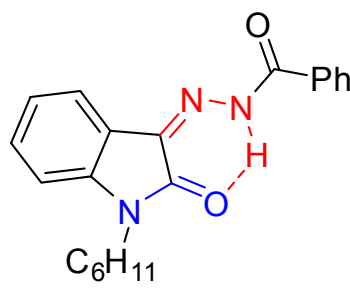

20b Z-isomer

Scheme 36

In the case of the presence of groups bearing heteroatoms with lone electron pair at position 4, an alternative hydrogen bond with the linker $\mathrm{NH}$ can be formed allowing the formation of the $E$ (trans)-conformation. ${ }^{13 a}{ }^{1} \mathrm{H}$ NMR spectra of equilibrated samples $20 \mathbf{c}\left(\mathrm{R}^{1}=\mathrm{OPh}\right)$ and $20 d\left(\mathrm{R}^{1}=\right.$ 
$\mathrm{CONH}_{2}$ ) correspond to a mixture of $Z$ - and $E$-isomers. For example, the 4-phenoxy derivate 20c was observed as $5: 2 Z: E$ mixture after 10 days of equilibration (Scheme 37), and 20d was found as $1: 7 Z: E$ mixture. ${ }^{13 a}$

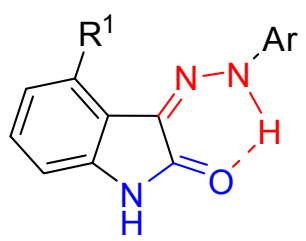

20c Z-isomer

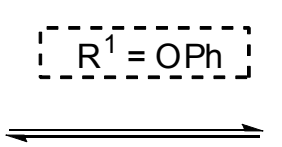

$\mathrm{Ar}=4-\mathrm{NH}_{2} \mathrm{SO}_{2} \mathrm{C}_{6} \mathrm{H}_{4}$

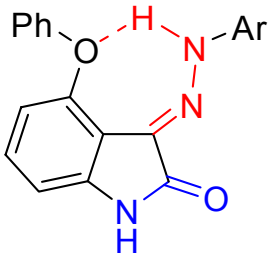

20c E-isomer

\section{Scheme 37}

In principle, hydrazono-pyrazoles $\mathbf{3 8}(\mathrm{X}=\mathrm{O})$ and $\mathbf{5 2}(\mathrm{X}=\mathrm{S})($ Schemes 13,19$)$ can exist in four isomeric froms A-D (Scheme 38). ${ }^{22 \mathrm{a}, \mathrm{d}, 36}$ As shown by NMR spectroscopy in solution and X-ray structural determinations in the solid state, the tautomer A represents the energy preferred isomeric forms for most compounds $\mathbf{3 8 , 5 2}$.

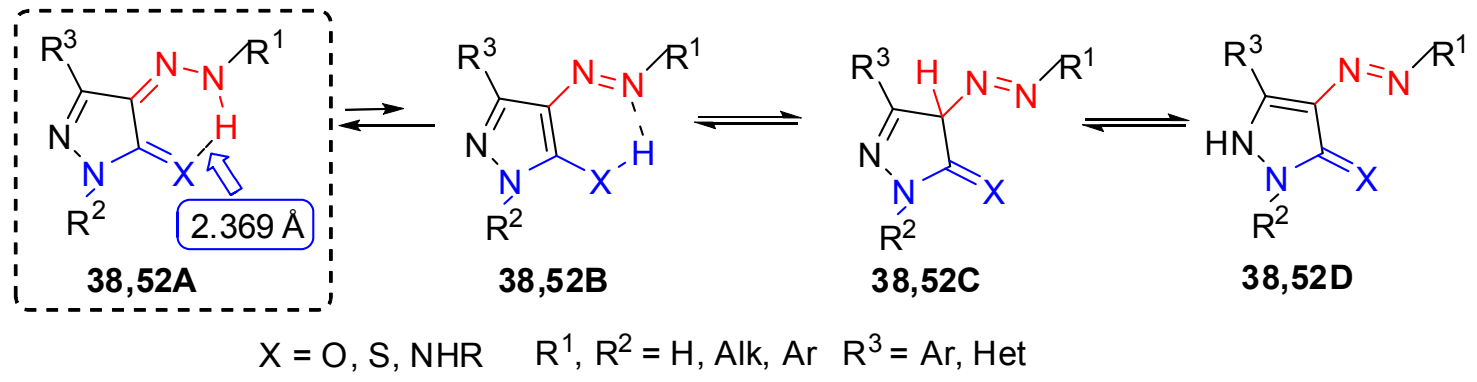

\section{Scheme 38}

To study the tautomerism of these compounds, 4-hydrazono-1H-pyrazol-5(4H)-ones 38 $(\mathrm{X}=\mathrm{O})$ labeled with ${ }^{15} \mathrm{~N}$ in the $\mathrm{NHR}^{1}$ fragment were synthesized and their ${ }^{1} \mathrm{H}$ NMR spectra were carefully studied. ${ }^{22 \mathrm{a}}$ In chloroform solution at 38 and $60^{\circ} \mathrm{C}$, the unlabeled material $\mathbf{3 8} \mathbf{a}, \mathbf{b}(\mathrm{X}=\mathrm{O}$, $\left.\mathrm{R}^{1}=\mathrm{R}^{2}=\mathrm{Ph}, \mathrm{R}^{3}=\mathrm{Me}(\mathbf{a}), \mathrm{X}=\mathrm{NHPh}, \mathrm{R}^{1}=\mathrm{R}^{2}=\mathrm{Ph}, \mathrm{R}^{3}=\mathrm{Me}(\mathbf{b})\right)$ gave a broad singlet at $13.5 \mathrm{ppm}$, whereas the compound labeled by ${ }^{15} \mathrm{~N}$ showed a doublet at $13.5 \mathrm{ppm}$, indicative of a proton attached to ${ }^{15} \mathrm{~N}$. Since the value of the spin-spin coupling constant is quite large $(J=96 \mathrm{~Hz})$, and since the area of the ${ }^{15} \mathrm{~N}$ proton peaks relative to the aromatic protons was in good ratio, these compounds must exist entirely in the hydrazono form under these conditions. The presence of one ${ }^{15} \mathrm{~N}$-induced doublet in the ${ }^{1} \mathrm{H}$ NMR spectrum of $\mathbf{3 8 a}, \mathbf{b}$ indicates that only one geometric isomer of the hydrazono form exists in this solvent, while the far-downfield position of the $\mathrm{NH}$ peak suggests that the proton is involved in strong intramolecular hydrogen bonds. 
${ }^{15} \mathrm{~N}$ NMR experiments carried out by Connors et al. ${ }^{36 \mathrm{~b}}$ (Scheme 39) and crystal structure determination support the formation of arylazopyrazolones as their hydrazone tautomers both in solution and the solid state.
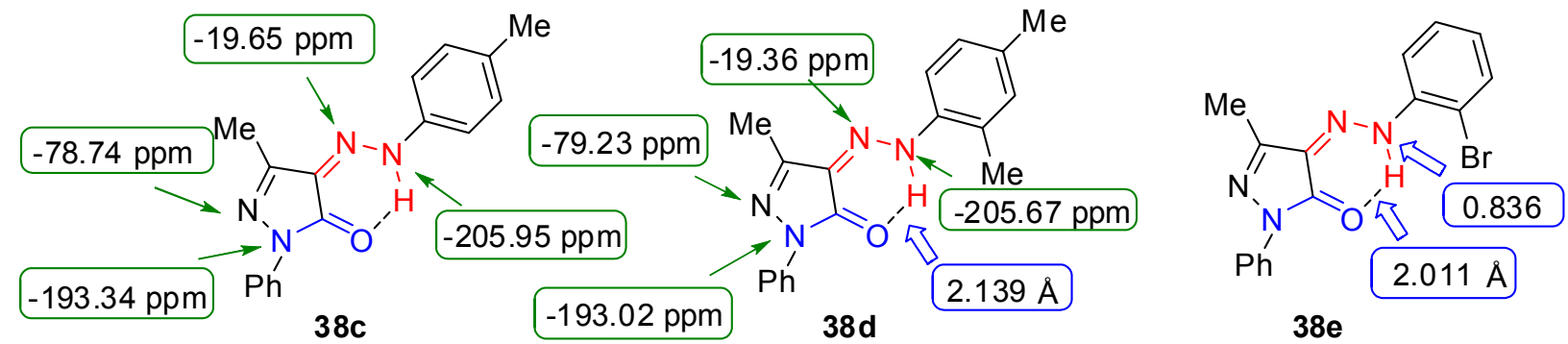

Scheme 39

For the imino derivatives $\mathbf{3 8}(\mathrm{X}=\mathrm{NR})$ the equilibrium is shifted to the amino-azo form $\mathrm{B} .^{22 \mathrm{~d}}$

\subsection{Hydrazono-amidines}

In principle 2-arylhydrazonoacetamidines 54 can exist in three tautomeric forms A-C (Scheme 40). ${ }^{27}$

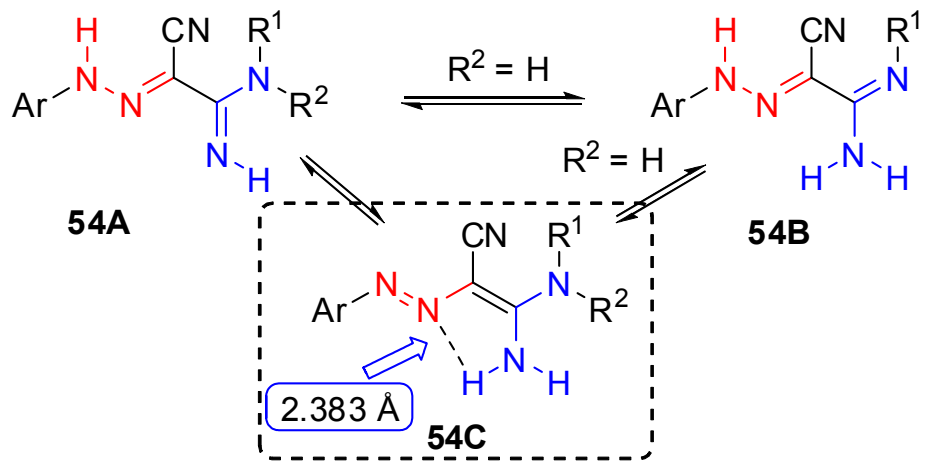

\section{Scheme 40}

There are no NH proton signals in the ${ }^{1} \mathrm{H}$ NMR spectra of compounds 54 that would correspond to the hydrazono group. The signals of the amino groups of the amidine fragment are shown as a broad four proton singlet for compounds $54\left(\mathrm{R}^{1}=\mathrm{R}^{2}=\mathrm{H}\right)$ at $6.65-7.18 \mathrm{ppm}$; as a one proton singlet and a two proton singlet for compounds $54\left(\mathrm{R}^{1}=\mathrm{H}, \mathrm{R}^{2}=\mathrm{Me}, \mathrm{Cy}\right)$ at $7.15-7.42$ ppm; and as a two proton singlet for compounds $54\left(\mathrm{NR}^{1} \mathrm{R}^{2}=\mathrm{NAlk} \mathrm{k}_{2}\right)$ at $6.58-6.97 \mathrm{ppm}$. IR spectra of compounds 54 show a few broad bands between $3200-3450 \mathrm{~cm}^{-1}$ confirming the presence of amino groups. X-Ray diffraction analysis of single crystal for $54\left(\mathrm{NR}^{1} \mathrm{R}^{2}=\right.$ piperidin1-yl, $\mathrm{Ar}=4-\mathrm{MeOC}_{6} \mathrm{H}_{4}$ ) show the existence of compounds 54 in the $E$, $E$-arylazo tautomeric form $\mathrm{C}$ with planarity of double bonds $\mathrm{C}=\mathrm{C}$ and $\mathrm{N}=\mathrm{N}$ bonds. It is worth noting the presence of the 
hydrogen bond of the amidine hydrogen with the nitrogen atom of the azo group as shown in Scheme 40.

Indeed, of hydrazonoamide, -thioamide and -amidine molecules contain hydrogen bonds that take part in stabilization of various isomeric forms. In contrast to hydrazonoamides and thioamides that exist in the hydrazono form, hydrazonoamidines exist preferably in the arylazo tautomeric form both in solution and in the solid state.

\section{Chemical properties of hydrazono-amides, -thioamides and -amidines}

Hydrazones exhibit a varied reactivity, taking part in reactions with nucleophiles, electrophiles and other chemical reagents. Being ambident nucleophiles, hydrazones react with electrophilic reagents with participation of either the nitrogen atom (compounds $\mathbf{6 5 , 6 6}$ ), ${ }^{3 \mathrm{a}, 10}$ or the carbon atom of the azomethine group (compounds 67). ${ }^{3 a, 10}$ Strong bases deprotonate hydrazones to form anions of types 68,69, whereas nucleophiles attack the azomethine carbon atom to form products of both addition 70,71 and substitution 72. ${ }^{3,6}$ Furthermore, hydrazones can be reduced to amines $\mathbf{7 3}$ or oxidized to diazo compounds $\mathbf{7 4}^{3}$ (Scheme 41 ).

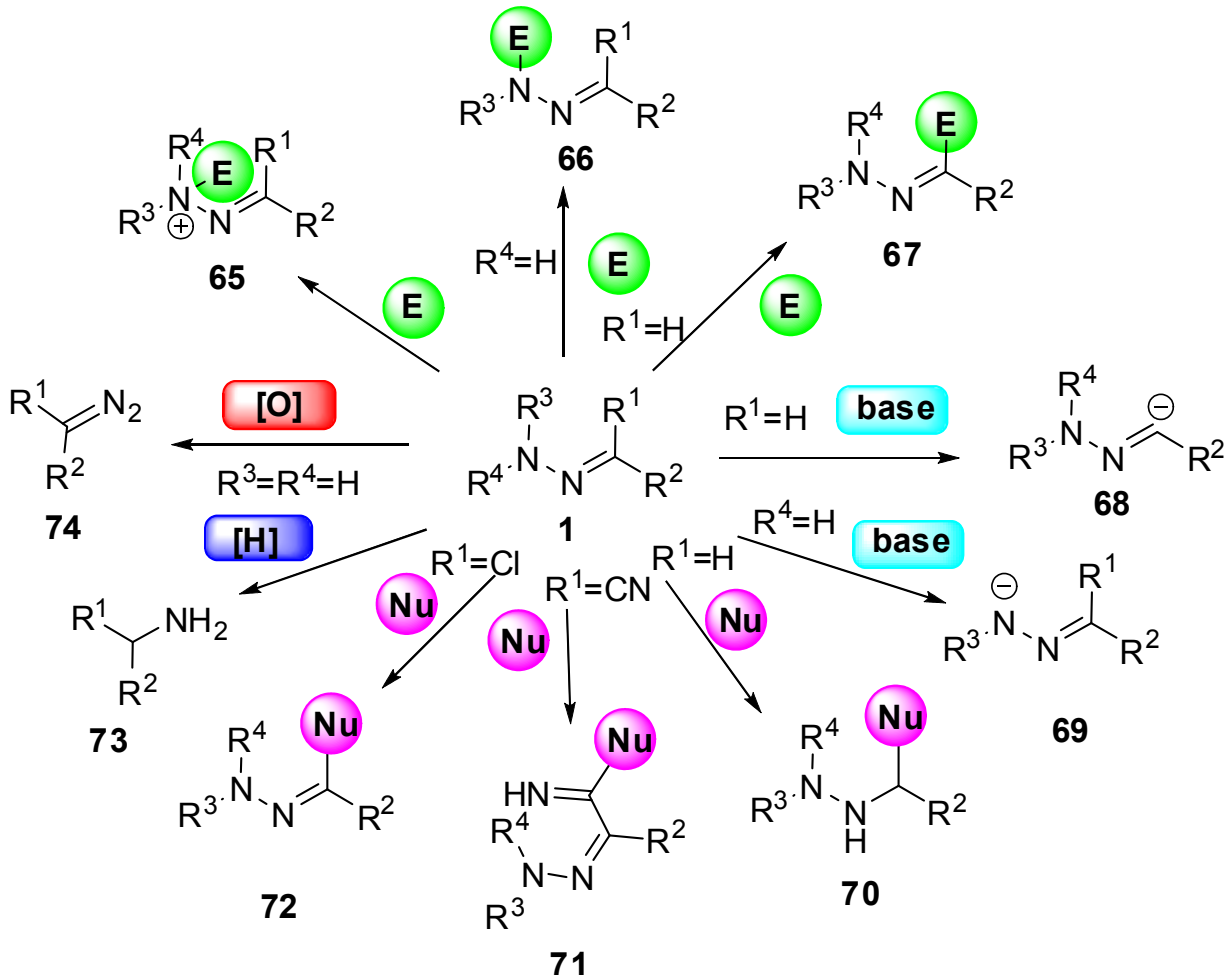

Scheme 41. Reactions of hydrazones with different type of reagents. 


\subsection{Reactions with nucleophiles}

Hydrazones of aldehydes and ketones are prone to form the addition products to the $\mathrm{C}=\mathrm{N}$ bond, rather than to form the products of substitution. In contrast, in the case of the presence of good leaving groups at the carbon atom, the substitution reactions occur smoothly to give compounds with new substituents. ${ }^{6}$ The nucleophilic reagents that can be used in these reactions are alkali hydroxides, alkoxides, azides, ammonia, amines and hydrazines. Thus, substitution reaction of halogen by amines is used to prepare amidrazones 60 (Scheme 22).

The introduction of amide and thioamide groups to the molecules of hydrazones drastically expands the scope of these reactions. Most of such reactions are used to prepare new derivatives of hydrazones bearing amide, thioamide and amidine groups. Thus, 2-hydrazonoacetamides 11, isatine hydrazones 36, 49, and hydrazonopyrazolones 38 react with Lawesson's reagent to form the substitution products of the oxygen atom by sulfur, namely the thioamides 45-47,50,52 (Scheme 17-19). The cyano group of hydrazonomalononitriles 41 is capable of adding hydrogen sulfide to give 2-hydrazonothioacetamide 44 (Scheme 16). Primary and secondary amines can also react with hydrazonomalononitriles 41 to form hydrazono-amidines 54 (Scheme 20).

\subsection{Reactions with electrophiles}

The introducing of amide, thioamide and amidine groups to molecules of hydrazones of aldehydes and ketones gives new centers that are capable of reacting with electropilic reagents. Alternative reactions can take place to give products of substitution at both hydrazono and new groups. Alkylation of arylhydrazones $\mathbf{2 8}(\mathrm{X}=\mathrm{O})$ is directed to $\mathrm{NH}$ of hydrazono group to afford disubstituted hydrazones 75. This reaction can be recommended as the methods of choice to prepare disubstituted hydrazones of type 75 (Scheme 45). ${ }^{161, t, 37}$

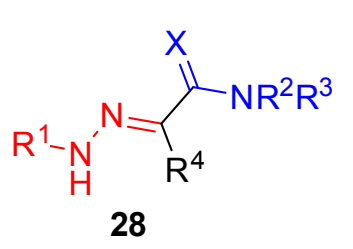

Method A: KOH, EtOH, DMF Method B: KN(SiMe $)_{2}$, Toluene

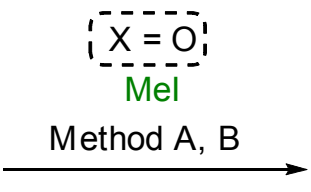

$\mathrm{R}^{1}=4-\mathrm{MeC}_{6} \mathrm{H}_{4}, \mathrm{Ph}$ $\mathrm{NR}^{2} \mathrm{R}^{3}=\mathrm{NH}_{2}, \mathrm{NMe}_{2}, \mathrm{NEt}_{2}$ $\mathrm{R}^{4}=\mathrm{Et}, \mathrm{CN}$

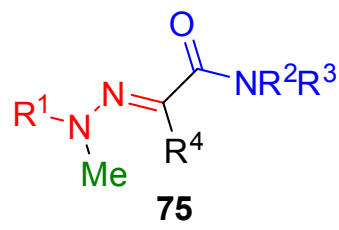

\section{Scheme 42}

The sulfur atom of 2-arylhydrazonothioacetamides $28(\mathrm{X}=\mathrm{S})$ takes part in reaction with alkyl halides to form thioimidates $\mathbf{7 6}$ or thioaminals 77 (Scheme 43). ${ }^{17 \mathrm{~b}, 27}$ 

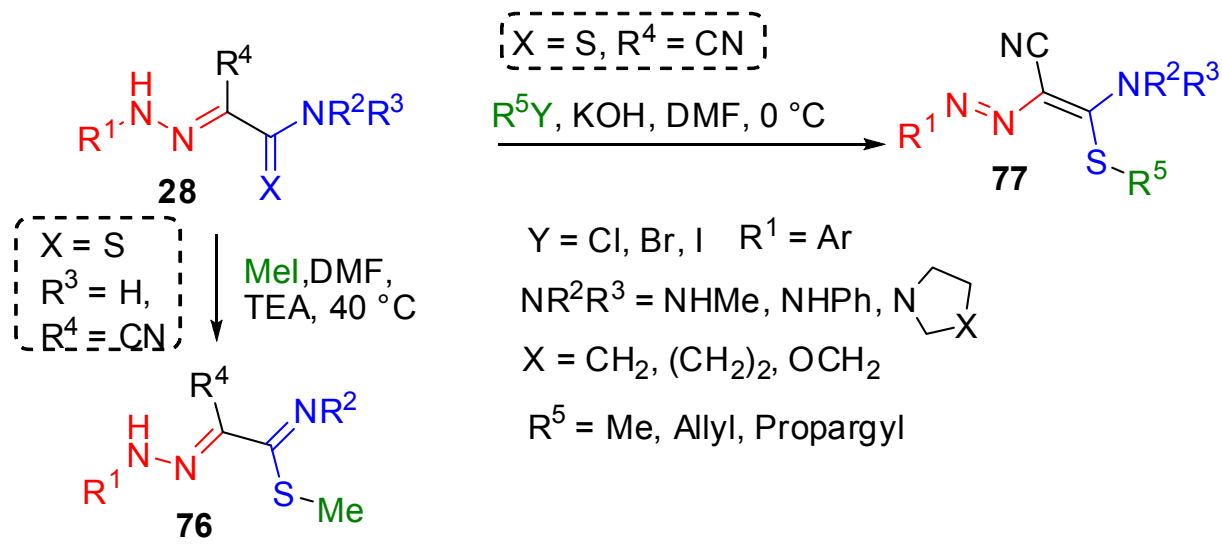

$\mathrm{Y}=\mathrm{Cl}, \mathrm{Br}, \mathrm{I} \quad \mathrm{R}^{1}=\mathrm{Ar}$

$\mathrm{NR}^{2} \mathrm{R}^{3}=\mathrm{NHMe}, \mathrm{NHPh}, \mathrm{N}_{\mathrm{X}}$

$X=\mathrm{CH}_{2},\left(\mathrm{CH}_{2}\right)_{2}, \mathrm{OCH}_{2}$

$\mathrm{R}^{5}=\mathrm{Me}$, Allyl, Propargyl

\section{Scheme 43}

In contrast to 2-cyano hydrazones 28, 2-phenylhydrazones 45 can slowly react with alkyl iodide in the absence of a base to form thioimminium salts 78 (Scheme 44). ${ }^{11 \mathrm{a}}$

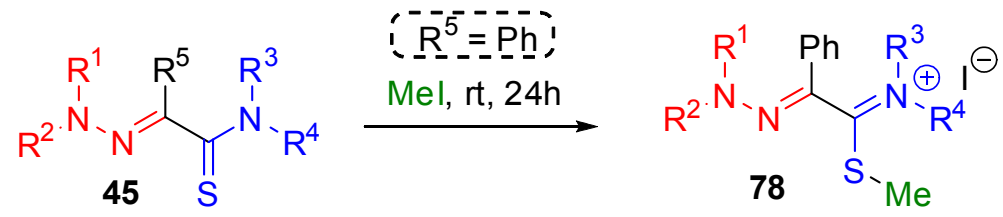

$$
\mathrm{NR}^{1} \mathrm{R}^{2}=\mathrm{NMe}_{2}, \mathrm{NHPh}, \mathrm{N} \mathrm{N} \quad \text { Yield 96-100\% }
$$

\section{Scheme 44}

Reactions of 2-alkylhydrazono-2-phenylethanethioamides 45 with less polarizable electrophiles take place at the nitrogen atom of the thioamide function to give $\mathrm{N}$-acyl (or sulfonyl) thioamides $79 .{ }^{11 \mathrm{c}}$
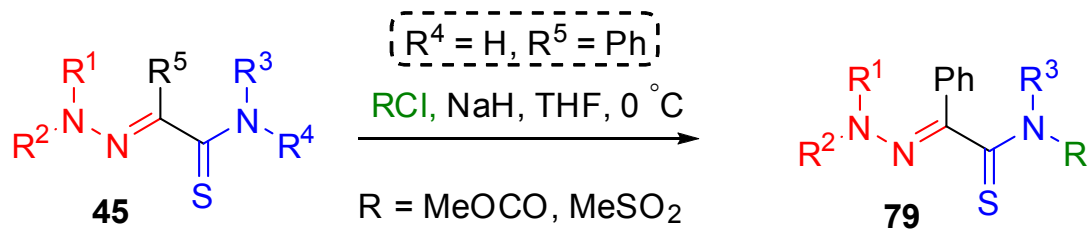

$$
\mathrm{NR}^{1} \mathrm{R}^{2}=\mathrm{NMePh}, \mathrm{NPh}_{2}, \mathrm{~N} \mathrm{O} \quad \mathrm{R}^{3}=\mathrm{Me}, \mathrm{Bn} \quad \text { Yield } 57-81 \%
$$

\section{Scheme 45}

Arylhydrazonoacetamides $\mathbf{2 8}$ react with chloroacetic acid and ethyl chloroformate to give corresponding acylated hydrazones $\mathbf{8 1}{ }^{16 \mathrm{~b}, \mathrm{f}, 38}$ (Scheme 46). 
<smiles>[R]NN=C([R])C([X])N([R])[R]</smiles>

80<smiles>[R]NC(=O)/C(N)=N/N([R])C([R])=O</smiles>

81 Yield $50-88 \%$

$$
\begin{aligned}
& \mathrm{R}^{1}=4-\mathrm{MeOC}_{6} \mathrm{H}_{4}, 4-\mathrm{EtOC}_{6} \mathrm{H}_{4}, 4-\mathrm{MeC}_{6} \mathrm{H}_{4}, 2-\mathrm{MeC}_{6} \mathrm{H}_{4}, \mathrm{Ph}, 4-\mathrm{ClC}_{6} \mathrm{H}_{4}, 4-\mathrm{BrC}_{6} \mathrm{H}_{4}, \\
& \quad 4-\mathrm{IC}_{6} \mathrm{H}_{4}, 4-\mathrm{NO}_{2} \mathrm{C}_{6} \mathrm{H}_{4}, 2-\mathrm{Naphtyl}, 1-\mathrm{Naphtyl} ; \\
& \mathrm{NR}^{2} \mathrm{R}^{3}=\mathrm{NH}_{2}, \mathrm{NHMe}, \stackrel{\mathrm{O}}{\mathrm{O}} ; \mathrm{R}^{5}=\mathrm{OEt}, \mathrm{CH}_{2} \mathrm{Cl}
\end{aligned}
$$

\section{Scheme 46}

Reactions of 2-phenylhydrazonoacetamide $\mathbf{2 8}$ with acetyl chloride and benzoyl chloride are directed to the amide group to form $\mathrm{N}$-acylamide 82 (Scheme 47). ${ }^{161}$

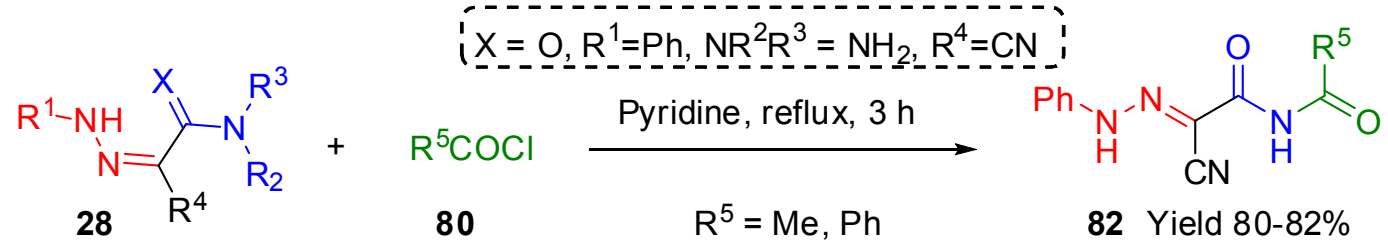

\section{Scheme 47}

Arylhydrazono-1H-pyrazol-5(4H)-imines $38(\mathrm{X}=\mathrm{NH})$ react with benzoyl isothiocyanate to form 4-(2-arylhydrazono)-1 $H$-pyrazol-5(4H)-ylidene)carbamothioyl)benzamide 83 . $^{39,29 \mathrm{~h}}$
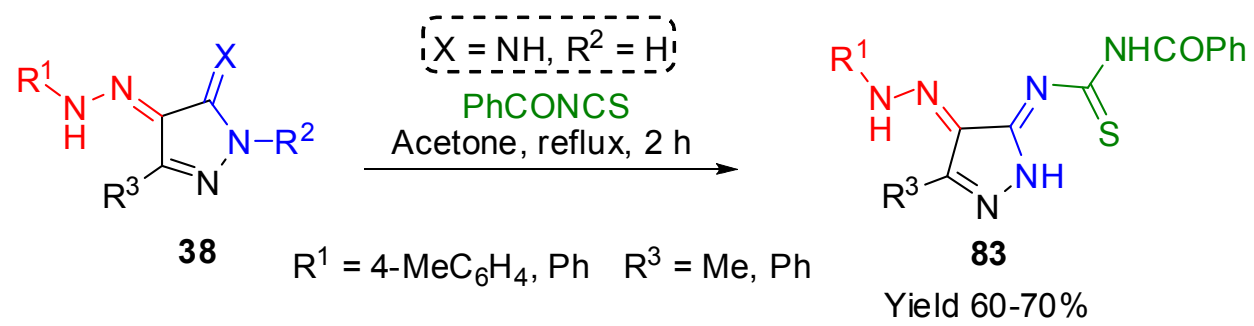

\section{Scheme 48}

Indeed, the examples of the study of alkylation and acylation reactions of hydrazono-amides and thioamides are sometimes contradictive and not numerous enough to make conclusions on the general reactivity of these compounds in reactions of electrophilic substitution. They are not studied at all for hydrazono-amidines. More information on the matter can be found in part 4.4. 


\subsection{Oxidation and reduction}

Oxidative substitution of hydrazono group by oxygen occurs when hydrazones $28(X=0)$ were reacted with ozone at low temperature to form 1,2-dicarbonyl compounds 84 (Scheme 49) ${ }^{16 t}$

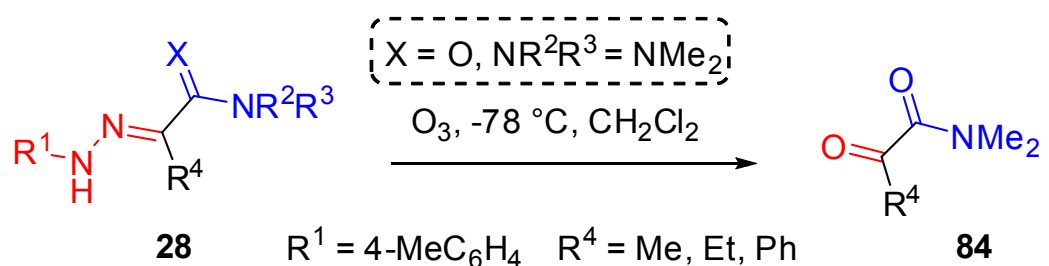

\section{Scheme 49}

Reduction of 2-phenylhydrazonoacetamidine 40a with zinc dust in acidic medium led to the cleavage of the hydrazono N-N bond to form 2,3-diamino-3-iminopropanamide $\mathbf{8 5}$ in good yield (Scheme 50). ${ }^{23 a, b, e}$

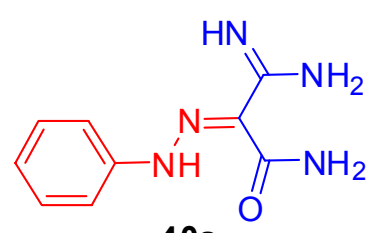

40a

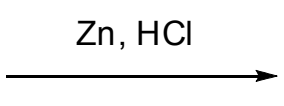<smiles>N=C(N)C(N)C(N)=O</smiles>

\section{Scheme 50}

In somewhat similar manner, both polarographic reduction and reduction with tin of 4-(2arylhydrazono)- $1 H$-pyrazol-5(4H)-ones $38(\mathrm{X}=\mathrm{O})$ may take place, cleaving the hydrazono group to afford 4-amino-1 $H$-pyrazol-5(4H)-ones 87 (Scheme 51 ). ${ }^{40}$

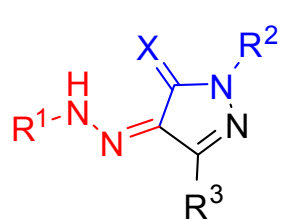

38

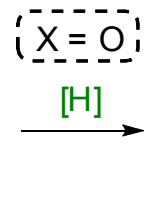

H]

$[\mathrm{H}]$ : 1. DMF, aq. $\mathrm{HCl}$, electrolysis

2. Sn, $\mathrm{EtOH}$, aq $\mathrm{HCl}$

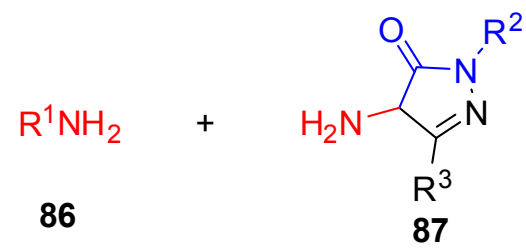

\section{Scheme 51}




\subsection{Use of hydrazono-amides, -thioamides and -amidines in the synthesis of heterocyclic compounds}

The hydrazono-amide, -thioamide and -amidine molecules contain a number of nucleophilic and electrophilic centers. Therefore, one can envisage that these compounds will react with bifunctional chemical reagents to form cyclic systems. Depending on the nature of the reagents, and the reactivity of the nucleophilic and electrophilic centers of the hydrazones, different interactive combinations can be realized to afford a large variety of heterocyclic compounds (Figure 3).

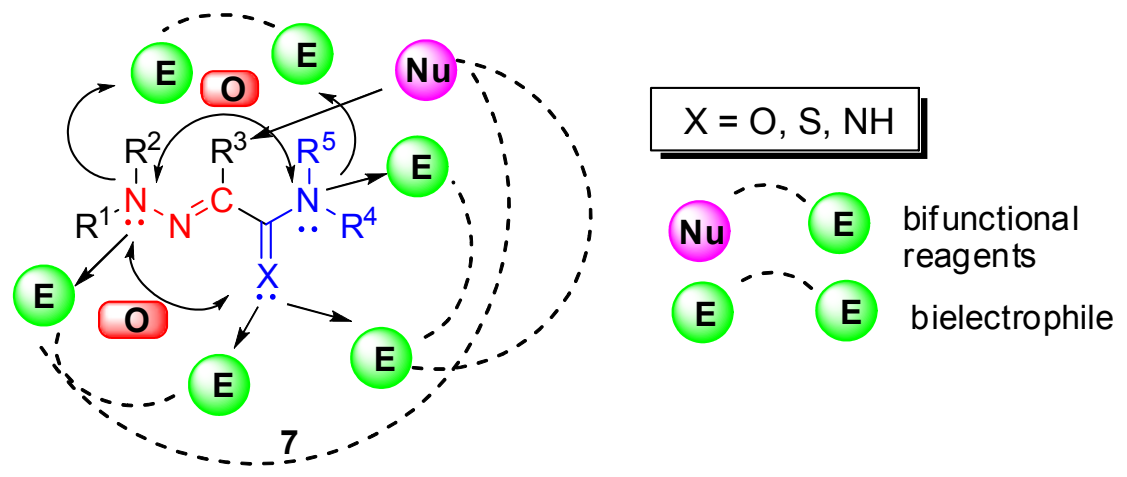

Figure 3. The variety of options leading to heterocyclic compounds.

Heterocyclization reactions of compounds 7 are the result of the reactions (i) with bifunctional reagents bearing two electrophilic groups, (ii) with bifunctional reagents having one electrophilic and one nucleophilic group; (iii) by cycloaddition reactions; (iv) intramolecular condensation and $(\mathrm{v})$ reactions with oxidation reagents.

\subsubsection{Reactions with derivatives of formic acid, ketones, carbon disulfide and thiophosgene.} This part summarizes the literature on the reactions of bielectrophilic reagents providing one atom (carbon) to the newly formed heterocycle. Reactions of arylhydrazonoacetamides $\mathbf{2 8}(\mathrm{X}=\mathrm{O}$, $\mathrm{NR}^{2} \mathrm{R}^{3}=\mathrm{NH}_{2}$ ) with orthoesters $\mathbf{8 8}$ were shown to afford 1,2,4-triazinones $\mathbf{9 0}$ in high to moderate yields. A systematic study of the reaction conditions with variation of the solvent, temperature and catalyst led to a method of choice involving the use of dry boiling meta-xylene while azeotropically removing the ethanol formed (Scheme 52). ${ }^{16 q-s}$ 


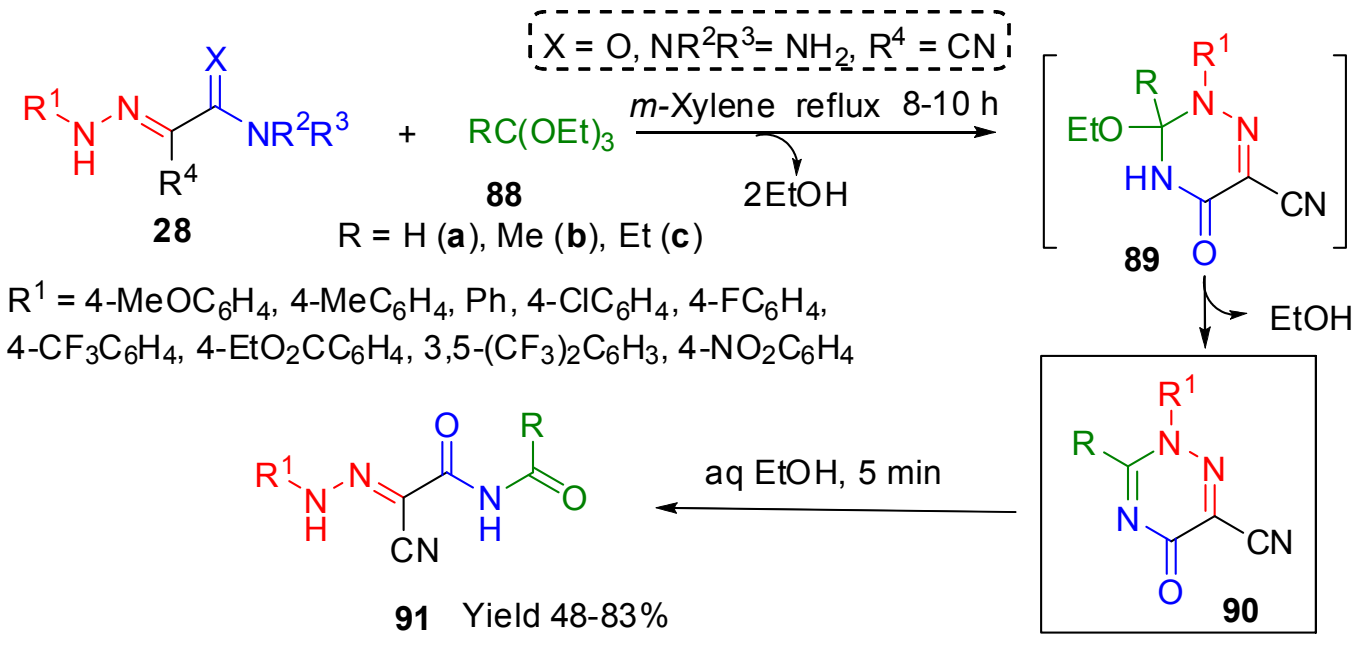

\section{Scheme 52}

The reaction mechanism involves the formation of a double and a single $\mathrm{C}-\mathrm{N}$ bond accompanied by the elimination of three molecules of ethanol. 2,5-Dihydro-1,2,4-triazines 90 are not stable in the presence of water and transform to acyl amides 91 presumably by addition of a molecule of water to the $\mathrm{C}=\mathrm{N}$ bond of the 1,2,4-triazine ring, followed by cleavage of the $\mathrm{C}-\mathrm{N}$ bond and formation of an acyl group. This process is accelerated by addition of acids.

Reaction of hydrazones $28\left(\mathrm{X}=\mathrm{O}, \mathrm{R}^{2}=\mathrm{Alk}\right.$, Het, $\left.\mathrm{R}^{3}=\mathrm{H}\right)$ ) with triethyl orthoformate or dimethylformamide dimethylacetal (DMFDMA) under reflux leads to the formation of isolable 2,3,4,5-tetrahydro-1,2,4-triazines 89 and 92 respectively (Scheme 53). ${ }^{\text {16q-s,u }}$
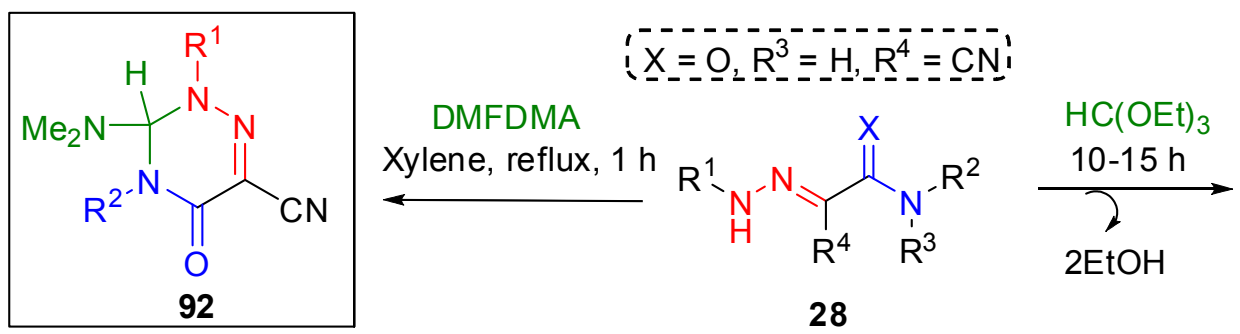

$\mathrm{R}^{1}=4-\mathrm{MeOC}_{6} \mathrm{H}_{4}, 4-\mathrm{MeC}_{6} \mathrm{H}_{4}, \mathrm{Ph}, 4-\mathrm{ClC}_{6} \mathrm{H}_{4}, 4-\mathrm{FC}_{6} \mathrm{H}_{4}$, $4-\mathrm{CF}_{3} \mathrm{C}_{6} \mathrm{H}_{4}, 3,5-\left(\mathrm{CF}_{3}\right)_{2} \mathrm{C}_{6} \mathrm{H}_{3}, 4-\mathrm{NO}_{2} \mathrm{C}_{6} \mathrm{H}_{4}$

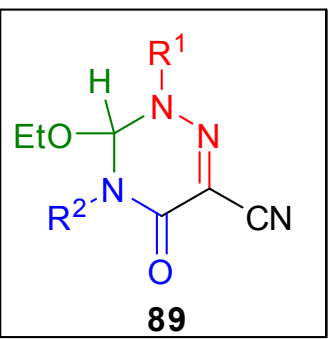

Yield 36-76\% $\mathrm{R}^{2}=\mathrm{Me}, \mathrm{Et}, \mathrm{C}_{2} \mathrm{H}_{4} \mathrm{OMe}, n-\mathrm{Bu}, \mathrm{Bn}$, Het

\section{Scheme 53}

The formation of the product $89\left(\mathrm{R}^{2}=\mathrm{Alk}\right)$ confirms that the reaction mechanism of hydrazono-amides $28\left(\mathrm{X}=\mathrm{O}, \mathrm{NR}^{2} \mathrm{R}^{3}=\mathrm{NH}_{2}, \mathrm{R}^{4}=\mathrm{CN}\right)$ with orthoethers takes place via triazines 89 $\left(\mathrm{R}^{2}=\mathrm{H}\right)$ (Scheme 52). Tetrahydrotriazinones $89\left(\mathrm{R}^{2}=\mathrm{Alk}\right)$ are crystalline substances which are quite stable to acids and bases at room temperature but when boiled in ethanol with an equimolar amount of sulfuric acid they decompose to the starting hydrazones $28(\mathrm{X}=\mathrm{O})$. 
In contrast to the reaction of derivatives $\mathbf{2 8}\left(\mathrm{X}=\mathrm{O}, \mathrm{NR}^{2} \mathrm{R}^{3}=\mathrm{NH}_{2}, \mathrm{R}^{4}=\mathrm{CN}\right)$ with orthoesters $\mathbf{8 8}$ (Scheme 52), the reactions of compounds $28\left(X=O, N^{2} R^{3}=N H A l k, R^{4}=C N\right)$ with triethyl orthoacetate $\mathbf{8 8 b}$ and orthopropionate $88 \mathrm{c}$ and the reaction of hydrazones $28(X=O$, $\mathrm{NR}^{2} \mathrm{R}^{3}=\mathrm{NHPh}, \mathrm{NHCy}$ ) with all types of orthoesters $\mathbf{8 8}$ leads to N-ethylhydrazones $\mathbf{9 3}$ (Scheme 54). Their formation was explained by the decrease in reactivity of the amide $\mathrm{NH}$ group of hydrazone $28\left(\mathrm{X}=\mathrm{O}, \mathrm{NR}^{2} \mathrm{R}^{3}=\mathrm{NHCy}, \mathrm{NHPh}, \mathrm{R}^{4}=\mathrm{CN}\right)$ by introducing of a bulkier aryl or cyclohexyl substituent that hinder cyclization of the intermediates. ${ }^{16 s}$ Migration of the ethyl group to the $\mathrm{N}$-atom of the hydrazone fragment and elimination of ethyl formate then occurs.

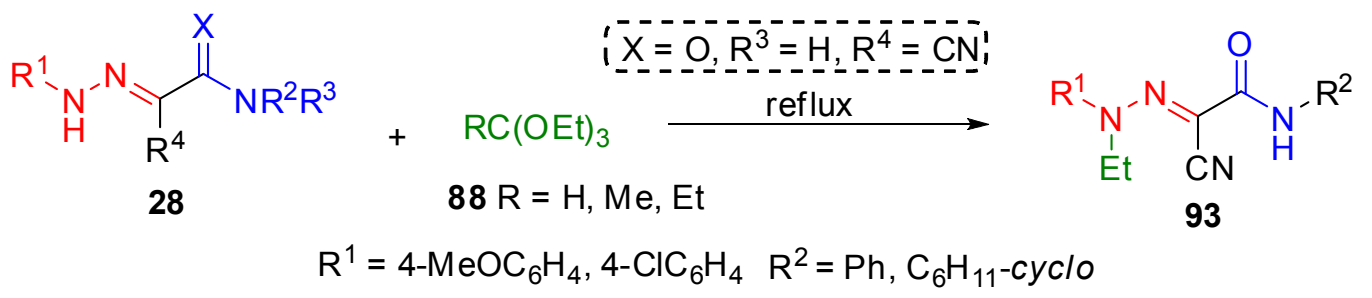

\section{Scheme 54}

Reactions of 2-arylhydrazonothioacetamides $28(\mathrm{X}=\mathrm{S})$ with ethyl orthoformate 88a, irrespective of the substituents, take place with participation of the nitrogen atoms of both the thioamide and hydrazono group to afford 1-aryl-1,4-dihydro-1,2,4-triazine-4-thiones 94 rather than thiazines 95 or triazine-4-ones 96 (Scheme 55). ${ }^{17 \mathrm{~b}}$ The observed selective formation of product 96 in the reaction of thioamide $28\left(\mathrm{X}=\mathrm{S}, \mathrm{NR}^{2} \mathrm{R}^{3}=\mathrm{NH}_{2}, \mathrm{R}^{4}=\mathrm{CONH}_{2}\right)$ is indicative of the higher reactivity of the thioamide nitrogen in comparison to its sulfur atom; and also shows that the hydrazono $\mathrm{NH}$ group is more reactive than the carboxamide $\mathrm{NH}$.

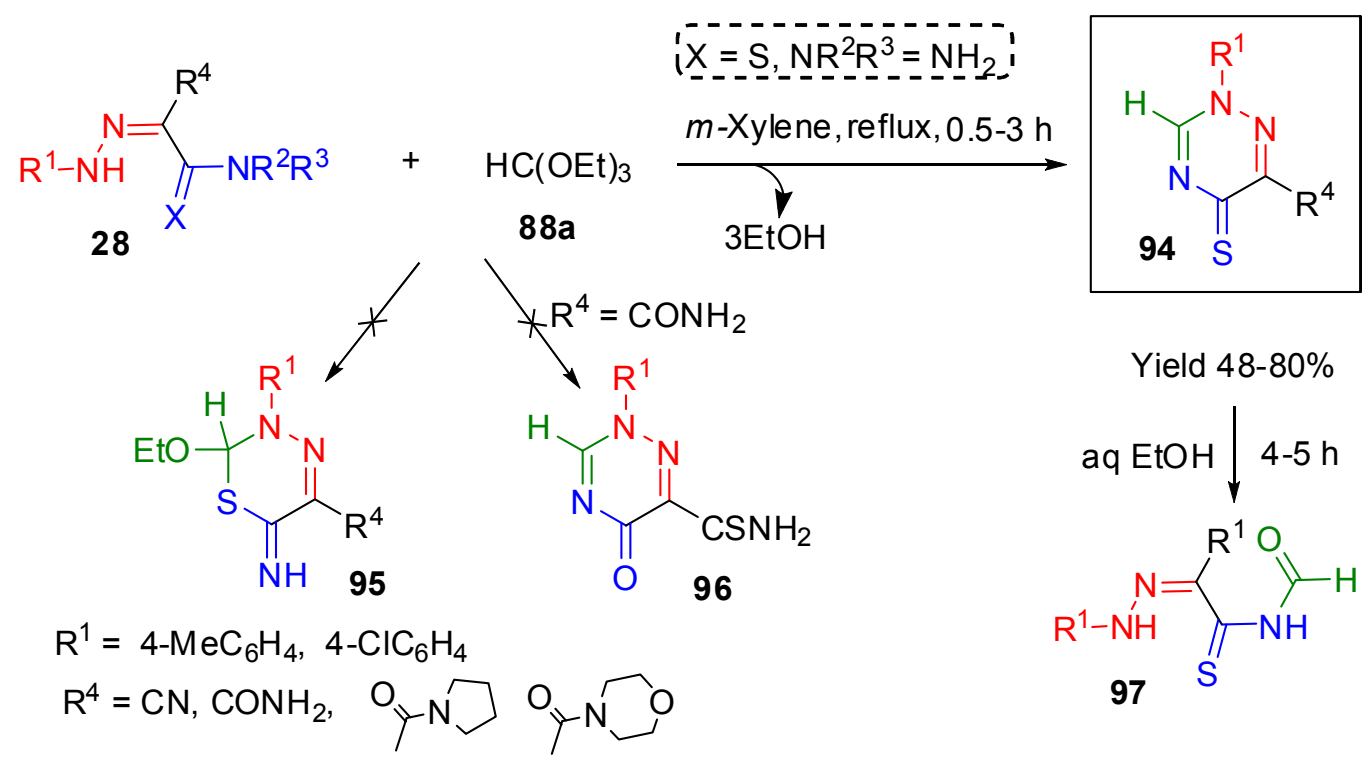

Scheme 55 
5-Thioxo-2,5-dihydro-[1,2,4]triazines 94 similar to the corresponding 5-oxo-[1,2,4]triazines 90 are capable of transforming to formylthioamides 97 after heating at reflux in organic solvents in the presence trace of water. It is worth noting that compounds 94 are slightly more stable than their oxygen analogs 90.

The amidinohydrazones $40\left(X=\mathrm{NH}, \mathrm{R}=\mathrm{NH}_{2}\right)$ react with two moles of ethyl chloroformate to give ethyl 2,3-dihydro-5-ethoxycarbonylamino-1,2,4-triazine-6-carboxylates 99 (Scheme 56). ${ }^{23 \mathrm{~d}}$

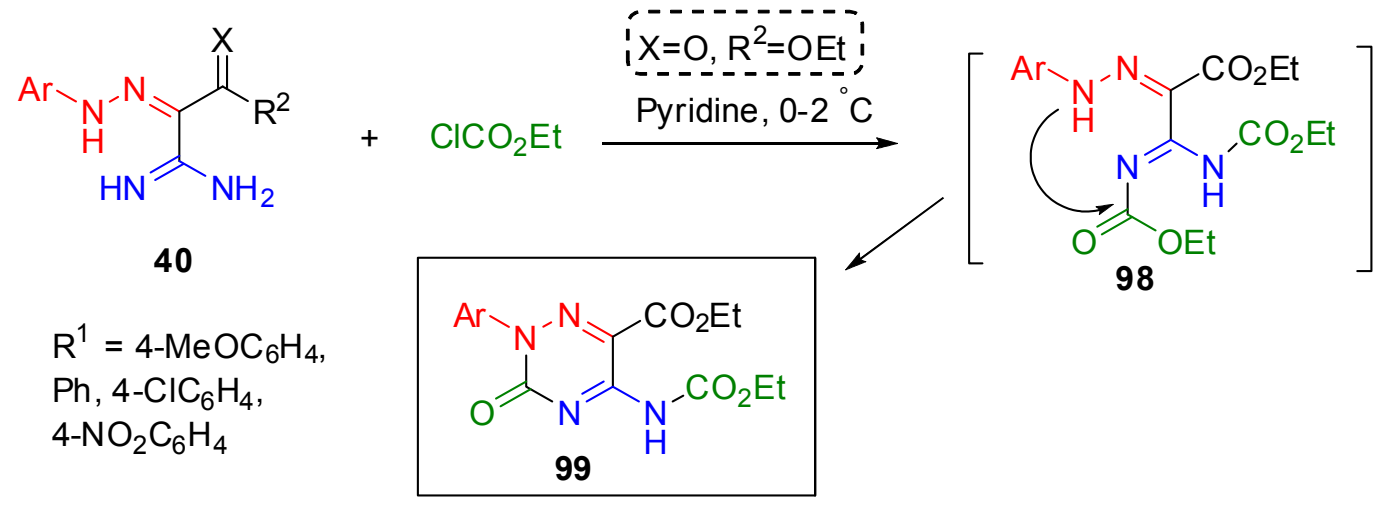

Yield $34-78 \%$

\section{Scheme 56}

Arylhydrazonoacetamides 28 cyclize on heating with ethyl chloroformate in anhydrous pyridine solution to give the corresponding 1-aryl-5-cyano-6-azauracils $100{ }^{11 \mathrm{~d}, 16 \mathrm{a}-\mathrm{f}, 23 \mathrm{~d}, 38}$ Intermediates in this reaction are the product of acylation of the hydrazone group, $\mathrm{N}$ carbethoxyhydrazones 81. Their intramolecular cyclization leads to the same 1,2,4-triazin-3,5dione 100 (Scheme 57).<smiles></smiles>

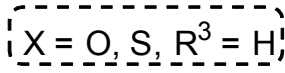

$\mathrm{ClCO}_{2} \mathrm{Et}$ Method A, B

$50 \% \mathrm{H}_{2} \mathrm{SO}_{4}$

Method A: Pyridine, reflux, $10 \mathrm{~h}$

Method B: THF, $\mathrm{NaH}, 0^{\circ} \mathrm{C}$,

Method C: Xylene, reflux, 30h

Method D: $5 \% \mathrm{KOH}$, reflux, 1-2 min

Method E: $5 \% \mathrm{KOH}$, reflux, $2 \mathrm{~h}$

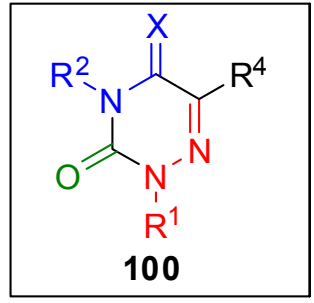

Yield 33-83\%

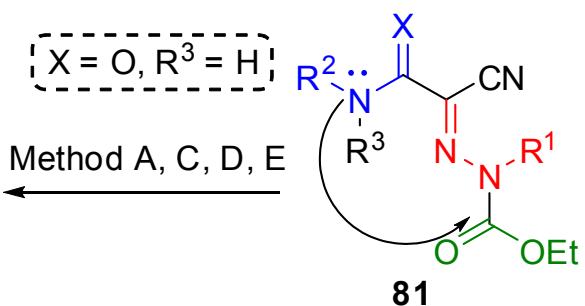

$\mathrm{R}^{1}=4-\mathrm{AlkOC}_{6} \mathrm{H}_{4}, 4-\mathrm{MeC}_{6} \mathrm{H}_{4}, \mathrm{Ph}$, 4-CIC ${ }_{6} \mathrm{H}_{4}, 2-\mathrm{Naphtyl}$, 1-Naphtyl $\mathrm{R}^{2}=\mathrm{H}, \mathrm{Me}, \mathrm{Ar}$ $\mathrm{R}^{4}=\mathrm{Ph}, \mathrm{CN}, \mathrm{CONH}_{2}, \mathrm{COOH}$

\section{Scheme 57}

Arylhydrazones 28 with an ethoxycarbonyl group attached to the nitrogen atom of the carbamoyl group undergo similar cyclization to $1,2,4$-triazines $\mathbf{1 0 0} .^{16 \mathrm{a}-\mathrm{f}}$ Depending on the 
conditions of the process depicted in Scheme 57, 2,3,4,5-tetrahydro-[1,2,4]triazines 100 were prepared containing cyano-, carboxamide or carboxy groups at position 6 of the ring. ${ }^{16 a}$ Based on this reaction the authors ${ }^{16 e}$ have prepared 1,3-bis(6-azauracil-1-yl)benzenes 102 and 1,3,5-tris(6-azauracil-1-yl)benzenes $\mathbf{1 0 3}$ from 3-amino-5-nitroacetanilide $\mathbf{1 0 1}$ via several intermediates (Scheme 58).

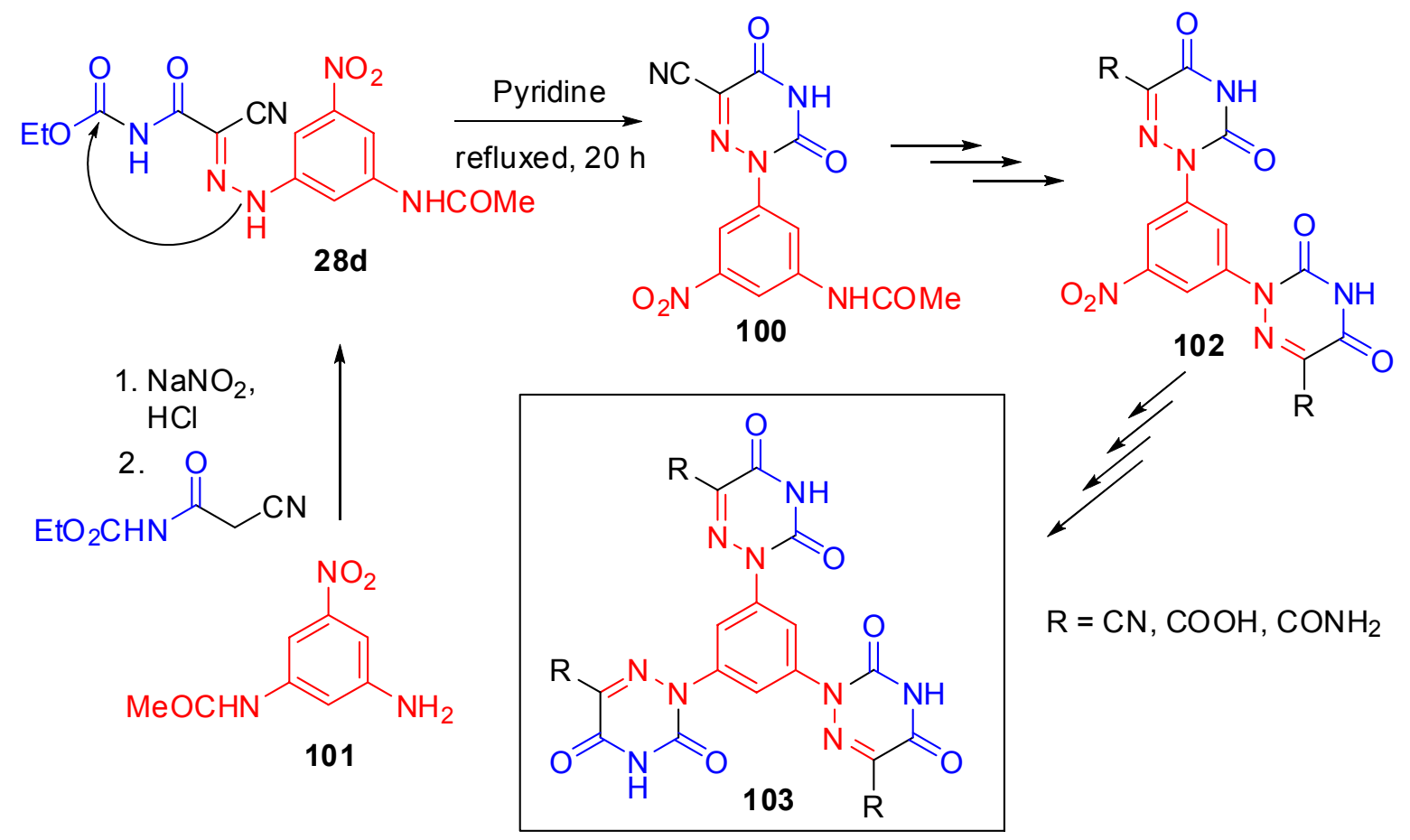

\section{Scheme 58}

Reaction of amidrazones $\mathbf{6 0}$ with alkyl ketones 104 under acidic catalysis includes attack of the latter at the $\mathrm{NH}$ functions of the hydrazono and amino groups of compounds $\mathbf{6 0}$ to afford 4,5dihydro-1 $H-1,2,4$-triazoles 105 (Scheme 59). ${ }^{28 b, d}$

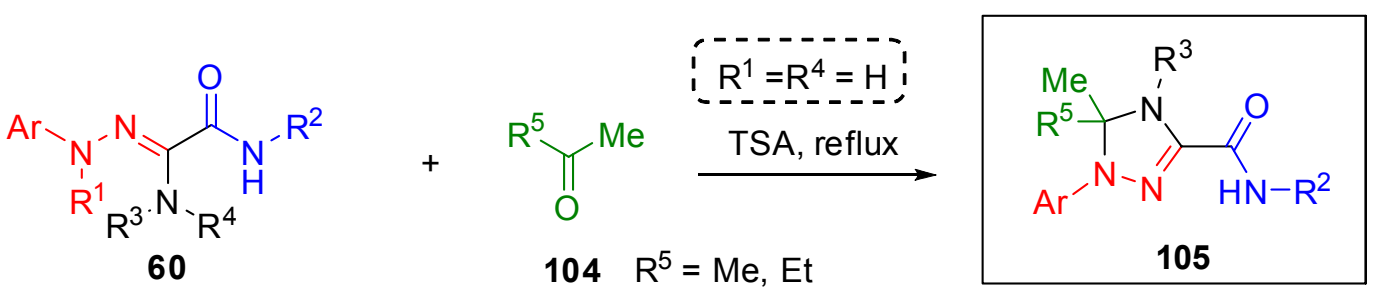

$\mathrm{Ar}=4-\mathrm{MeC}_{6} \mathrm{H}_{4}, \mathrm{Ph}, 2-\mathrm{FC}_{6} \mathrm{H}_{4}, 3-\mathrm{FC}_{6} \mathrm{H}_{4}, 4-\mathrm{FC}_{6} \mathrm{H}_{4}, 2-\mathrm{ClC}_{6} \mathrm{H}_{4}$, $3-\mathrm{ClC}_{6} \mathrm{H}_{4}, 4-\mathrm{ClC}_{6} \mathrm{H}_{4}, 2-\mathrm{CNC}_{6} \mathrm{H}_{4}, 2-\mathrm{MeCOC}_{6} \mathrm{H}_{4}$

Yield $14-75 \%$ $\mathrm{R}^{2}=\mathrm{Ph}, 2-\mathrm{ClC}_{6} \mathrm{H}_{4}, 3-\mathrm{ClC}_{6} \mathrm{H}_{4}, 4-\mathrm{ClC}_{6} \mathrm{H}_{4}, 4-\mathrm{FC}_{6} \mathrm{H}_{4}, \mathrm{R}^{3}=\mathrm{H}, \mathrm{Me}, \mathrm{Ph}, 4-\mathrm{ClC}_{6} \mathrm{H}_{4}$, 2-naphthyl

\section{Scheme 59}


Reaction of amidrazones 60 with aldehydes 106, depending of the nature of the hydrazono, 2-amino and amide groups led to formation of five-, six- and seven-membered heterocyclic compounds: 2,3,4,5-tetrahydro-1,2,4-triazin-5-ones $\quad \mathbf{1 0 7}, \quad$ 1-aryl-1H-1,2,4-triazole-3carboxanilide 108, or benzo- dihydrotriazepines 109, respectively (Scheme 60). ${ }^{28 \mathrm{~b}, \mathrm{~d}}$

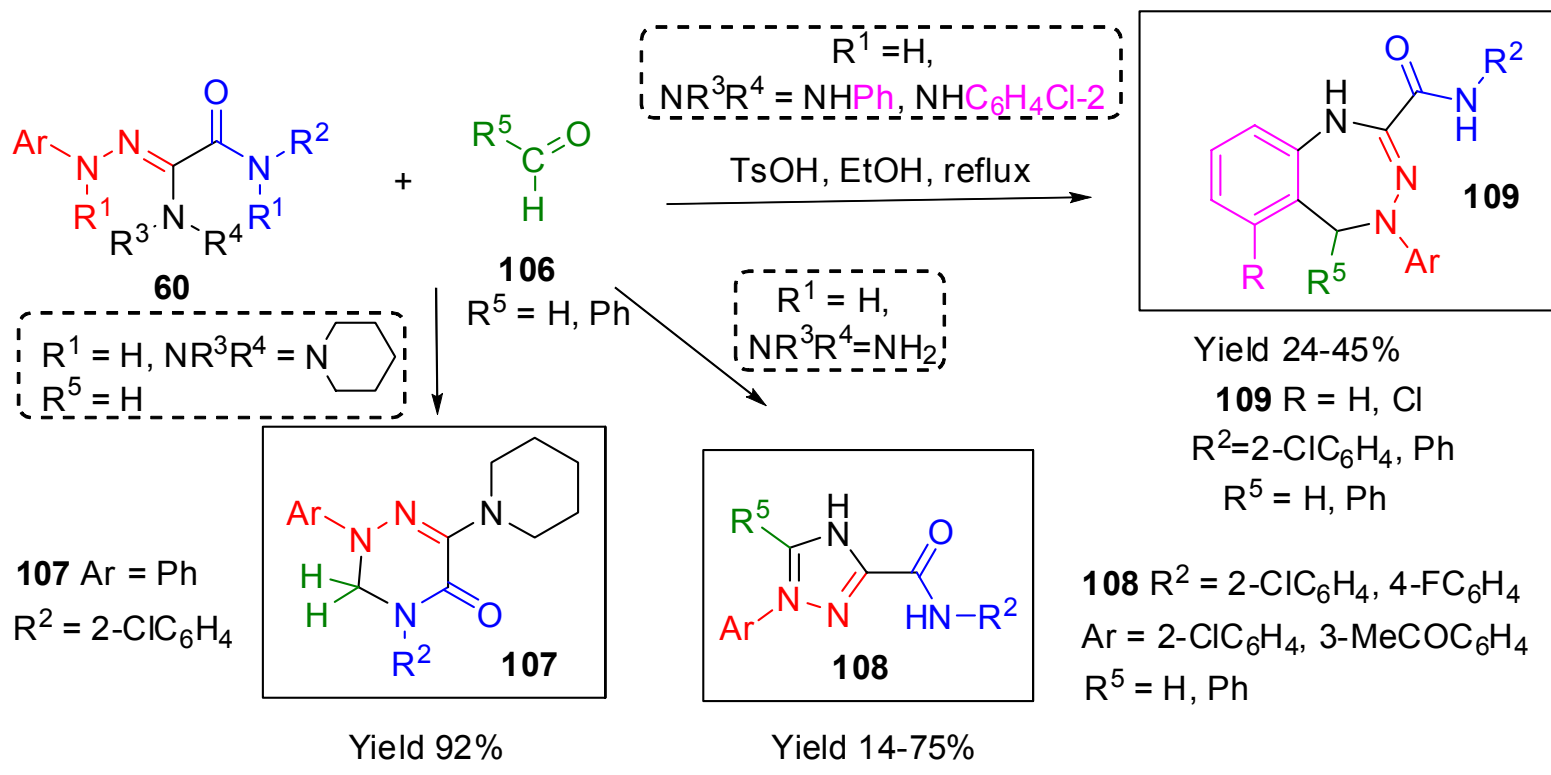

\section{Scheme 60}

Reaction of hydrazones of type $\mathbf{4 0}$ with formamide takes place with participation of the amidine and $\mathrm{C}(\mathrm{X}) \mathrm{NH}_{2}$ groups to give 5-phenylazopyrimidine 110. It is worth noting that the hydrazono group of compounds $\mathbf{4 0}$ does not take part in the cyclization process (Scheme 61 ). ${ }^{23 \mathrm{c}}$

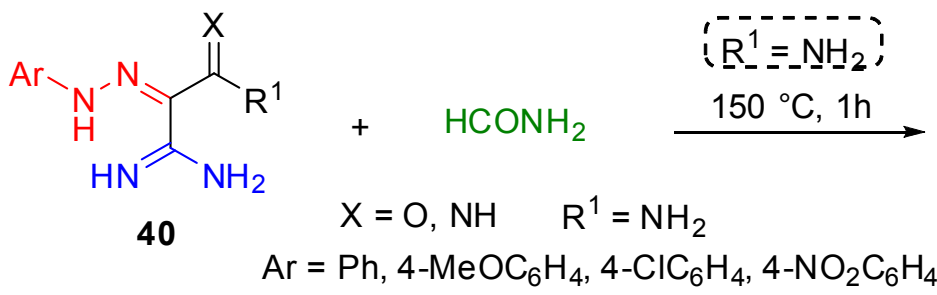

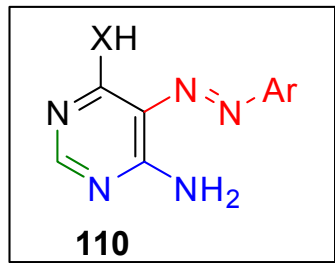

Yield $70 \%$

\section{Scheme 61}

Cyclocondensation of arylhydrazonoacetamides $28(\mathrm{X}=\mathrm{O})$ with carbon disulfide in pyridine at reflux temperature furnished the 1,2,4-triazinone derivative $\mathbf{1 1 2}$ in good yield. The formation of compound $\mathbf{1 1 2}$ is assumed to proceed via initial attack of the secondary amino group of hydrazone $28(\mathrm{X}=\mathrm{O})$ to the thiocarbonyl group of the carbon disulfide followed by intramolecular cyclisation accompanied by elimination of hydrogen sulfide (Scheme 62). ${ }^{16 u, 41}$ 


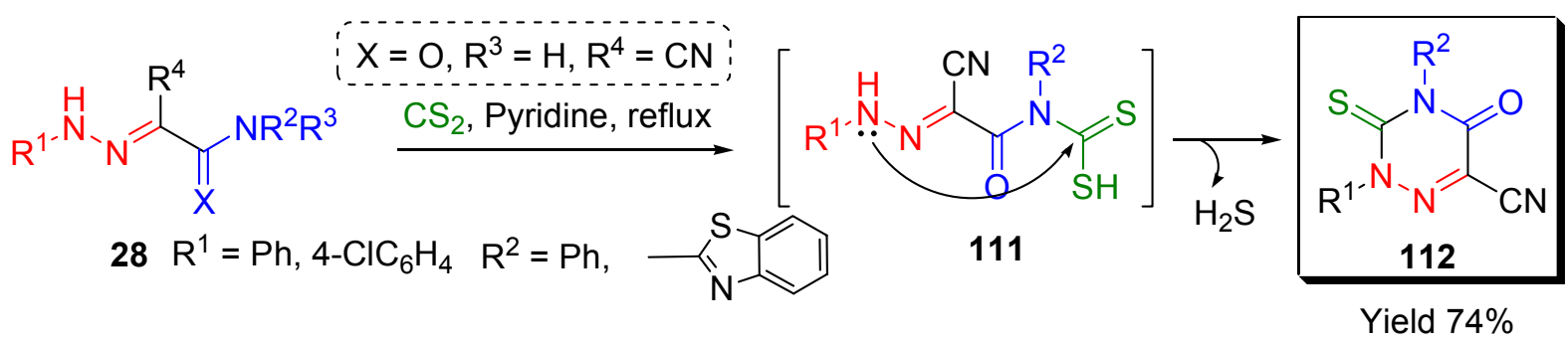

\section{Scheme 62}

2-Arylhydrazonoacetamides $\mathbf{2 8}$ can react with thiophosgene, similarly to the reaction with carbon disulfide, to give 3-thioxo-3,4-dihydro-1,2,4-triazin-5(2H)-one 113. ${ }^{11 \mathrm{~d}}$ Thioacetamides 28 $(\mathrm{X}=\mathrm{S})$ react with thiophosgene by an alternative way, involving the thioamide sulfur atom and the NH fragment to form 3,6-dihydro- $2 H$-1,3,4-thiadiazine-2-thiones $114 .^{17 \mathrm{~h}}$
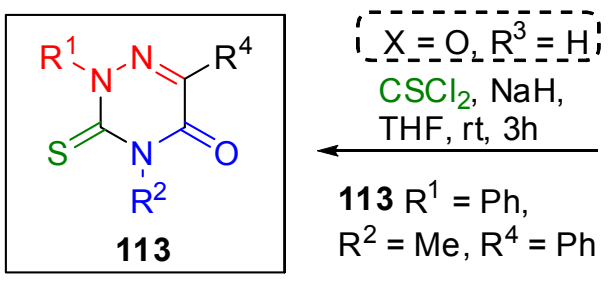

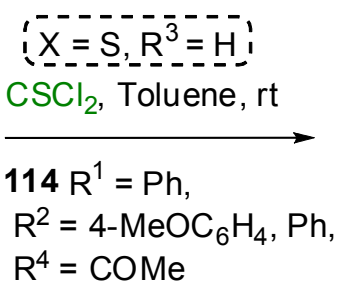

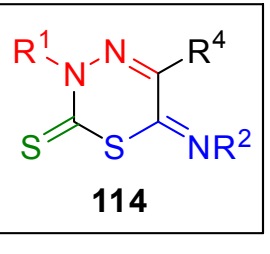

Yield $30-73 \%$

\section{Scheme 63}

4.4.2 Reactions with $\alpha$-halocarbonyl compounds. $\alpha$-Halocarbonyl compounds, such as $\alpha$ chloroacetic acid derivatives and ketones bearing in $\alpha$-position halo atoms can react as both alkylating and acylating reagents and therefore are widely used in organic syntheses to prepare various heterocyclic compounds. Reactions of hydrazones with halocarbonyl compounds have been used in the synthesis of compounds bearing both cyano and active methylene groups, capable of participating in Thorpe-Ziegler cyclization to form various five- and six-membered heterocyclic compounds. ${ }^{160, \mathrm{v}, \mathrm{w}, 17 \mathrm{~b}-\mathrm{e}, 38 \mathrm{~b}, 42}$ Arylhydrazonoacetamides 28 (X=O) react with chloroacetic acid chloride to give N-chloracetyl derivatives 81. ${ }^{38 \mathrm{~b}}$ Subsequent reaction with pyridines generates hydrazonoacetonitriles that undergo Thorpe-Ziegler cyclization, affording 1(4-amino-6-oxo-pyridazin-5-yl)pyridinium chlorides 116 (Scheme 64). Based on these data we assume another structure for intermediate product in reaction of hydrazone $\mathbf{2 8}$ with carbon disulfide (Scheme 62). 


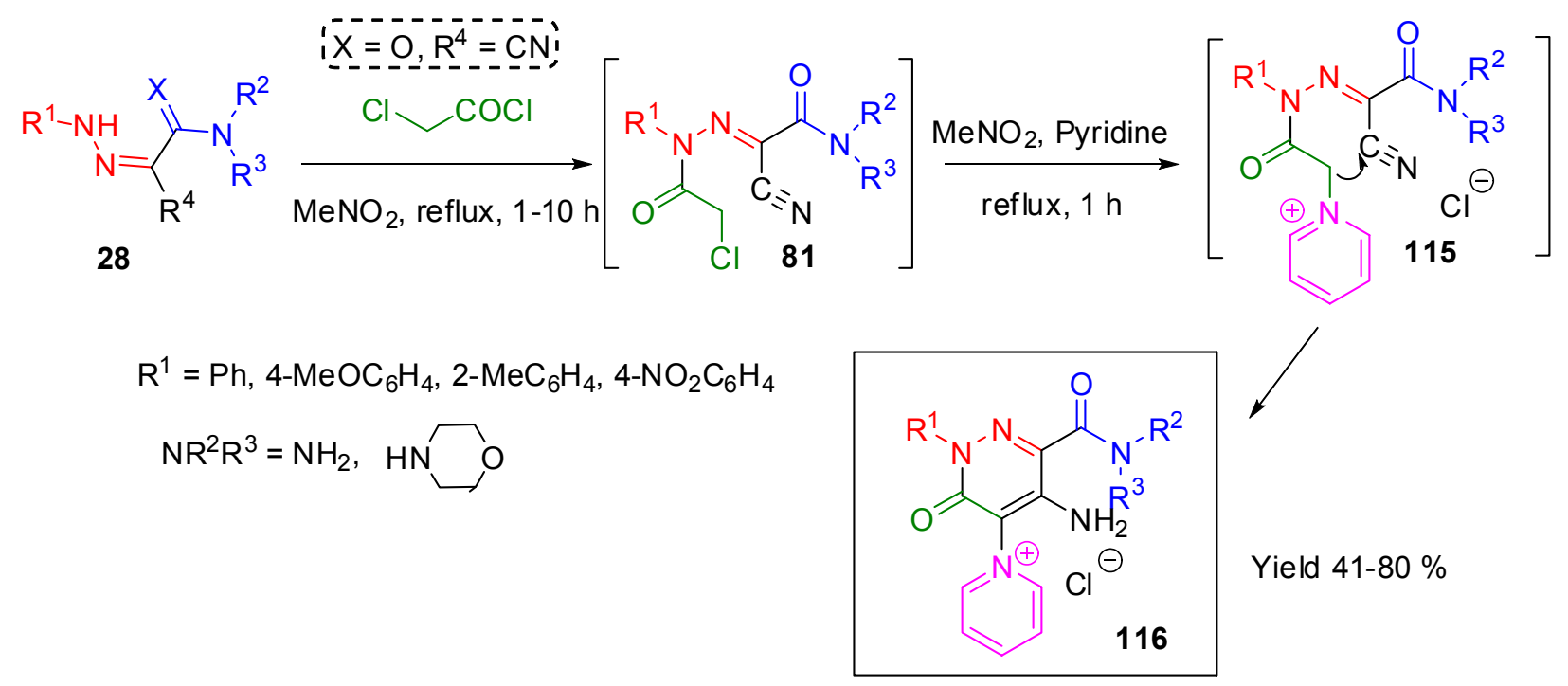

\section{Scheme 64}

It is worth noting that the reaction of hydrazones $28(\mathrm{X}=\mathrm{O})$ with chloroacetyl chloride occurs on the nitrogen atom of the hydrazono group, similarly to the reaction with other acylating reagents.

Thorpe-Ziegler cyclization of $\alpha$-arylhydrazono cyanacetamide $28(\mathrm{X}=\mathrm{O})$ with $\alpha$-bromo ketones, esters or nitriles 117 in different type base catalyst including phase transfer conditions ( $\mathrm{CHSO}_{4}$ - tetrabutylammonium hydrogen sulfate) resulted in 4-amino-1-aryl-3,5-disubstituted$1 H$-pyrazoles 121 which represent an important building block for the construction of the fused heterocycles (Scheme 65). ${ }^{160, \mathrm{v}, \mathrm{w}}$

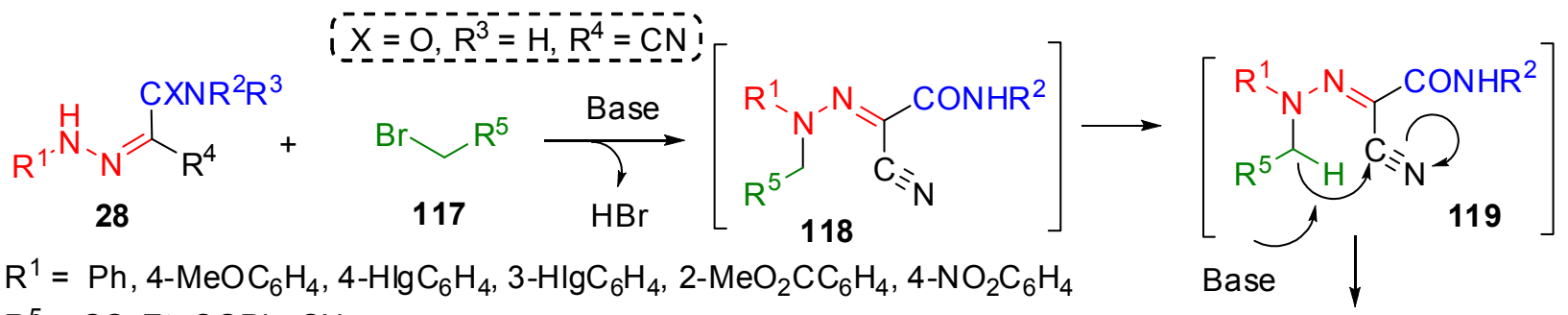

$\mathrm{R}^{5}=\mathrm{CO}_{2} \mathrm{Et}, \mathrm{COPh}, \mathrm{CN}$

Method A: 18-Crown-6, $\mathrm{KOH}$, MeCN or Toluene, $80-90{ }^{\circ} \mathrm{C}, 2 \mathrm{~h}$

Method B: $\mathrm{TBHSO}_{4}, \mathrm{KOH}$ (aq 40\%) $\mathrm{CH}_{2} \mathrm{Cl}_{2}, 60-70{ }^{\circ} \mathrm{C}, 3 \mathrm{~h}$

Method C: TEA, reflux, $30 \mathrm{~min}$

Method D: TEA, MW

Method E: TEA, US, $40^{\circ} \mathrm{C}, 30 \mathrm{~min}$

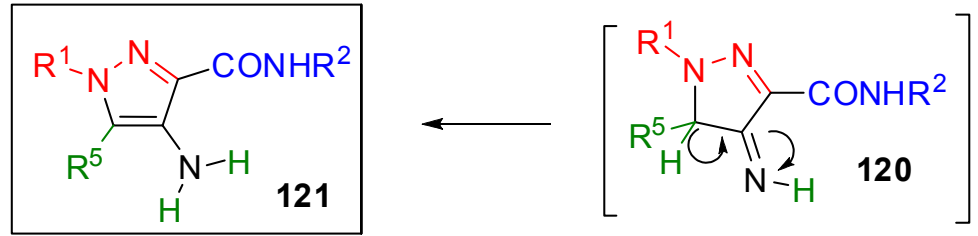

Yield A: $74-84 \%$; B: $58-60 \%$;

C: $52-67 \%$; D: $80-88 \%$; E: $75-79 \%$

Scheme 65 
A plausible mechanism for the Thorpe reaction is proposed in Scheme 65. The initial $\mathrm{HBr}$ removal from $\alpha$-bromo ketone or ester and $\alpha$-arylhydrazononitriles $28(X=O)$ resulting in intermediate 118 followed by the intramolecular nucleophilic addition of $\mathrm{CH}$ onto the nitrile group, gave imines $\mathbf{1 2 0}$ that could tautomerize to the aromatic enamines (4-amino-1-aryl-3,5substituted-1H-pyrazoles 121). The yield of the reaction increased under microwave (Method D) and ultrasound (Method $\mathrm{C}$ ) irradiation. ${ }^{16 \mathrm{w}}$

In contrast to $28(X=O)$ the alkylation of unsubstituted thioamides $28\left(X=S, N R^{2} R^{3}=\mathrm{NH}_{2}\right)$ with bielectrophiles 122 is directed to the sulfur atom, generating thioimidates 123. Subsequent cyclization of the latter leads to thiazoles 124 (Scheme 66). ${ }^{17 b-e, 42}$

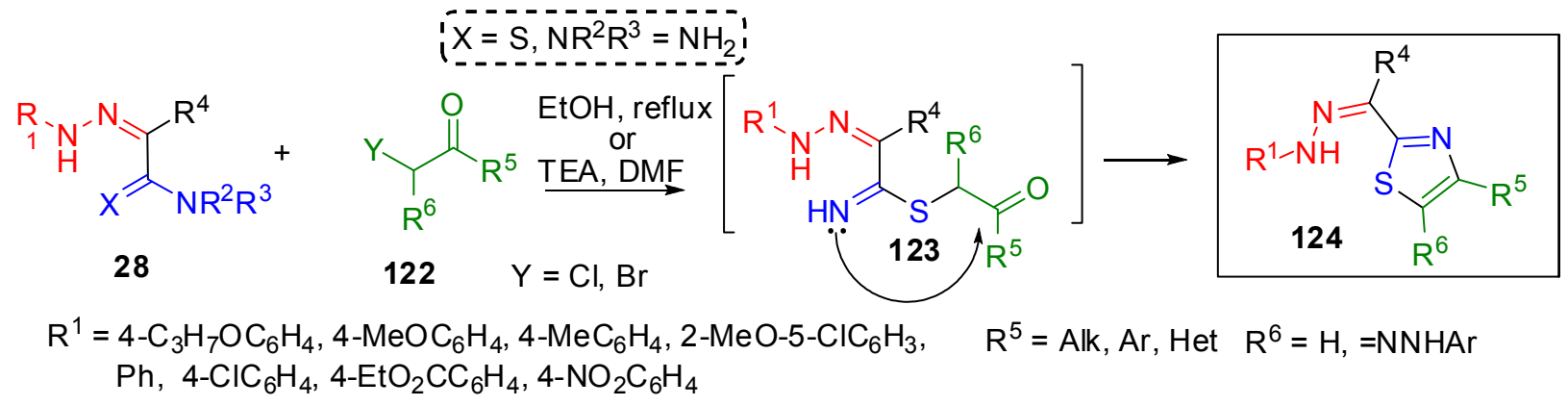

\section{Scheme 66}

However, the introduction of a phenyl group at the nitrogen atom of the thiocarbamoyl radical leads to the formation of thiazol-2(3H)-ylidenes 126 and 4,5-dihydrothiophenes 127 or their mixture via both Hantsch (A) and Thorpe-Ziegler (B) pathways, respectively (Scheme $67) .^{17 c, d}$

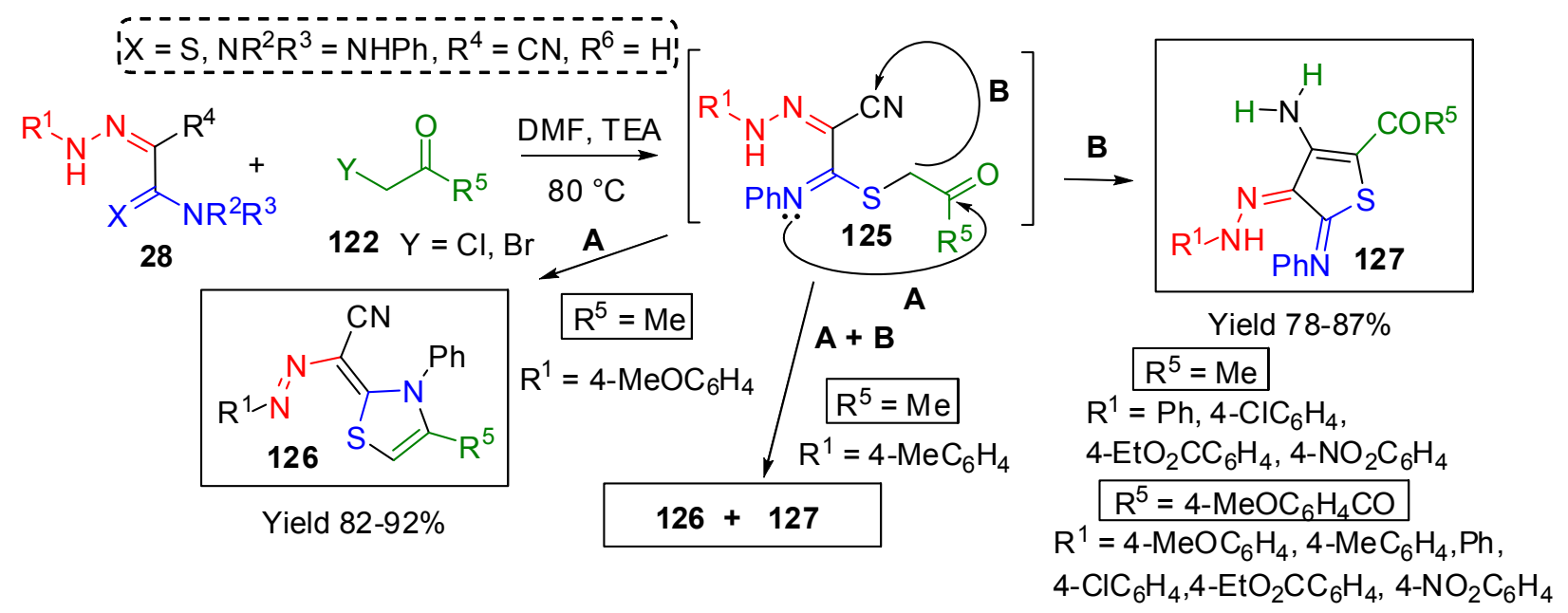

\section{Scheme 67}


The formation of the thiophene ring in the reaction of $\mathrm{N}$-phenylthioacetamides $\mathbf{2 8}(\mathrm{X}=\mathrm{S}$, $\left.\mathrm{NR}^{2} \mathrm{R}^{3}=\mathrm{NHPh}\right)$ with halo ketones $122\left(\mathrm{R}^{6}=\mathrm{H}\right)$ can be explained by the decrease of the nucleophilicity of the thioamide nitrogen atom and the higher acidity of the $\mathrm{SCH}_{2}$ group of compounds with electron-withdrawing substituents that enhance the Thorpe-Ziegler reaction leading to thiophenes $\mathbf{1 2 7}$.

The arylhydrazone group does not participate directly in the reaction, but affects the direction of the cyclization since it is a "transmitter" of the electronic effects from rather distant parts of the molecule to the reaction site.

The reaction of arylhydrazonocyanothioacetamides $28\left(X=S, N R{ }^{1}{ }^{2}=C y\right)$ containing an Ncyclohexyl fragment with chloroacetone, phenacyl bromide, ethyl chloroacetate, and chloroacetonitrile was studied and it was shown that such a substituent with a large steric effect in the thioamide group alters the direction of intramolecular cyclization of the thioimidate intermediate (Scheme 68). ${ }^{17 \mathrm{f}, \mathrm{g}}$ Rather than the expected Hantsch reaction, which usually leads to the formation of thiazol-2(3H)-ylidenes $\mathbf{1 2 9}$ under these conditions, the only products were 3amino-4-arylhydrazono-4,5-dihydrothiophenes $\mathbf{1 3 0 .}$

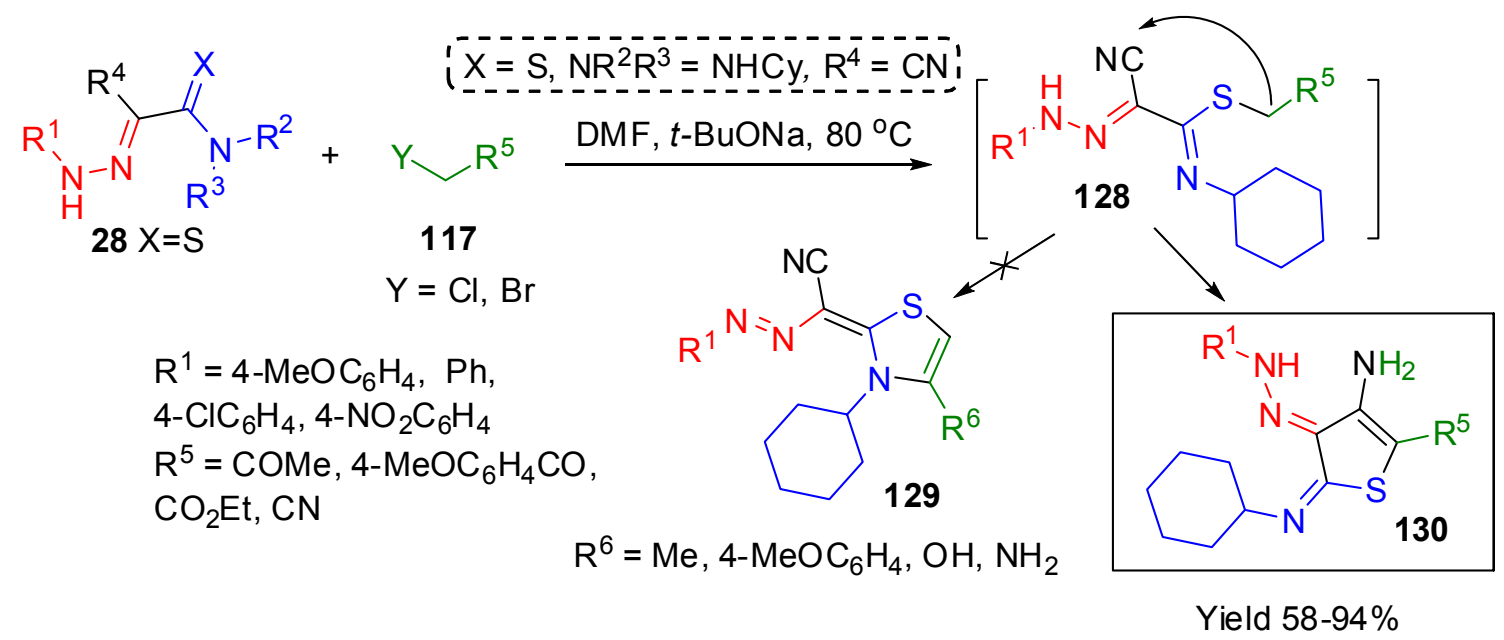

\section{Scheme 68}

4.4.3 Reactions with of acetylene carboxylic esters. Reactions of acetylenecarboxylic esters with compounds with a number of nucleophilic centers are of interest to organic chemists as convenient methods for the synthesis of various heterocyclic compounds. ${ }^{43}$ Various directions for this reaction can take place, resulting in the formation of regio- and stereoisomers.

Despite of the presence of five nucleophilic centers, hydrazonothioacetamides $28\left(\mathrm{R}^{1}=\mathrm{NR}_{2}\right)$ react with DMAD to afford thiazolidines 131 selectively (Scheme 69). ${ }^{17 \mathrm{j}}$ 


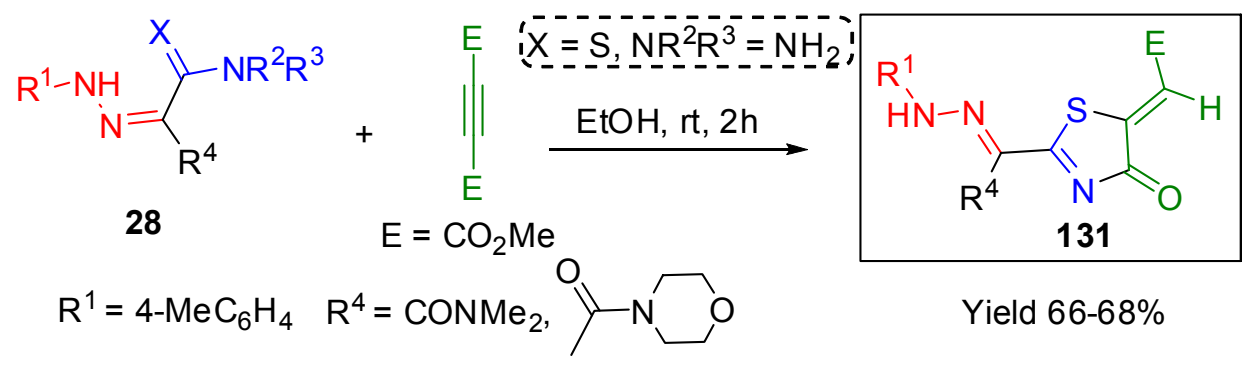

\section{Scheme 69}

The formation of a six-membered ring occurs in the reaction of 4-arylhydrazonopyrazole-5thiones $\mathbf{5 2}$ with of acetylene carboxylic esters $\mathbf{1 3 2}$ in methanol in the presence of triethylamine to afford thiazino-pyrazoles $\mathbf{1 3 4}$ as exclusive products. The hydrazono group does not take part in the formation of the bonds of the new ring, but enhances the formation of the final product, providing a hydrogen atom to the nitrogen-2 atom of the first ring (Scheme 70). ${ }^{22 \mathrm{c}}$

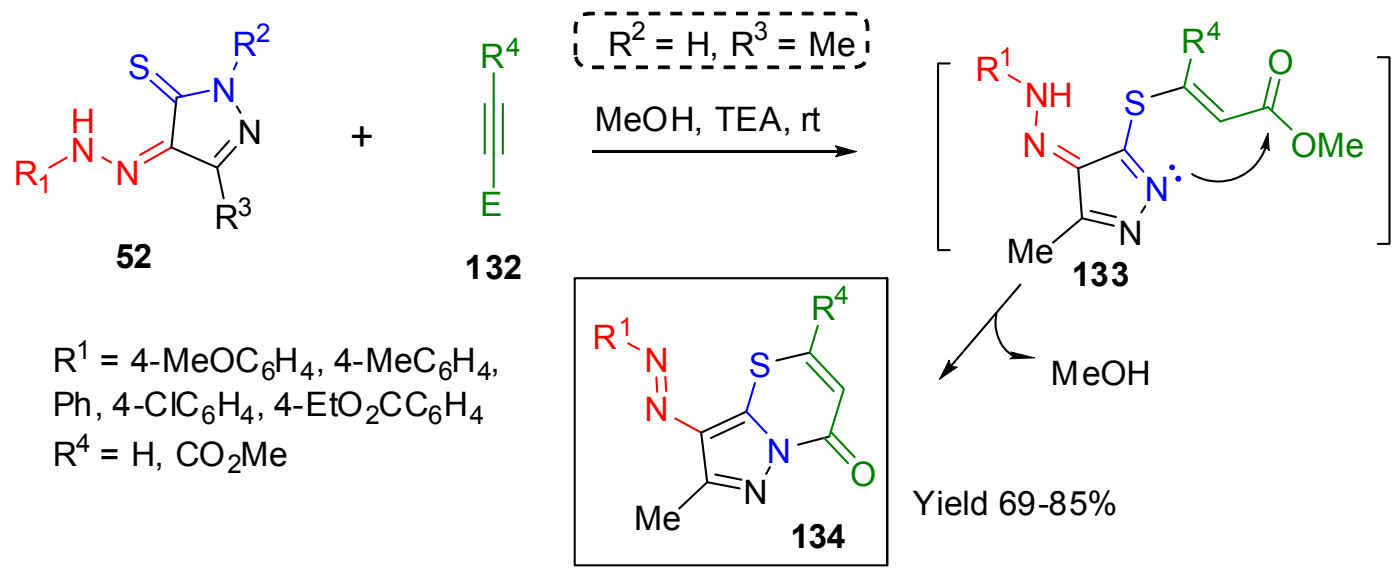

\section{Scheme 70}

The reactions shown in the schemes 69 and 70 prove that the diene systems $(\mathrm{C}=\mathrm{N}+\mathrm{C}=\mathrm{S}$ bonds) of compounds $28(\mathrm{X}=\mathrm{S})$ and $\mathbf{5 2}$ are not reactive, although the close structural analogs of 28, 2-cyanothioacrylamides readily react with DMAD, methyl propiolate, and N-phenyl maleimides via a 4+2 cycloaddition pathway to give thiopyrans, irrespective of the electronic or spatial effects of the substituents in the thioamide group and in position 3 of the 1-thiabuta-1,3diene system. ${ }^{44}$

\subsubsection{Reactions with reagents containing both electrophilic and nucleophilic functions.} Hydrazones can react with isothiocyanates to form compounds with a thiocarbamoyl group. In the case of presence of the cyano group at position 2 of the hydrazone, the highly electrophilic carbon atom of the intermediate thiosemicarbazone 135 undergoes cyclisation to 4,5-dihydro- 
1,2,4-triazine-3(2H)-thiones $\mathbf{1 3 6}^{45}$ Indeed, both nucleophilic and electrophilic centers of hydrazones $\mathbf{2 8}$ take part in the process of heterocyclization (Scheme 71).

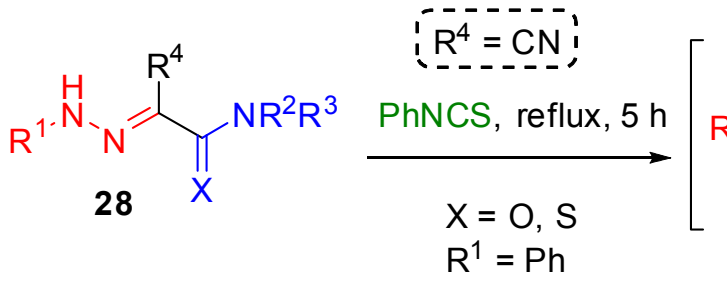

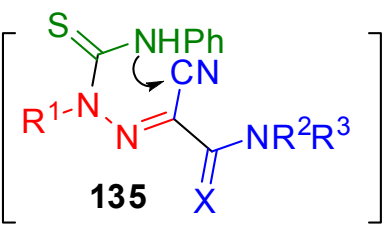<smiles>[X]C(N)c1nn([R])c(=S)n(-c2ccccc2)c1=N</smiles>

\section{Scheme 71}

Reaction of hydrazono-amidine $\mathbf{5 4}$ with phenylisothiocyanate begins with the attack of the latter to the $\mathrm{NH}$ of the amidine group, followed by the reaction of the cyano group with the thiocarbamoyl fragment to form 5-arylazo-4-imino-1,4-dihydropyrimidin-2-thiones 137 . The hydrazono group does not take part in the reaction, other than of providing a hydrogen atom to the new ring (Scheme 72). ${ }^{24}$
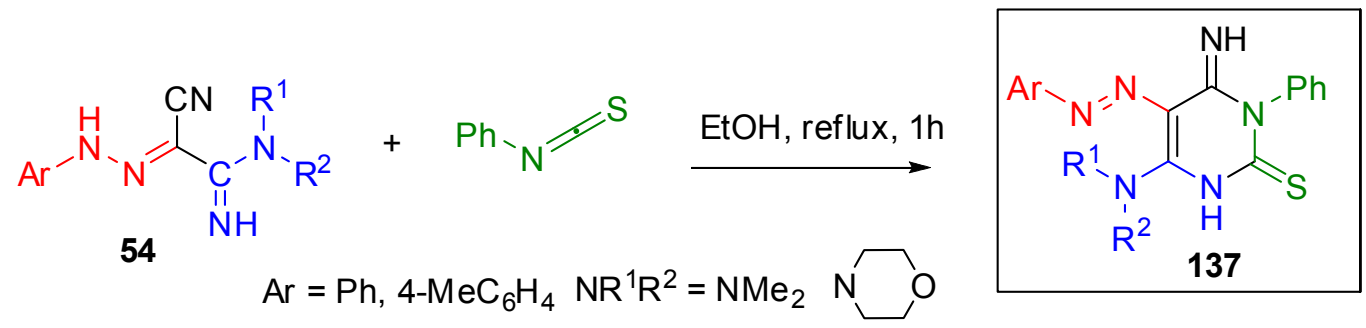

Yield $39-59 \%$

\section{Scheme 72}

Another type of heterocyclization occurs when pyrazol-5-yl-thioureas 83 (Scheme 48) were boiled in a mixture of acetic and hydrochloric acids to form 2,4-dihydro-pyrazolo[3,4e] $[1,2,4]$ triazin-3-ones 138 (Scheme 73). ${ }^{39}$
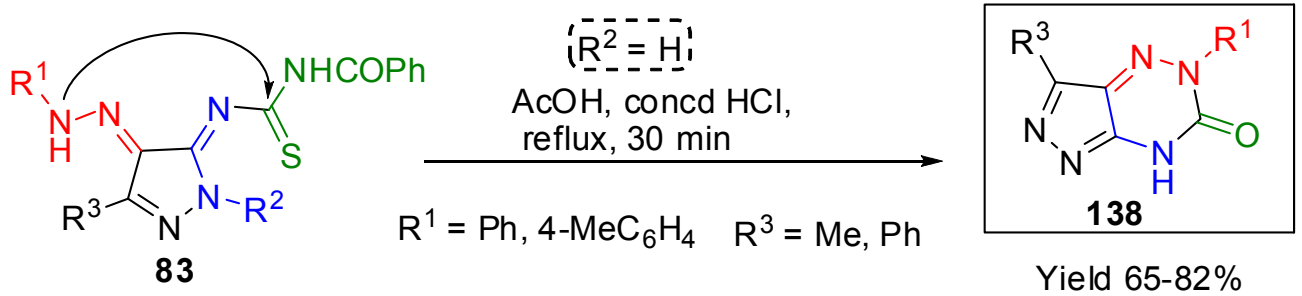

Scheme 73 
2-Cyano-2-phenylhydrazonoacetamide $28(\mathrm{X}=\mathrm{O})$ reacts with acrylonitrile in boiling pyridine to afford 2,3-dihydropyridazine 139, while its reaction with cyanogen bromide leads to 3-imino-3,4-dihydro-1,2,4-triazin-5(2H)-one 140 (Scheme 74). ${ }^{41}$

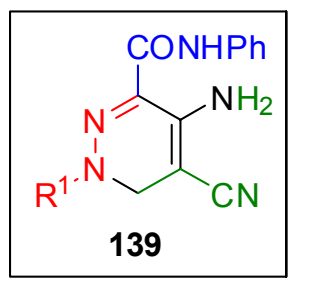

Yield $80 \%$

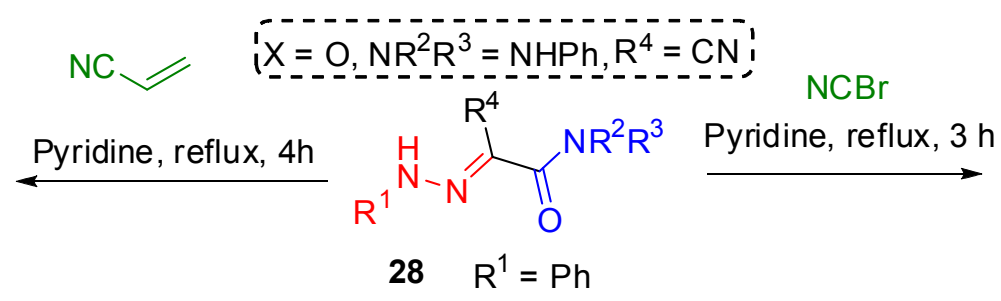

$28 \mathrm{R}^{1}=\mathrm{Ph}$

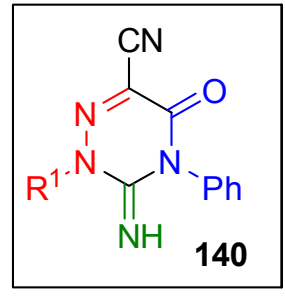

Yield $75 \%$

\section{Scheme 74}

Condensation of Wittig reagents 141 with arylhydrazonoacetamide $28(\mathrm{X}=\mathrm{O})$ by conventional and by microwave heating techniques furnished the corresponding pyridazinones and iminopyridazines 143 (Scheme 75$){ }^{46}$

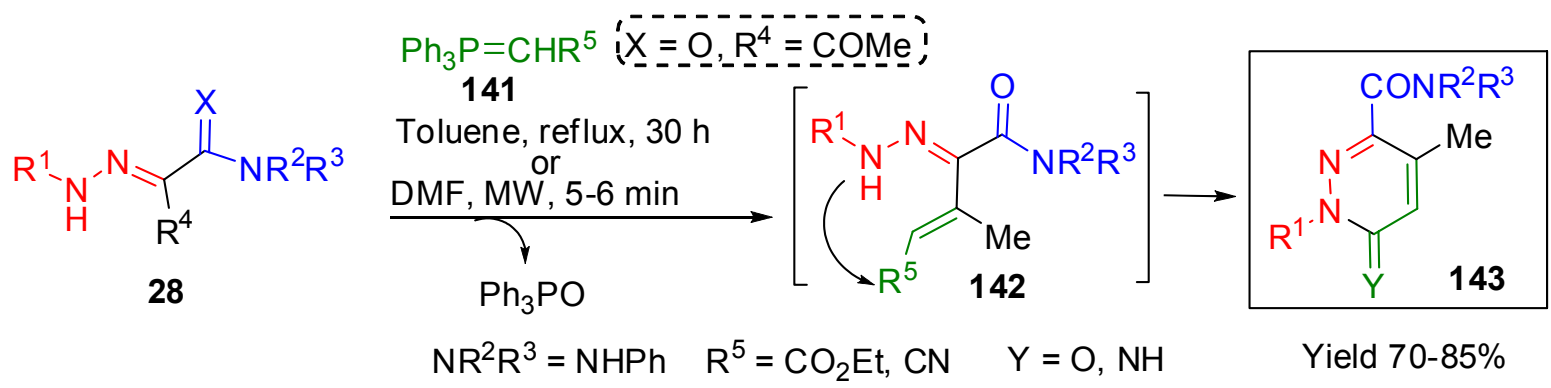

\section{Scheme 75}

The reaction of more active phosphacumulen-ylide 144 with 2-hydrazonothioacetamide 28 $(\mathrm{X}=\mathrm{S})$ takes place by another way to form pyridine-thione 146 via intermediate 145 as depicted in the Scheme 76. The ring formation is the result of bridging of thioamide and ketone groups by ylide 144. It is worth noting that the nitrogen atoms of the hydrazono group do not take part in the heterocyclization. ${ }^{47}$

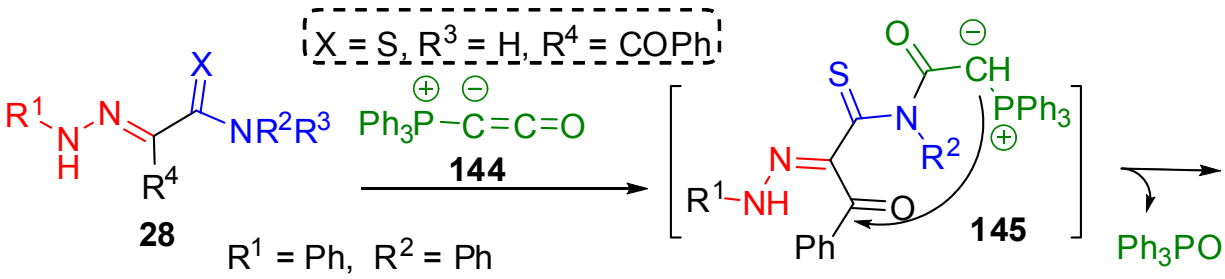

Scheme 76

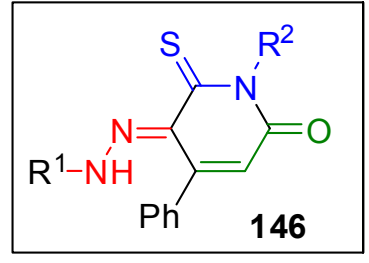

Yield $52 \%$ 
Active methylene compounds such as malononitrile and ethyl cyanoacetate 147 react with 2acetyl-2-hydrazonoacetamide $28(\mathrm{X}=\mathrm{O})$ in ethanol in the presence of a catalytic amount of piperidine to generate a hydrazone of type 148. ${ }^{48}$ The latter, via interaction of the hydrazono group with cyano- or ester functions, affords 6-imino- and 6-oxo-pyridazines 149, respectively (Scheme 77).

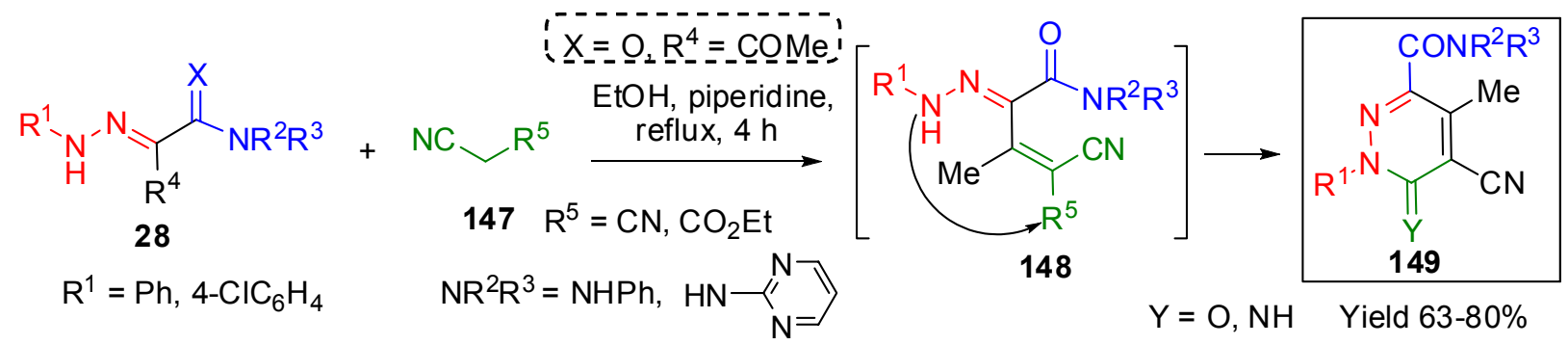

\section{Scheme 77}

4.4.5 Intramolecular cyclization reactions. Intramolecular transamidation took place when 6methoxy-2-(2-phenylhydrazono)-2H-chromene-3-carboxamide 22 was heated in boiling DMF with acetic anhydride for $3 \mathrm{~h}$ to form 6-methoxychromeno[2,3-c]pyrazol-3(2H)-one 150 (Scheme 78). It was concluded that the presence of acetic anhydride assisted the lactamisation reaction. Applying acetic acid as a reaction medium under microwave irradiation at $190{ }^{\circ} \mathrm{C}$ for 5 min led to full conversion of the starting hydrazone $\mathbf{2 2}$ into the desired compounds $\mathbf{1 5 0}$ with a small amount of by-product $\mathbf{1 5 1}$ in the final reaction mixture. ${ }^{14}$ It is interesting to note that heating of hydrazones 22 with acetic anhydride at reflux leads mainly to the product of double acylation (151) with an impurity of pyrazolone $\mathbf{1 5 0 .}$

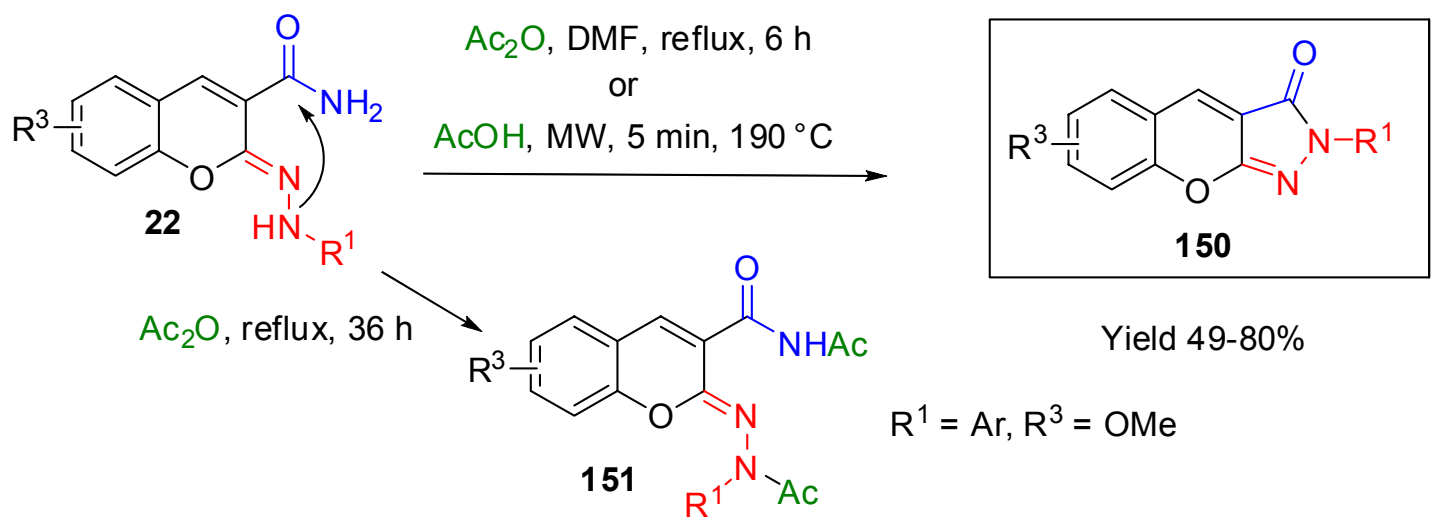

\section{Scheme 78}

It is worth noting that highly electrophilic cyano- and keto groups located at position 4 often take part in a step of the heterocyclization process of hydrazones as shown in the Schemes 64, 
$65,67,68,71$. Intramolecular cyclization takes place when hydrazones $\mathbf{2 8}$ bearing a cyano group at position 4 were heated in chlorobenzene in the presence of a Lewis acidic catalyst. ${ }^{49}$

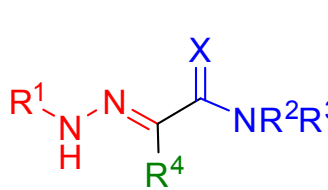

28

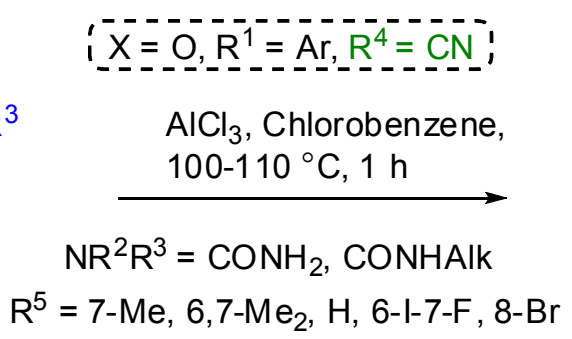

Yield $71-97 \%$

\section{Scheme 79}

Intramolecular alkylation and arylation reactions occur during the cyclizations of hydrazones $28(\mathrm{X}=\mathrm{O})$ bearing $\alpha$-carbonyl bromide and polyhalobenzene moieties (Scheme 80$).{ }^{50}$

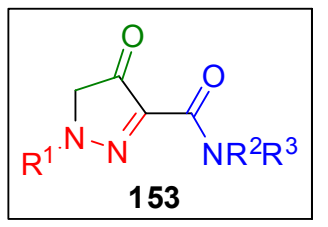

X $=\mathrm{O}, \mathrm{R}^{4}=\mathrm{COCH}_{2} \mathrm{Br}^{\prime}$

$\mathrm{PrOH}, \mathrm{NaOAc}$<smiles>[R1]N/N=C(/[R])C([X])/C=C\C</smiles>

28<smiles>[R]#[R]CNc1ccc2[nH]c(=O)[nH]c2c1</smiles>

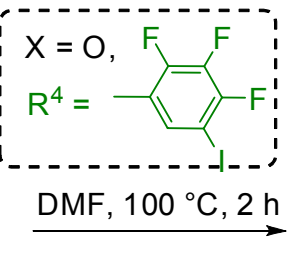

Yield $71 \%$

$\mathrm{R}^{1}=4-\mathrm{HSO}_{3} \mathrm{C}_{6} \mathrm{H}_{4}, 2,5-\mathrm{Cl}_{2}-4-\mathrm{HSO}_{3} \mathrm{C}_{6} \mathrm{H}_{2}$ 8- $\mathrm{HSO}_{3} \mathrm{Naphtyl,6}-\mathrm{HSO}_{3} \mathrm{Naphtyl}$

$N R^{2} R^{3}=H N$

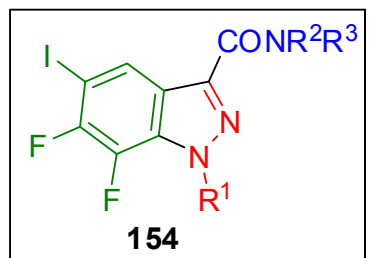

Yield $95 \%$

$\mathrm{R}^{1}=3-\mathrm{CNC}_{6} \mathrm{H}_{4}, 4-\mathrm{FC}_{6} \mathrm{H}_{4}$ $\mathrm{NR}^{2} \mathrm{R}^{3}=\mathrm{NH}_{2}$

\section{Scheme 80}

4.4.6 Cycloaddition reactions. The $\mathrm{C}=\mathrm{N}$ bond of hydrazones 28 can easily react with ketenes 156 generated in situ from phenoxyacetyl chloride $\mathbf{1 5 5}$ to form the 2-azetidinones 157, products of [2+2] cycloaddition. ${ }^{37 \mathrm{~b}}$ The reaction was completely diastereoselective for all hydrazones $\mathbf{2 8}$ of this series (Scheme 81).

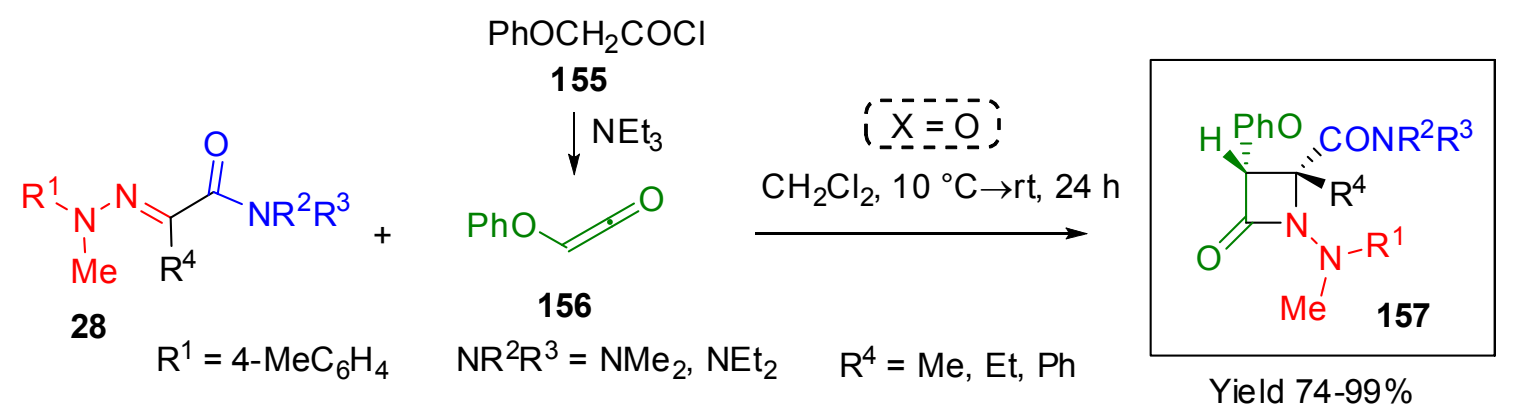

\section{Scheme 81}


4.4.7 Oxidative cyclization reactions. In this part, the literature on oxidative cyclization of hydrazones with thiocarbamoyl and amidine groups is summarized. The dehydrative cyclization reaction of 2-arylhydrazonothioacetamides $28(\mathrm{X}=\mathrm{S})$ leading to 2-aryl-2,5-dihydro-1,2,3thiadiazole 158 was first described by Gewald and Hain for a number of derivatives of 158 (Scheme 82). ${ }^{16 \mathrm{j}, \mathrm{k}}$

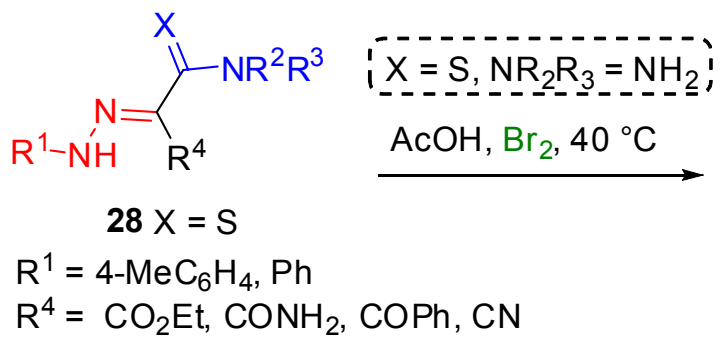

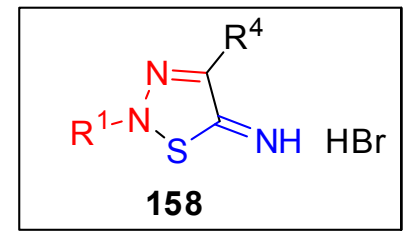

5 examples Yield 65-90\%

\section{Scheme 82}

We have expanded this method, involving a large series of starting thioamido-hydrazones 28 $(\mathrm{X}=\mathrm{S})$ and using a number of oxidation reagents. The scope and limitations of the reaction were also determined. ${ }^{25 \mathrm{~b}}$ In all cases, the oxidation of arylhydrazonothioacetamides with bromine in acetic acid afforded 5-imino-2,5-dihydro-1,2,3-thiadiazole salts $\mathbf{1 5 8}$ as the major products (Scheme 83).
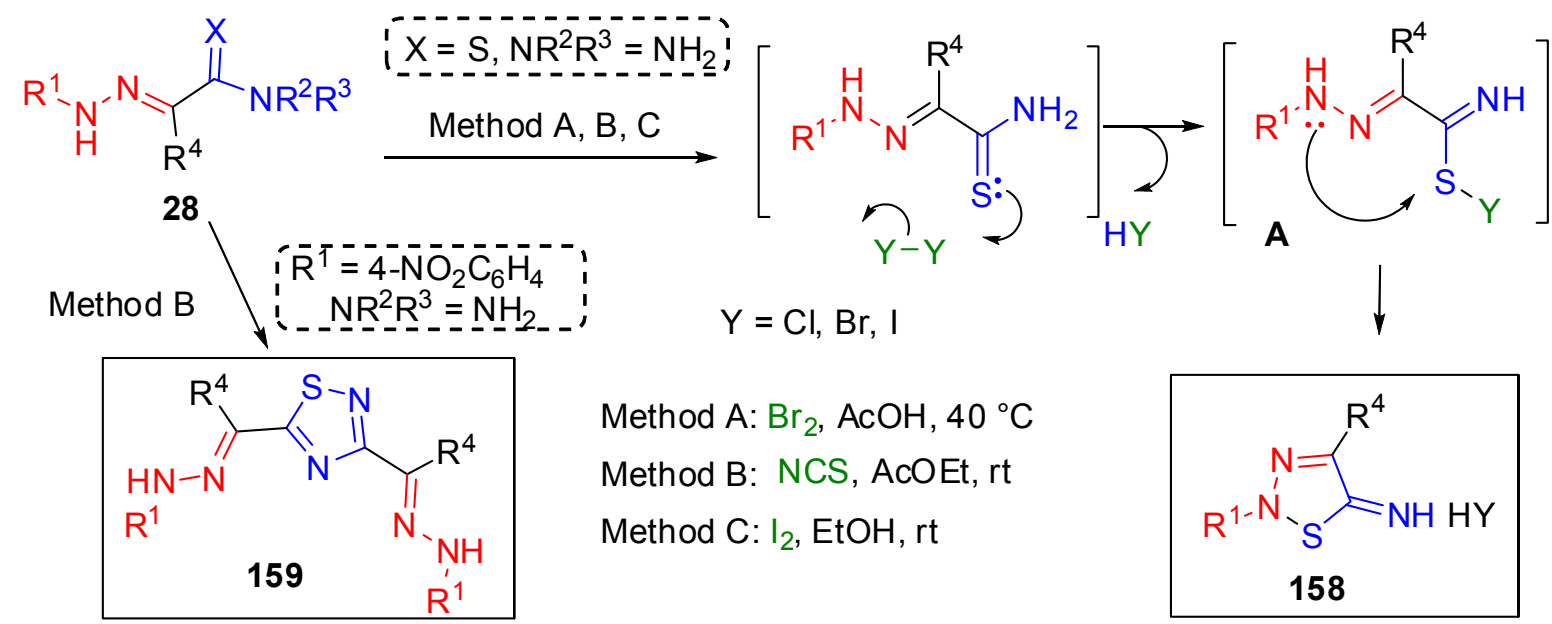

Method $\mathrm{A}: \mathrm{Br}_{2}, \mathrm{AcOH}, 40^{\circ} \mathrm{C}$

Method B: NCS, AcOEt, rt

Method C: $\mathrm{I}_{2}$, EtOH, rt

$\mathrm{R}^{1}=4-\mathrm{MeOC}_{6} \mathrm{H}_{4}, \mathrm{Ph}, 4-\mathrm{FC}_{6} \mathrm{H}_{4}, 4-\mathrm{ClC}_{6} \mathrm{H}_{4}, 4-\mathrm{H}_{2} \mathrm{NCOC}_{6} \mathrm{H}_{4}$,

$4-\mathrm{EtO}_{2} \mathrm{CC}_{6} \mathrm{H}_{4}, 3-\mathrm{CF}_{3} \mathrm{C}_{6} \mathrm{H}_{4}, 2-\mathrm{ClC}_{6} \mathrm{H}_{4}, 2,6-\mathrm{Cl}_{2} \mathrm{C}_{6} \mathrm{H}_{4}, 4-\mathrm{NO}_{2} \mathrm{C}_{6} \mathrm{H}_{4}$

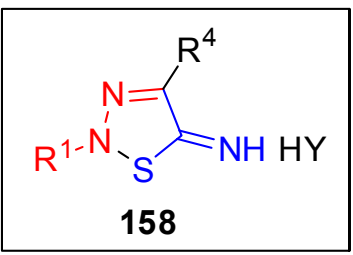

Yield 13-99\%

42 examples

$\mathrm{R}^{4}=\mathrm{CN}, \mathrm{CO}_{2} \mathrm{Et}, \mathrm{CONH}_{2}$, CONHAlk, CONHPh,

$\mathrm{O}^{\mathrm{N}} \mathrm{X}=\mathrm{CH}_{2},\left(\mathrm{CH}_{2}\right)_{2} \mathrm{OCH}_{2}$

\section{Scheme 83}


This process is characterized by good yields, with exception for the starting materials with a strong electron-acceptor substituent on the aromatic ring $\left(\mathrm{CF}_{3}, \mathrm{NO}_{2}\right)$. The oxidation of 4nitrophenylhydrazonothioacetamide $28\left(X=S, \quad R^{1}=4-\mathrm{NO}_{2} \mathrm{C}_{6} \mathrm{H}_{4}\right)$ with $\mathrm{NCS}$ afforded 1,2,4thiadiazoles $\mathbf{1 5 9}$ as the only cyclic product (Scheme 83).

The oxidative dehydration of arylhydrazonothioacetamides $\mathbf{2 8}(\mathrm{X}=\mathrm{S})$ by iodine was used to prepare 5-iminosubstituted-1,2,3-thiadiazolium salts of type $\mathbf{1 6 0}$ (Scheme 84). ${ }^{11 \mathrm{a}-\mathrm{c}}$

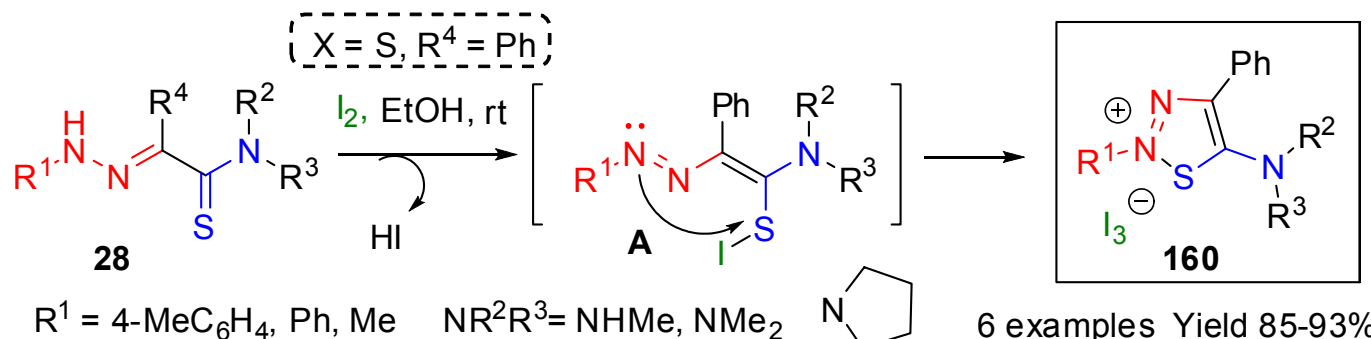

\section{Scheme 84}

N-Monosubstituted thioacetamides $28\left(X=S, R^{3}=H\right)$ can be also oxidized with the mild oxidant manganese dioxide. The 5-imino substituted-2,5-dihydro-1,2,3-thiadiazoles 161 prepared are shown to be stable even as free bases (Scheme 85). ${ }^{11 \mathrm{~b}}$
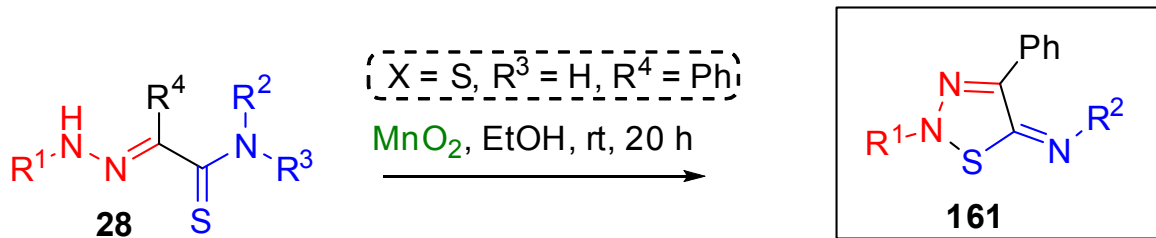

$\mathrm{R}^{1}=\mathrm{Me}, \mathrm{Ph}, 4-\mathrm{MeC}_{6} \mathrm{H}_{4}, 4-\mathrm{ClC}_{6} \mathrm{H}_{4} \quad \mathrm{R}^{2}=\mathrm{Me}, \mathrm{Et}, i-\mathrm{Pr} 6$ examples Yield $70-89 \%$

\section{Scheme 85}

A systematic study of the oxidative cyclization of 3-hydrazono-1,3-dihydroindole-2-thiones $\mathbf{4 7 ,} \mathbf{5 0}$ has been carried out and a series of novel $2 H$-[1,2,3]-thiadiazolo[5,4-b]-indoles $\mathbf{1 6 2}$ were obtained. $^{21}$ 


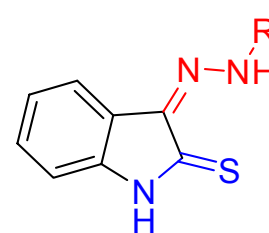

47,50

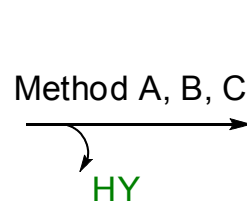

$\mathrm{Y}=\mathrm{Cl}, \mathrm{Br}, \mathrm{I}$

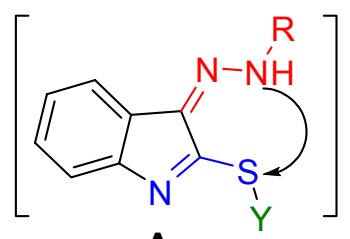

A
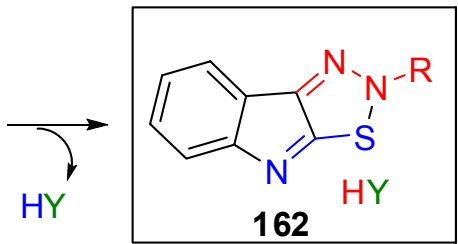

10 examples Yield $40-96 \%$

$\mathrm{R}=\mathrm{Me}, \mathrm{Bn}, 4-\mathrm{EtOC}_{6} \mathrm{H}_{4}, \mathrm{BnOC}_{6} \mathrm{H}_{4}, \mathrm{Ph}, 4-\mathrm{ClC}_{6} \mathrm{H}_{4}$

Method A: $\mathrm{Br}_{2}, \mathrm{AcOH}, 40{ }^{\circ} \mathrm{C} \quad$ Method B: NCS, AcOEt, rt Method C: $\mathrm{I}_{2}, \mathrm{EtOH}, \mathrm{rt}$

\section{Scheme 86}

The successful synthesis of heterocycles $\mathbf{1 6 2}$ demonstrated that the oxidative cyclization of hydrazonothiocarbonyl compounds can be used for the synthesis of 1,2,3-thiadiazoles fused with other heterocyclic rings.

The oxidative cyclization of hydrazones bearing an amidine group was first initiated within a program to prepare $2 \mathrm{H}-1,2,3$-triazol-4-amine $\mathbf{1 6 3}$ as precursors of aza-analogs of hypoxanthine and adenine, potent inhibitors of biological systems. ${ }^{23 \mathrm{~d}}$ Thus, phenylazomalonamidine hydrochlorides 40 were converted smoothly by oxidation with copper sulfate to 4-amino-1,2,3triazole 163 (Scheme 87).
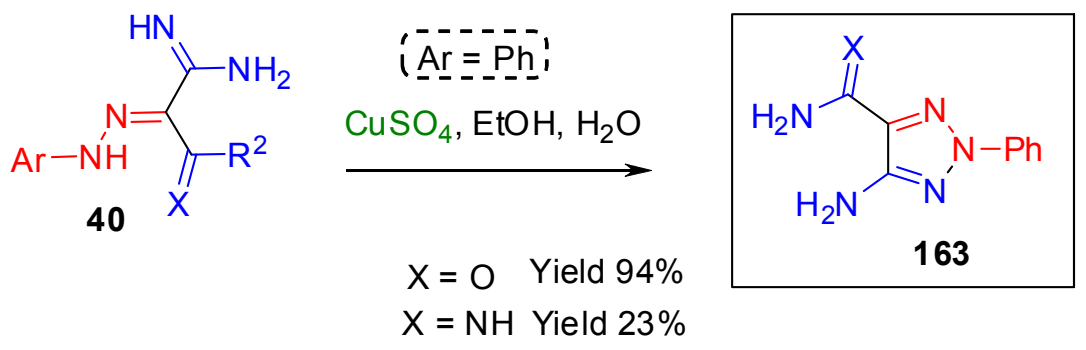

\section{Scheme 87}

Hydrazones 110 containing an amidine group can be oxidized with copper sulfate in pyridine to $2 H-[1,2,3]$ triazolo[4,5- $d]$ pyrimidines $\mathbf{1 6 4}$ in moderate yields (Scheme 88 ). ${ }^{23 \mathrm{c}}$
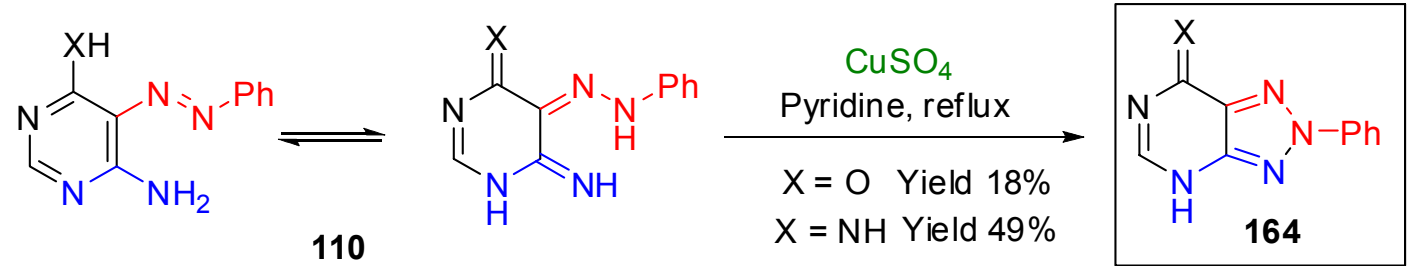

\section{Scheme 88}


2-Arylhydrazono-N,N-dialkyl-acetamidines $\mathbf{5 4}$ undergo cyclizations by treatment with copper sulfate in pyridine to form only the 5-dialkylamino-2-aryl-1,2,3-triazole-4-carbonitriles 165, but not trazoles 166 (Scheme 89 ). ${ }^{24,27}$

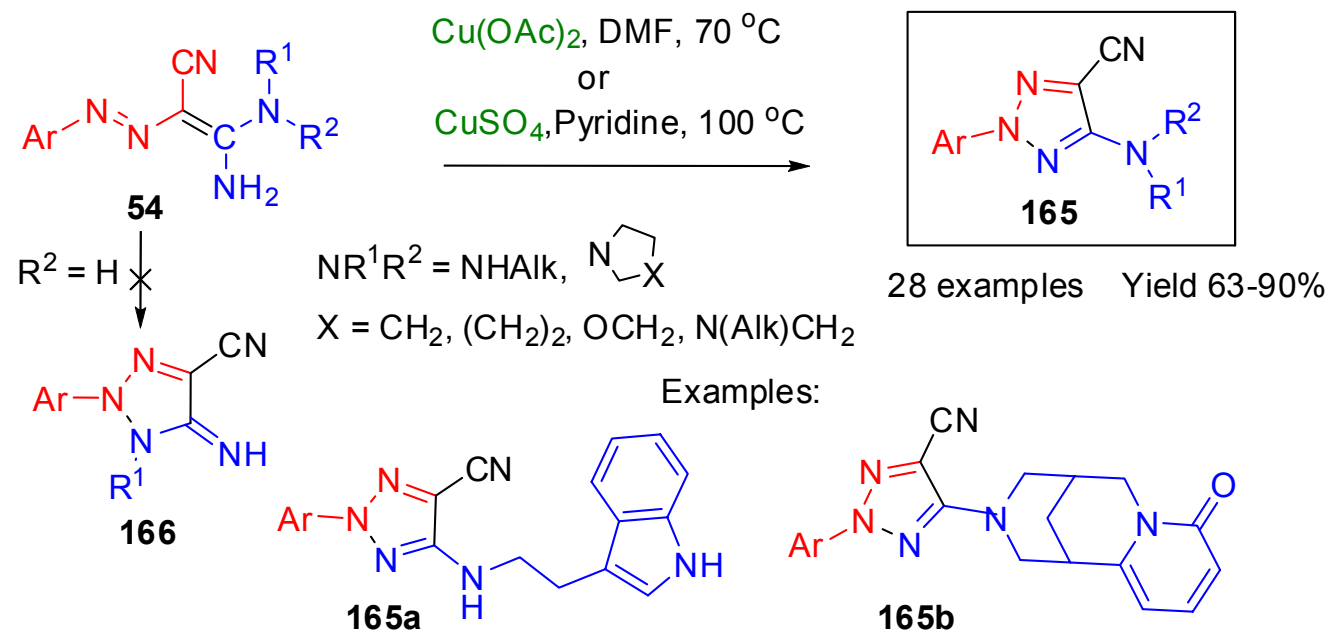

\section{Scheme 89}

It should be noted that in all cases the involvement of the primary rather than the secondary amino group in the oxidative cyclization process is observed. The scale of the present investigation shows that this reaction is a general method for the synthesis of a large variety 2aryl-2H-1,2,3-triazole-5-amines. Furthermore, this allowed to prepare compounds $\mathbf{1 6 5 a}$ and 165b with natural product moieties, e.g. tryptamine and the alkaloid cytisine.

\section{Hydrazono-thioamides for the synthesis of substrates for pericyclic transformations}

Due to the presence of electron lone pairs, the $\pi$-conjugated system and the mobility of some of their protons, arylhydrazones are often used as starting materials in the synthesis of active substrates for cycloaddition reactions. ${ }^{6,7}$

Gil et al. have found that reaction of arylhydrazonothioacetamides with acid chlorides or mesyl chloride in the presence of sodium hydride took place at the nitrogen atom of the thioamide group to form disubstituted thioamides 79 (Scheme 90). ${ }^{11 \mathrm{c}}$ In most cases compounds 79 are not isolated and undergo intramolecular cyclisation to give 6-acylamino-3,6- dihydro- $2 \mathrm{H}$ 1,3,4-thiadiazines 167. This reaction passes probably through the zwitterionic form A which isomerizes to a tautomer B via 1,5-sigmatropic shift of hydrogen atom. In the latter the thiolate adds to the iminium carbon atom to form the final product (Scheme 90). 


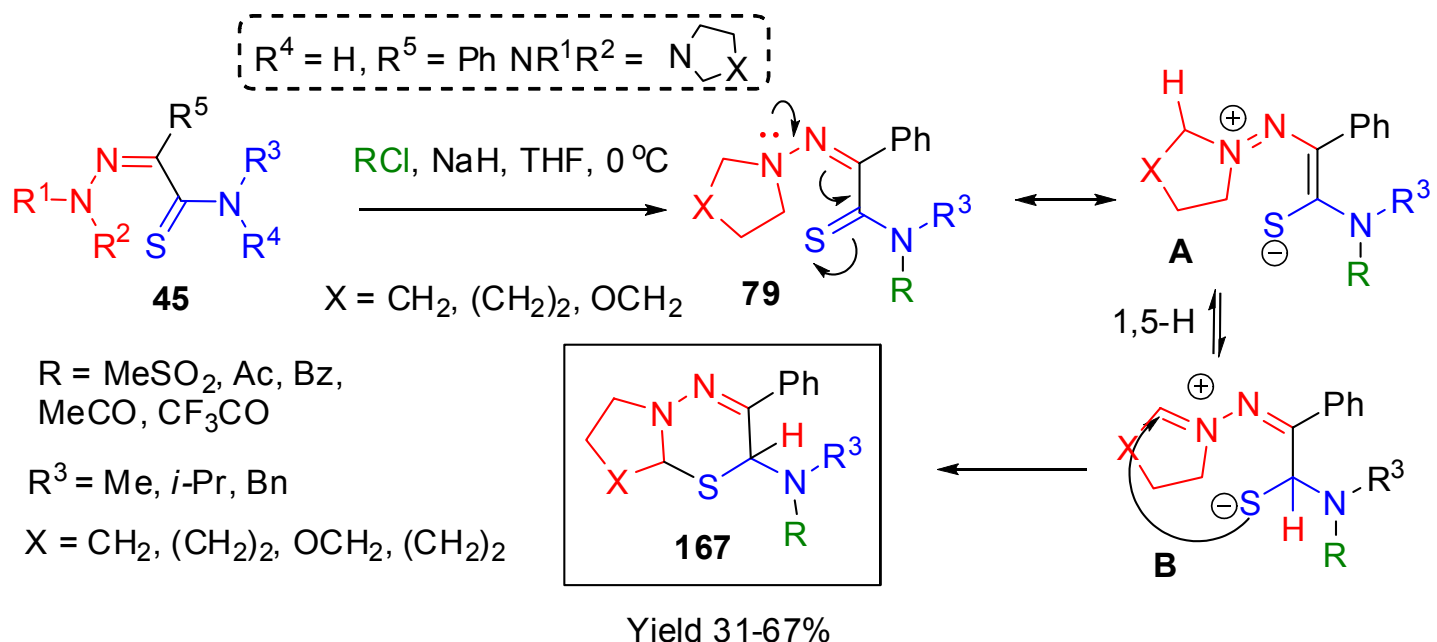

\section{Scheme 90}

We have found that 1,2-diazadienes 77, bearing an S,N-acetal group, that were obtained by the reaction of arylhydrazonoacetothioamides $28(\mathrm{X}=\mathrm{S})$ with haloalkanes (Scheme 43) take part in various pericyclic transformations. ${ }^{26}$ It has been shown that on standing in $\mathrm{CHCl}_{3}$, benzene, acetone and acetonitrile at room or high temperature compounds $\mathbf{7 7}$ were gradually transformed into fused 1,2,4-triazines 168 as the main products in moderate yields. ${ }^{26 a}$ (Scheme 91).
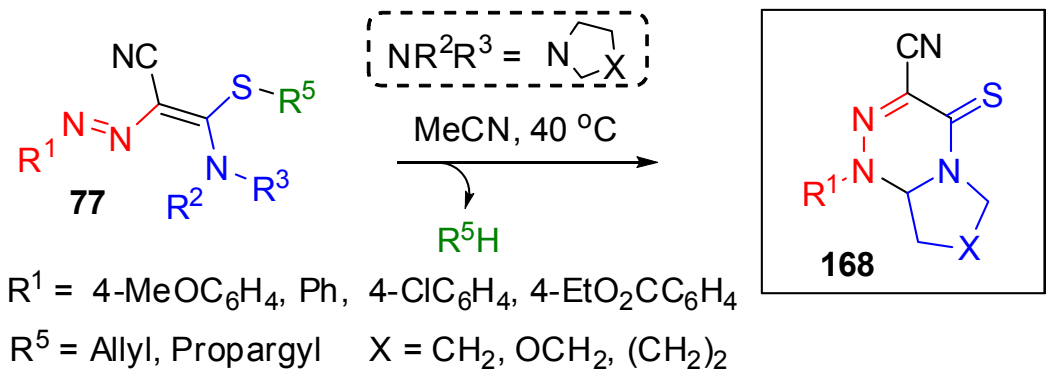

\section{Scheme 91}

Two mechanistic possibilities for the transformation of 3-allyl- and 3-prop-1-ynylsulfanyl-2arylazo-3-cycloalkylaminoacrylonitriles 77 to fused 1,2,4-triazines 168 were discussed. The first one can be described in analogy to cyclizations relying on the so called "tert-amino-effect" as compounds 77 contain both tert-amino function and a conjugated system. ${ }^{51}$ An alternative mechanism depicted in Scheme 92 involves the elimination of $\mathrm{R}^{5} \mathrm{H}$ (propene in the case of allylthioimidates 77) to afford intermediate $\mathbf{A}$, containing a conjugated hetero-hexatriene system. The latter undergoes a $6 \pi$-electrocyclic reaction to furnish the final product. 


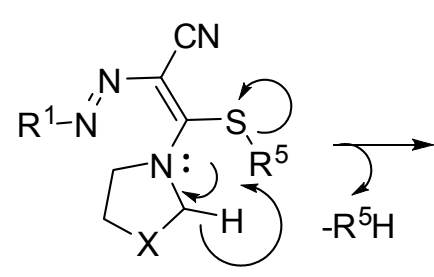<smiles>[R1]N=N/C(C#N)=C(/S)N1C=C[X]C1</smiles>

77<smiles>[X]CC1NC(=O)C(C)=NN1[R]</smiles>

168

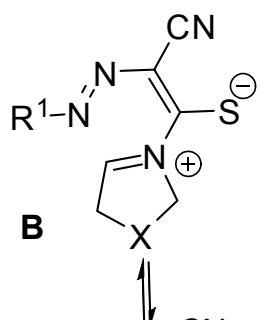<smiles>[R1][n+]1nc(C#N)c([S-])[n+]2[Y]1CCCC2</smiles>

\section{Scheme 92}

The presence of allyl(propargyl)thio group along with active $\alpha$-protons makes the compounds 77 well suited for the pericyclic group transfer reactions leading to final products 168 by elimination of propene(propyne) via intermediate $\mathbf{A}$. It is worth noting that the formation of propene as the principal gas-phase product of the reaction for $77\left(\mathrm{R}^{5}=\mathrm{Allyl}\right)$ was confirmed by a GC-MS experiment.

Interestingly, another type of pericyclic reaction occurred when 3-alkylsulfanyl-3pyrrolidin-1-yl-2-arylazo-acrylonitrile 77 was treated with compounds that bear active triple and double bonds. $^{26 \mathrm{~b}, \mathrm{c}}$ Thus, the reaction of compound 77 with DMAD is accomplished with elimination of alkylthiols to give the product of [3+2] addition, bicyclic pyrrole 170. Reactions with dimethyl maleate take place in a similar way to give the mixture of isomeric pyrrolizines 171. Compounds 173 containing three nonaromatic rings were prepared by treatment of N,Sthioacetals $\mathbf{7 7}$ with maleimides $\mathbf{1 7 2}$ in similar conditions (Scheme 93). 


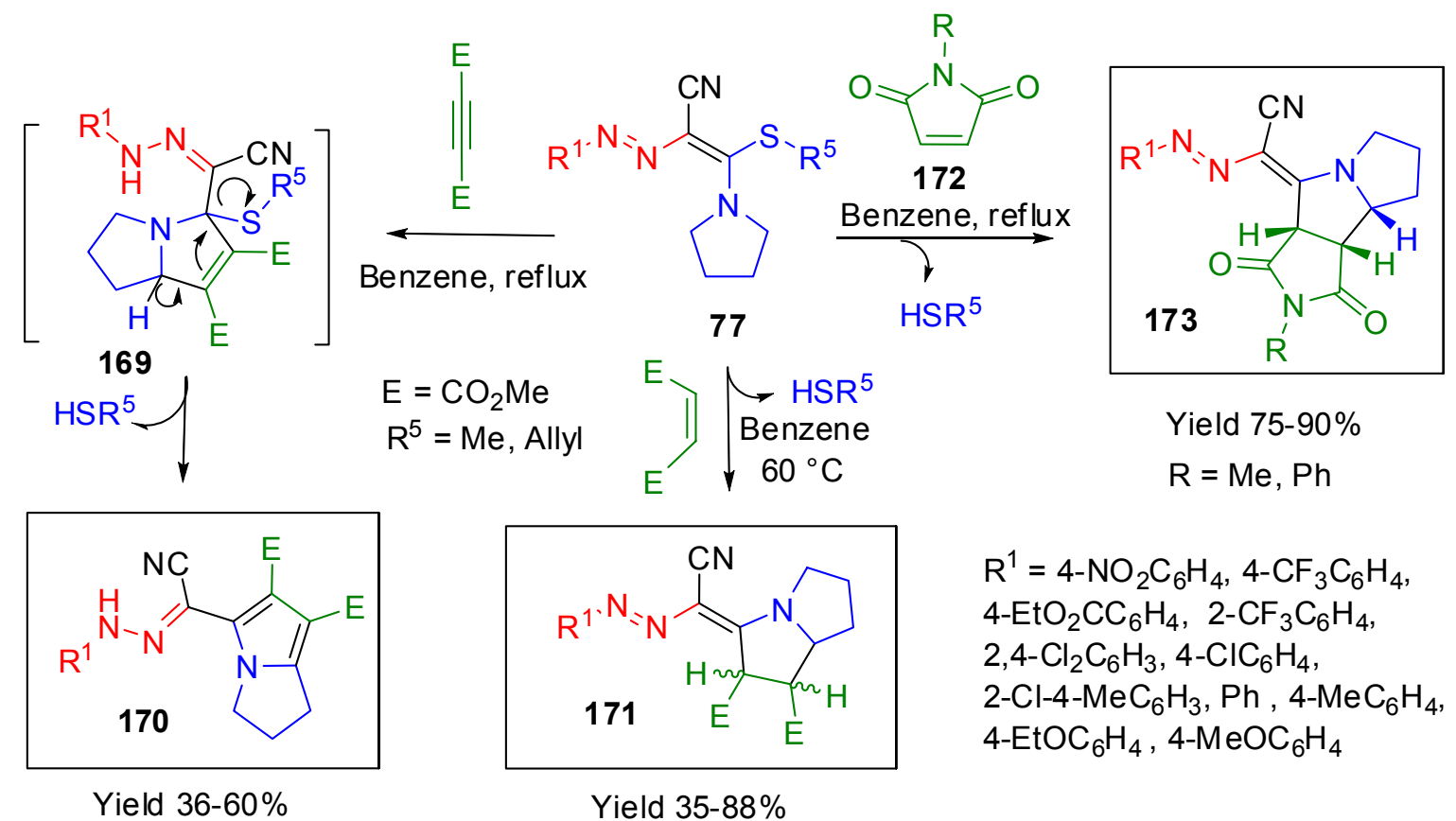

\section{Scheme 93}

The formation of these compounds was explained by a 1,3-dipolar cycloaddition of an in situ generated azomethine ylides. Experimental and theoretical investigation of the mechanisms of these reactions by DFT calculations allowed one to conclude that although the azo group is not included into the cyclic products it affects the mechanism of the generation of the azomethine ylides. The first step is a 1,6-hydrogen shift occurring in compounds 77 yielding the intermediate A (Scheme 94). The process depends on the type of the structural fragments on the sulfur and at the aromatic ring.

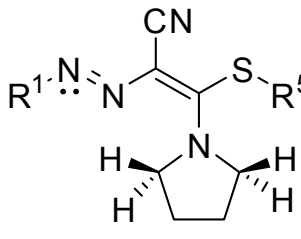

77
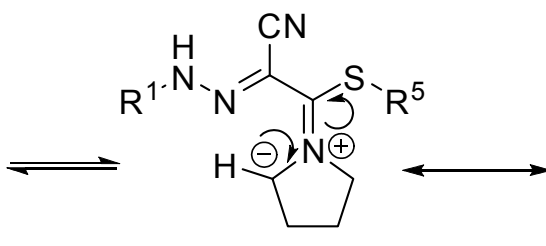

dipole $\mathbf{A}$

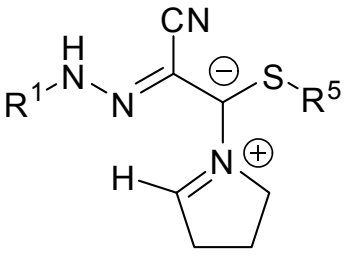

(1)

\section{Scheme 94}

Indeed, 3-alkylsulfanyl-2-arylazo-3-(pyrrolidin-1-yl)acrylonitriles 77 are shown to be masked azomethine ylides that react with dipolarophiles via a 1,3-dipolar cycloaddition mechanism.

We have discovered that 5-imino-1,2,3-thiadiazoles 158 that were prepared from hydrazonothioamides $28(\mathrm{X}=\mathrm{S})$ (Scheme 83), are also masked 1,3-dipoles and react with alkynes and 
activated alkenes to form the product of $3+2$ addition. Thus treatment of imines 168 with DMAD and maleimides in toluene at reflux affords monocyclic and bicyclic products 174 and $\mathbf{1 7 5}$, respectively (Scheme 95). ${ }^{52}$

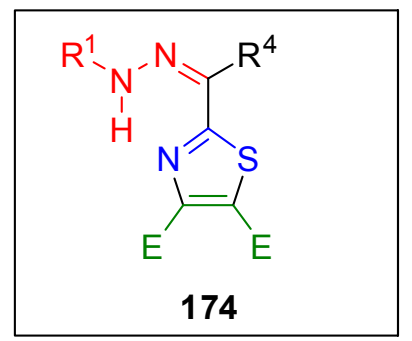

Yield $89 \%$<smiles>[R]c1nn([R])sc1=N</smiles>

Toluene, reflux

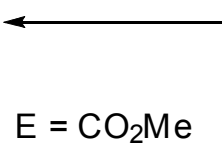

$$
\mathrm{R}^{1}=4-\mathrm{MeOC}_{6} \mathrm{H}_{4}
$$

158
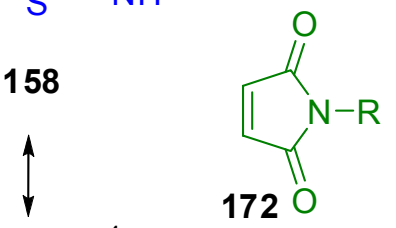

172

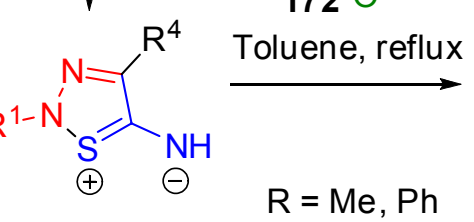

$\mathrm{R}^{4}=\mathrm{CONH}_{2}$

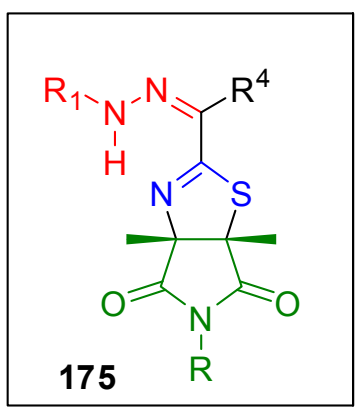

Yield $86 \%$

\section{Scheme 95}

\section{Conclusions}

The introduction of amide, thioamide and amidine groups containing nucleophilic and electrophilic centers, electron lone pairs, mobile bonds C-heteroatom leads to new structural features and novel chemical reactions of hydrazones. The presence of several nucleophilic centers causes the hydrazones to react with various bielectrophilic reagents affording a variety of heterocyclic compounds. The presence of electrophilic centers leads to an increase of the possibilities for heterocyclizations. Both factors are the background to the use of functionalized hydrazones in the synthesis of heterocyclic compounds and for the preparations of substrates for the pericyclic reaction.

\section{Acknowledgements}

We thank RFBR for the financial support (grant № 08-03-00376_a, RFBR/NNSF № 08-0392208_a) 


\section{References}

1. (a) Rollas, S.; Kucukguzel, S. G. Molecules 2007, 12, 1910. (b) Chimenti, F.; Maccioni, E.; Secci, D.; Bolasco, A.; Chimenti, P.; Granese, A.; Befani, O.; Turini, P.; Alcaro, S.; Ortuso, F.; Cardia, M. C.; Distinto, S. J. Med. Chem. 2007, 50, 707. (c) Mao, J.; Wang, Y.; Wan, B.; Kozikowski, A. P.; Franzblau, S. G. Chem. Med. Chem. 2007, 2, 1624. (d) Andreani, A.; Burnelli, S.; Granaiola, M.; Leoni, A.; Locatelli, A.; Morigi, R.; Rambaldi, M.; Varoli, L.; Calonghi, N.; Cappadone, C.; Farruggia, G.; Zini, M.; Stefanelli, C.; Masotti, L.; Radin, N. S.; Shoemaker, R. H. J. Med. Chem. 2008, 51, 809. (e) Noulsri, E.; Richardson, R.; Lerdwana, S.; Fucharoen, S.; Yamagishi, T.; Kalinowski, D. S.; Pattanapanyasat, K. Am. J. Hematology 2009, 84, 170. (f) Vicini, P.; Incerti, M.; Doytchinova, I. A.; Colla, P.; Busonera, B.; Loddo, R. Eur. J. Med. Chem. 2006, 41, 624.

2. (a) Barbazan, P.; Carballo, R.; Covelo, B.; Lodeiro C.; Lima, J. C.; Vazquez-Lopez, E. M. Eur. J. Inorg. Chem. 2008, 2713. (b) Banerjee, S.; Mondal, S.; Chakraborty, W.; Sen. S.; Gachhui, R.; Butcher, R. J.; Slawin, A. M. Z.; Mandal, C.; Mitra, S. Polyhedron 2009, 28, 2785. (c) Ghavtadze, N.; Frohlich, R.; Wurthwein, E.-U. Eur. J. Org. Chem. 2008, 3656. (d) Inamoto, K.; Katsuno, M.; Yoshino, T.; Arai, Y.; Hiroya, K.; Sakamoto, T. Tetrahedron 2007, 63, 2695. (e) Dang, T. T.; Dang, T. T.; Langer, P. Tetrahedron Lett. 2007, 48, 3591. (f) Sridharan, V.; Perumal, P. T.; Avendano, C.; Menendez, J. C. Org. Biomol. Chem. 2007, 5, 1351. (g) Colotta, V.; Catarzi, D.; Varano, F.; Capelli, F.; Lenzi, O.; Filacchioni, G.; Martini, C.; Trincavelli, L.; Ciampi, O.; Pugliese, A. M.; Pedata, F.; Schiesaro, A.; Morizzo, E.; Moro, S. J. Med. Chem. 2007, 50, 4061. (h) Filak, L.; Rokob, T. A.; Vasko, G. A.; Egyed, O.; Gomory, A.; Riedl, Z.; Hajos, G. J. Org. Chem. 2008, 73, 3900. (i) El-Gendy, A. A.; Said, M. M.; Ghareb, N.; Mostafa, Y. M.; El-Ashry, E. S. H. Arch. Pharm. Chem. Life. Sci. 2008, 341, 294. (j) Huang, K. H.; Veal, J. M.; Fadden, R. P.; Rice, J. W.; Eaves, J.; Strachan, J.-P.; Barabasz, A. F.; Foley B. E.; Barta, T. E.; Ma, W.; Silinski, M. A.; Hu, M.; Partridge, J. M.; Scott, A.; DuBois, L. G.; Freed, T.; Steed, P. M.; Ommen, A. J.; Smith, E. D.; Hughes, P. F.; Woodward, A. R.; Hanson, G. J.; McCall, W. S.; Markworth, C. J.; Hinkley, L.; Jenks, M.; Geng, L.; Lewis, M.; Otto, J.; Pronk, B.; Verleysen, K.; Hall, S. E. J. Med. Chem. 2009, 52, 4288.

3. (a) Kim, S.; Yoon, J.-Y. Sci. Synth. 2004, 27, 671. (b). Brehme, R.; Enders, D.; Fernandez, R.; Lassaletta, J. M. Eur. J. Org. Chem. 2007, 5629.

4. Martin-Zamora, E.; Ferrete, A.; Llera, J. M.; Munoz, J. M.; Pappalardo, R. R.; Fernandez, R.; Lassaletta, J. M. Chem. Eur. J. 2004, 10, 6111.

5. (a) Grigg, R. Chem. Soc. Rev. 1987, 16, 89. (b) Deng, X.; Mani, N. S. J. Org. Chem. 2008, $73,2412$.

6. (a) Shawali, A. S.; Parkanyi, C. J. Heterocycl. Chem. 1980, 17, 833. (b) Shawali, A. S.; Edrees, M. M. Arkivoc 2006, (ix), 292. 
7. 7 (a) Attanasi, O. A.; De Crescentini, L.; Filippone, P.; Mantellini, F.; Santeusanio, S. Arkivoc 2002, (xi), 274. (b) Attanasi, O. A.; De Crescentini, L.; Favi, G.; Filippone, P.; Mantellini, F.; Perrulli, F. R.; Santeusanio, S. Eur. J. Org. Chem. 2009, 3109.

8. (a) Khafagy, M. M.; El-Maghraby, A. A.; Hassan, S. M.; Bashandy, M. S. Phosphorus, Sulfur Silicon 2004, 179, 2113. (b) Aly, A. A.; Nour-El-Din, A. M. Arkivoc 2008, (i), 153. (c) Aly, A. A.; Brown, A. B.; El-Emary, T. I.; Ewas, A. M. M.; Ramadan, M. Arkivoc 2009, (i), 150 .

9. Elassar, A.-Z. A.; Dib, H. H.; Al-Awadi, N. A.; Elnagdi, M. H. Arkivoc 2007, (ii), 272.

10. Enders, E. In Methoden der Organischen Chemie; Stroh, H. Eds: Georg Thieme: Stuttgart, 1967; Vol. 10/2, pp. 410-497.

11. (a) Gil, M. J.; Reliquet, A.; Reliquet, F.; Meslin, J. C. Phosphorus, Sulfur Silicon 1994, 97, 89. (b) Gil, M. J.; Reliquet, A.; Reliquet, F.; Meslin, J. C. Phosphorus, Sulfur Silicon 1996, 117, 89. (c) Gil, M. J.; Reliquet, A.; Meslin, J. C. Phosphorus, Sulfur Silicon 1997, 126, 39. (d) Gil, M. J.; Reliquet, A.; Meslin, J. C. Phosphorus, Sulfur Silicon 1997, 128, 105. (e) Gil, M. J.; Reliquet, A.; Reliquet, F.; Meslin, J. C. Phosphorus, Sulfur Silicon Relat. Elem. 2000, 164, 161. (f) Charrier, J.-D.; Reliquet, A.; Meslin, J. C. Tetrahedron Lett. 1998, 39, 8645. (g) Charrier, J.-D.; Deniaud, D.; Reliquet, A.; Meslin, J. C. J. Chem. Soc., Perkin Trans.1 2001, 1212.

12. Zhao, W. G.; Li, Z. M.; Yang, Z. J. Heterocycl. Chem. 2003, 40, 925.

13. (a) Bramson, H. N.; Corona, J.; Davis, S. T.; Dickerson, S. H.; Edelstein, M.; Frye, S. V.; Campe, Jr., R. T.; Harris, P. A.; Hassell, A.; Holmes, W. D.; Hunter, R. N.; Lackey, K. E.; Lovejoy, B.; Luzzio, M. J.; Montana, V.; Rocque, W. J.; Rusnak, D.; Shewchuk, L.; Veal, J. M.; Walker, D. H.; Kuyper, L. F. J. Med. Chem. 2001, 44, 4339. (b) Mazilis, L.; Stankevicius, A.; Terent'ev, P. B.; Korobchenko, L. V.; Boreko, E. I. Khim.-Farm. Zh. 1987, 21, 580. (c) Diaz, P.; Xu, J.; Astruc-Diaz, F.; Pan, H.-M.; Brown, D. L.; Naguib, M. J. Med. Chem. 2008, 51, 4932. (d) Diaz, P.; Phatak, S. S.; Xu, J.; Astruc-Diaz, F.; Cavasotto, C. N.; Naguib, M. J. Med. Chem. 2009, 52, 433.

14. Borisov, A. V.; Gorobets, N. Yu.; Yermolayev, S. A.; Zhuravel', I. O.; Kovalenko, S. M.; Desenko, S. M. J. Comb. Chem. 2007, 9, 909.

15. Parmeter, S. M. In Organic Reactions; John Wiley \& Sons, Inc: New York, 1959; Vol. 10, pp 3-135.

16. (a) Slouka, J. Monatsh. Chem. 1963, 94, 258. (b) Slouka, J. Monatsh. Chem. 1968, 99, 1808. (c) Slouka, J. Monatsh. Chem, 1969, 100, 342. (d) Slouka, J., Bekarek, V.; Kubata, J. Monatsh. Chem. 1974, 105, 535. (e) Bilek, P.; Slouka, J. J. Heterocyclic Chem. 2002, 39, 357. (f) Wiedermannova, I.; Slouka, J. J. Heterocycl. Chem. 2001, 38, 1465. (g) Shawali, A. S. A. S., Osman, A. Tetrahedron 1971, 27, 2517. (h) Shawali, A. S., El-Galil, M. A. Tetrahedron 1971, 27, 4305. (i) Shawalli, A. S. A. S.; Ali, M. I.; Naoum, M. M.; Elansari A. L. Tetrahedron 1972, 28, 3805. (j) Gewald, K.; Hain, U. J. Prakt. Chem. 1975, 317, 329. (k) Gewald, K.; Calderon, O.; Hain, U. J. Prakt. Chem. 1986, 328, 741. (1) Elnagdi, M. H.; Elghandour, A. H. H.; Harb, A. F. A.; Hussien, A. H. M.; Metwally, S. A. M. Heterocycles 
1994, 38, 739. (m) Yagi, Y. J. Am. Chem. Soc. 1962, 36, 487. (n) Hamzacebi, M. C.; Rollas, S.; Kucukguzel, S. G.; Kaymakciogly B. K. Arkivoc 2008, (xii), 188. (o) Al-Zaydi, K. M. Ultrason. Sonochem. 2009, 16, 805. (p) Bezmaternykh, M. A.; Mokrushin, V. S.; Pospelova, T. A.; El'tsov, O. S. Chem. Heterocycl. Compd. 1998, 34, 702. (q) Bel'skaya, N. P.; Zvereva, E. E.; Babushkina, L. A.; Bakulev, V. A. Chem. Heterocycl. Compd. 2000, 36, 1066. (r) Belskaia, N. P.; Zvereva, E. E.; Dehaen, W.; Bakulev, V. A. J. Chem. Res. (M) 2000, 12, 1367. (s) Zvereva, E. E.; Bel'skaya, N. P.; Bakulev, V. A. Chem. Heterocycl. Compd. 1998, 34, 1444. (t) Dell'Erba, C.; Novi, M.; Petrillo, G.; Tavani, C. Tetrahedron 1996, 52, 5889. (u) Hussein, A. M.; Abu-Shanab, F. A.; Raheim, M. A. M. A; El-Gaby, M. S. A. Phosphorus, Sulfur Silicon 2008, 183, 1722. (v) Desai, N. D.; Shah, R. D. Synth. Commun. 2008, 38, 316. (w) Ibrahim, H. M.; Makhseed, S.; Abdel-Motaleb, R. M.; Makhlouf, A.-C.; Elnagdi, M. H. Heterocycles 2007, 71, 1951.

17. (a) Al-Mosawi, S., Elassar, A.-Z.; El-Apasery, M. A. Phosphorus, Sulfur Silicon Relat. Elem. 2006, 181, 1755. (b) Bakulev, V. A.; Belskaia, N. P.; Mokrushin, V. S. Abhath AlYarmouk, "Basic Science and Engineering," 2001, 10, 199. (c) Paramonov, I. V.; Belskaia, N. P.; Bakulev, V. A. Chem. Heterocycl. Compd. 2003, 39, 1385. (d) Bel'skaya, N. P.; Paramonov, I. V.; Mikhacheva, M. V.; Bakulev, V. A. Chem. Heterocycl. Compd. 2000, 36, 111. (e) Bel'skaya, N. P.; Paramonov, I. V.; Mukhacheva M. V.; Bakulev, V. A. Chem. Heterocycl. Compd. 1998, 34, 1447. (f) Paramonov, I. V.; Bel'skaya, N. P.; Bakulev, V. A. Chem. Heterocycl. Compd. 2001, 37, 1298. (g) Deryabina, T. G.; Bel'skaya, N. P.; Kodess, M. I.; Bakulev, V. A. Chem. Heterocycl. Compd. 2007, 43, 18. (h) Elneairy, M. A. A.; Abbas, A. A.; Mabkhout, Y. N. Phosphorus, Sulfur Silicon 2003, 178, 1747. (i) Zaleska, B.; Trzewik, B.; Grochowski, J.; Serda, P. Synthesis 2003, 2559. (j) Berseneva, V. S. Tkachev, A. V. Morzherin, Y. Y.; Dehaen, W.; Luyten I.; Toppet, S.; Bakulev, V. A. J. Chem. Soc., Perkin. Trans. 1, 1998, 2133. (k) El-Reedy, A. M., Hussain, S. M.; Youssef, M. M. M. J. Prakt. Chem. 1988, 330, 521. (1) Islam, I. E.; El-Amin, S. M. Rev. Roum. Chem. 1994, 39, 577.

18. Kurasawa, Y.; Hosaka, T.; Takada, A.; Kim, S. K.; Okamoto, Y. J. Heterocyclic Chem. 1995, 32, 531 .

19. (a) Dubenko, R. G.; Konysheva, V. D.; Pel'kis, P. S. Zh. Org. Khim. 1981, 17, 490. (Russ). CA 95: 24704v. (b) Dubenko, R. G.; Gorbenko, E. F.; Pel'kis, P. S.; Lozinskii, M. O. Zh. Org. Khim. 1981, 17, 1704 (Russ). CA95: 203515f. (c) Dubenko, R. G.; Gorbenko, E. F.; Lozinskii, M. O. Zh. Org. Khim. 1984, 20, 573 (Russ). CA 101: 90529k. (d) Dubenko, R. G.; Bazavova, I. M.; Gorbenko, E. F. Zh. Org. Khim. 1984, 20, 577 (Russ). CA 101: 90811w.

20. (a) Lozinskii, M. O; Pel'kis, P. S. Zh. Org. Khim. 1965, 1, 1871. (b) Frohberg, P.; Drutkowski, G.; Wagner, C. Eur. J. Org. Chem. 2002, 1654.

21. Kondratieva, M. L., Pepeleva, A. V; Belskaia, N. P., Koksharov, A. V.; Groundwater, P. V.; Robeyns, K; Van Meervelt, L.; Dehaen, W.; Fan, J.-Z.; Bakulev, V. A. Tetrahedron 2007, 63, 3042. 
22. (a) Lestina, G. J.; Regan, T. H. J. Org. Chem. 1969, 34, 1685. (b) Hafez, E. A.-A.; Zayed, E. M.; Sadek, K. U. J. Heterocycl. Chem. 1985, 22, 241. (c) Bakulev, V. A.; Berseneva, V. S.; Belskaia, N. P.; Morzherin, Yu. Yu.; Zaitsev, A.; Dehaen, W.; Luyten, I.; Toppet, S. Org. Biomol. Chem. 2003, 1, 134. (d) Garnovskii, A. D.; Uraev, A. I.; Minkin, V. I. Arkivoc 2004, (iii), 29. (e) Snavely, F. A.; Trahanovsky, W. S.; Suydam, F. H. J. Org. Chem. 1962, 27, 994.

23. (a) Shaw, E. and Woolley, D. W. J. Biol. Chem. 1949, 181, 89. (b) Shaw, E. J. Biol. Chem. 1950, 185, 439. (c) Richter, E.; Taylor, E. C. J. Am. Chem. Soc. 1956, 78, 5848. (d) Styskala, J.; Slouka, J.; Svecova, V. Arkivoc 2006, (i), 68. (e) Smith, L. H.; Yates, P. J. Chem. Soc., Perkin Trans. 2 1954, 76, 6080

24. Schafer, H.; Gewald, K.; Bellmann, P.; Gruner, M. Monatsh. Chem. 1991, 122, 195.

25. (a) Rymareva, T. G.; Torgasheva, N. A.; Zelikhover, Ya. B.; Bel'skii, V. K. Russ. J. Gen. Chem. 1997, 67, 1417. (b) Vasil'eva, M. L.; Mukhacheva, M. V.; Bel'skaya, N. P.; Bakulev, V. A.; Anderson, R. J.; Groundwater, P. V. Russ. J. Org. Chem. 2004, 40, 859.

26. (a) Belskaia, N. P.; Deryabina, T. G.; Koksharov, A. V.; Kodess, M. I.; Dehaen, W.; Lebedev, A. T.; Bakulev, V. A. Tetrahedron Lett. 2007, 48, 9128. (b) Deryabina, T. G.; Belskaia, N. P.; Kodess, M. I.; Dehaen, W.; Toppet, S.; Bakulev, V. A. Tetrahedron Lett. 2006, 47, 1853. (c) Belskaia, N. P.; Bakulev, V. A.; Deryabina, T. G.; Subbotina, J. O.; Kodess, M. I.; Dehaen, W.; Toppet, T.; Robeyns K.; Van Meervelt, L. Tetrahedron 2009, 65, 7665 .

27. (a) Bel'skaya, N. P.; Demina, M. A., Sapognikova, S. G.; Fan, Z.-J.; Zhang, H.-K.; Dehaen, W.; Bakulev, V. A. Arkivoc 2008, (xvi), 9. (b) Demina, M. A., Belskaia, N. P.; Bakulev, V. A. Chem. Heterocycl. Comp. 2007, 43, 671.

28. (a) Frohberg, P.; Drutkowski, G.; Wagner, Ch. Eur. J. Org. Chem. 2002, 1654. (b) Drutkowski, G.; Donner C.; Schulze, I.; Frohberg, P. Tetrahedron 2002, 58, 5317. (c) Frohberg, P.; Wagner, C.; Meier, R.; Sippl, W. Tetrahedron 2006, 62, 6050. (d) Krauth, F.; Friedemann, R.; Ruttinger, H.-H.; Frohberg, P. Arkivoc 2009, (vii), 150.

29. (a) Krystof, V.; Cankar, P.; Frysova, I.; Slouka, J.; Kontopidis, G.; Dzubak, P.; Hajduch, M.; Srovnal, J.; Azevedo, Jr., W. F.; Orsag, M.; Paprskarova, M.; Rolcik, J.; Latr, A.; Fischer, P. M.; Strnad, M. J. Med. Chem. 2006, 49, 6500. (b) Elfahham, H. A.; Elgemeie, G. E. H.; Ibraheim, Y. R.; Elnagdi, M. H. Liebigs Ann. Chem. 1988, 819. (c) Wrubel, J.; Mayer, R. Z. Chem. 1984, 24, 256. (d) Shvekhgeimer, M.-G. A.; Ushakova, O. A. Chem. Heterocycl. Comp. 2001, 37, 370. (e) Abdelhamid, A. O.; Ismail, Z. H.; Abdel-Gawad, S. M.; AbdelAziem, A.; Ghorab, M. M. Phosphorus, Sulfur Silicon Relat. Elem. 2009, 184, 58. (f) Hassanien, A. Z. A. E.-B.; Hafiz, I. S. A.; Elnagdi, M. H. J. Chem. Res. (M), 1999, 129. (g) Kandeel, Z. E.-S. J. Chem. Res (S), 1995, 290. (h) El-Shafei, A.; Fadda, A. A.; Khalil, A. M.; Ameen, T. A. E.; Badria, F. A. Bioorg. Med. Chem. 2009, 17, 5096.

30. (a) Duffy, K. J.; Darcy, M. G.; Delorme, E.; Dillon, S. B.; Eppley, D. F.; Erickson-Miller, C.; Giampa, L.; Hopson, C. B.; Huang, Y.; Keenan, R. M.; Lamb, P.; Leong, L.; Liu, N.; Miller, S. G.; Price, A. T.; Rosen, J.; Shah, R.; Shaw, T. N.; Smith, H.; Stark, K. C.; Tian, 
S.-S.; Tyree, C.; Wiggall, K. J.; Zhang, L.; Luengo, J. I. J. Med. Chem. 2001, 44, 3730. (b) Elwahy, A. H. M.; Abbas, A. A. Synth. Comm. 2000, 30, 2903. (c) Saleh, M. A.; AbdelMegeed, M. F.; Abdo, M. A.; Shokr, A.-B. M. Molecules 2003, 8, 363. (d) Elgemeie, G. H.; Ekghandour, A. H.; Elshimy, H. M. J. Prakt. Chem. 1989, 331, 466. (e) Metwally, M. A., Yousif, M. Y. Ismaiel, A. M., Amer, F. A. J. Indian Chem. Soc. 1985, 62, 54.

31. (a) Manojkumar, P.; Ravi, T. K.; Gopalakrishnan, S. Eur. J. Med. Chem. 2009, 44, 4690. (b) Abu-Zaied, K. M.; Gaafar, A. M.; Aly, A. S. Phosphorus, Sulfur Silicon Relat. Elem. 2007, 182, 447. (c) Elneairy, M. A. A.; Gad-Elkareem, M. A. M.; Abdel-Fattah, A. M.; Phosphorus, Sulfur Silicon Relat. Elem. 2006, 181, 1451. (d) Kuecuekguezel, S. G.; Rollas, S. Farmaco 2002, 57, 583. (e) Mustroph, H. Z. Chem. 1985, 25, 270. (f) Rajeev, J.; Srivastava, M. K.; Gupta, S. J. Indian Chem. Soc. 1996, 73, 493. (g) Rajeev, J.; Gupta, S. J. Indian Chem. Soc. 1998, 75, 325. (h) Lycka, A.; Mustroph, H. J. Prakt. Chem. 1989, 331, 11. (i) Kalluraya, B.; Rahiman, A. M.; Banji, D. Arch. Pharm. 2001, 334, 263. (j) Kuecuekguezel, S. G.; Rollas, S.; Erdeniz, H.; Kiraz, M.; Ekinci, A. C.; Vidin, A. Eur. J. Med. Chem. 2000, 35, 761.

32. (a) Karci, F.; Sener, N.; Yamac, M.; Sener, I.; Demircali, A. Dyes and Pigments 2009, 80, 47. (b) Karci, F.; Karci, F. Dyes and Pigments 2008, 77, 451. (c) Karci, F.; Demircali, A., Karci, F.; Karra, I.; Ucun, F. J. Mol. Struct. 2009, 935, 19. (d) Khalik, M. M. A. J. Chem. Res. (S) 1997, 198. (d) Elnagdi, M. H.; Fleita, D. H.; El-Moghayar, M. R. H. Tetrahedron 1975, 31, 63.

33. (a) Price, P. C.; Grzesiak, A. L.; Kampf, J. W.; Matzger A. J. Cryst. Growth Des. 2003, 3, 1021. (b) Cui, Y.; Spann, A. P.; Couch, L. H.; Gopee, N. V.; Evans, F. E.; Churchwell, M. I.; Williams, L. D.; Doerge, D. R.; Howard, P. C. Photochem. Photobiol. 2004, 80, 175.

34. Yao, H. C. J. Org. Chem. 1964, 29, 2959.

35. Kaberia, F.; Vickery, B.; Willey, G. R.; Drew, M. G. B. J. Chem. Soc., Perkin Trans 2 1980, 1622.

36. (a) Emeleus, L. C.; Cupertino, D. C.; Harris, S. G; Owens, S.; Parsons, S.; Swart, R. M.; Tasker, P. A.; White, D. J. J. Chem. Soc., Dalton Trans. 2001, 1239. (b) Connors, J. A.; Kennedy, R. J.; Dawes, H. M.; Hursthouse, M. B.; Walker, N. P. C. J. Chem. Soc., Perkin Trans. 2 1990, 203. (c) Kuzmina, L. G.; Grigoryeva, L. P.; Struchkov, Y. T.; Yezhkova, Z. I.; Zaitsev, B. Y.; Zaitseva, V. A.; Pronkin P. P. Khim. Get. Soedin., 1985, 6, 617.

37. (a) Gewald, K; Rehwald, M.; Muller, H.; Bellmann, P.; Schafer, H. Monatsh. Chem. 1995, 126, 341. (b) Bianchi, L.; Dell'Erba, C.; Massagno, M.; Mugnoli, A.; Novi, M.; Petrillo, G.; Sancassan, F.; Tavani, C. Tetrahedron 2003, 59, 10195.

38. (a) Gewald, K; Rehwald, M.; Gruner, M. Liebigs Annal. Chem. 1993, 457. (b) Gewald, K; Rehwald, M.; Muller, H.; Bellmann, P.; Schafer, H. Monatsh. Chem. 1995, 126, 341. (c) Buchtik, R.; Slouka, J.; Hlavac, J. Arkivoc 2006, (v), 78.

39. Elnagdi, M. H.; El-Moghayar, M. R. H.; Fleita, D. H.; Hafez, E. A. A.; Fahmy, S. M. J. Org. Chem. 1976, 41, 3781. 
40. (a) Rajeev, J.; Damodharan, M. Can. J. Chem. 1995, 73, 176-180. (b) Kendall, D. J. Chem. Soc. 1955, 3969.

41. El-Bannany, A, A. A.; Ghozlan, S. A. S.; Ibraheim, L. I. Pharmazie 1987, 42, 695.

42. (a) Abdelhamid, A. O.; Alkhodshi, M. A. M. Phosphorus, Sulfur Silicon 2005, 180, 1647.

(b) Zohdi, H. F.; Rateb, N. M.; Abdelhamid, A. O. Phosphorus, Sulfur Silicon 1998, 133, 103. (c) Khafagy, M. M.; El-Maghraby, A. A.; Hassan, S. M.; Bashandy, M. S. Phosphorus, Sulfur Silicon 2004, 179, 2113.

43. (a) Danilkina, N. A.; Mikhailov, L. E.; Ivin, B. A. Russ. J. Org. Chem. 2006, 42, 783. (b) Jagodzinski, T. S. Chem. Rev. 2003, 103, 197.

44. Deryabina, T. G.; Demina, M. A.; Belskaya, N. P.; Bakulev, V. A. Russ. Chem. Bull., 2005, $54,2880$.

45. (a) Ibrahim, M. K. A.; El-Moghayar, M. R. H. Indian J. Chem., Sec. B; 1987, 26, 832. (b) Islam, I. E.; El-Amin, S. M. Rev. Roum. Chim. 1994, 39, 577.

46. Mohamed, N. R.; El-Saidi M. M. T.; Ali, Y. M.; Elnagdi, M. H. J. Heterocycl. Chem. 2007, 44, 1333.

47. (a) Bestmann, H. J.; Schmid, G.; Sandmeier, D.; Schade, G.; Oechsner, H. Chem. Ber. 1985, 118, 1709. (b) Bestmann, H. J.; Schmid, G.; Sandmeier, D. Tetrahedron Lett. 1980, 21 , 2939.

48. (a) Kheder, N. A.; Mabkhot, Y. N.; Fagar, A. M. Synth. Commun. 2008, 38, 3170. (b) Ibrahim, O. A.; Aziz, E. F. M. A.; Hilmy, S. M.; Ali, E. A. G. Indian J. Chem. B, 1998, 37, 399.

49. (a) Stanczak, A.; Kwapiszewski, W.; Lewgowd, W.; Ochocki, Zb.; Szadowska, A.; Pharmazie 1994, 49, 884. (b) Gewald, K.; Calderon, O.; Schaefer, H.; Ute, H. Liebigs Ann. Chim. 1984, 1390

50. (a) Hanna, M. A.; Al-Sarawy, A. A.; Rashed, I. G.; Wali, F. K. M. Phosphorus, Sulfur Silicon Relat. Elem. 2004, 179, 1209. (b) Lee, Y.-K.; Parks, D. J.; Lu, T.; Thieu, T. V.; Markotan, T.; Pan, W.; McComsey, D. F.; Milkiewicz, K. L.; Crysler, C. S.; Ninan, N.; Abad, M. C.; Giardino, E. C.; Maryanoff, B. E.; Damiano, B. P.; Player, M. R. J. Med. Chem. 2008, 51, 282.

51. (a) Verboom, W.; Reinhoudt, D. N. Recl. Trav. Chim. Pays-Bas. 1990, 109, 311. (b) MethCohn, O. Adv. Heterocycl. Chem. 1996, 65, 1. (c) Matyus, P.; Elias, O.; Tapolcsanyi, P.; Polonka-Balint, A.; Halasz-Dajka, B. Synthesis 2006, 2625.

52. Kondrat'eva, M. L.; Bel'skaya, N. P.; Bakulev, V. A. Russ. Chem. Bull. 2006, 55, 946. 


\section{Authors' biographies}

\section{Dr Belskaya Nataliya Biography}

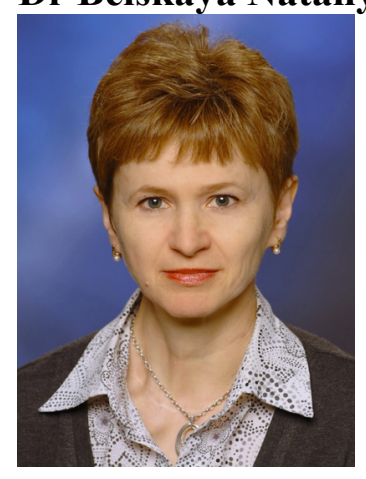

Belskaya Nataliya obtained her undergraduate chemistry degree in 1978 and her Ph.D in organic chemistry in 1988 from the Urals Technical Institute, Faculty of Chemistry Technology, Ekaterinburg, Russia. She was a Junior Researcher, Senior Researcher, and since 2005 she is currently associate professor at the Department of Technology for Organic Synthesis of the Urals State Technical University. Her research is focused on the chemistry of heterocyclic compounds, aromatic and heterocyclic diazo compounds, hydrazones, diazodienes, nitrilimines, nitrilylides and pericyclic reactions.

\section{Dr Wim Dehaen Biography}

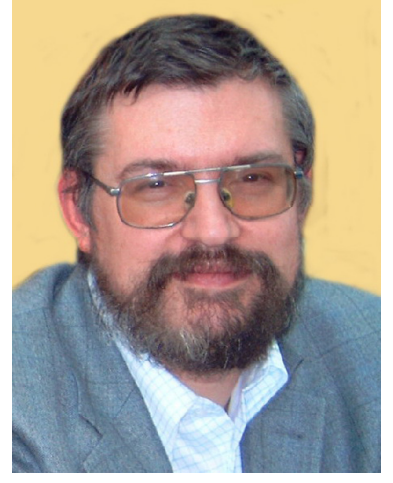

Wim Dehaen was born in Kortrijk, Belgium. He obtained his Ph D in 1988 under the guidance of Professor Gerrit L'abbé on a study concerning the rearrangements of 5-diazoalkyl-1,2,3-triazole derivatives. After postdoctoral stays in Israel (1988-1990), Denmark (3 months in 1990), the United Kingdom (three months in 1994) and Belgium (most of 1990-1998) he was appointed associate professor at the University of Leuven (Belgium) in 1998, becoming a full professor at the same university in 2004. Up to 2010 , close to 300 publications have appeared in international journals about his work on heterocyclic and supramolecular chemistry. 


\section{Dr Vasiliy A. Bakulev Biography}

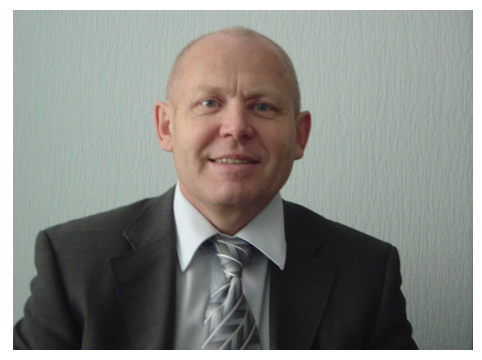

Vasiliy Bakulev was born in Ekaterinburg, Russia. He obtained PhD in 1979 under guidance of Professor Vladimir Mokrushin on the synthesis of imidazole derivatives. Then he was studding electrocyclic reactions of diazocompounds and azomethyneylides and defended in 1990 the second thesis of Doctor of Science (similar to Habilitation Work) at Moscow State University. He received a diploma of Professor in 1998. He jointly with Wim Dehaen published a book on chemistry of 1, 2, 3-thiadiazoles in 2004 and two chapters in Comprehensive Heterocyclic Chemistry III. He is currently employed as Chief of Organic Synthesis and Technology Department of the Urals State Technical University (Ekaterinburg, Russia). 